NBER WORKING PAPER SERIES

\title{
DEVIATIONS FROM COVERED INTEREST RATE PARITY
}

\author{
Wenxin Du \\ Alexander Tepper \\ Adrien Verdelhan \\ Working Paper 23170 \\ http://www.nber.org/papers/w23170 \\ NATIONAL BUREAU OF ECONOMIC RESEARCH \\ 1050 Massachusetts Avenue \\ Cambridge, MA 02138 \\ February 2017
}

First version: November 2015. The views in this paper are solely the responsibility of the authors and should not be interpreted as reflecting the views of the Board of Governors of the Federal Reserve System, any other person associated with the Federal Reserve System, or the National Bureau of Economic Research. We thank Claudio Borio, Francois Cocquemas, Pierre CollinDufresne, Doug Diamond, Xavier Gabaix, Benjamin Hebert, Arvind Krishnamurthy, Robert McCauley, Charles Engel, Pierre-Olivier Gourinchas, Sebastian Infante, Martin Lettau, Hanno Lustig, Matteo Maggiori, Warren Naphtal, Brent Neiman, Jonathan Parker, Thomas Philippon, Arvind Rajan, Adriano Rampini, Fabiola Ravazzolo, Andrew Rose, Hyun Song Shin, Jeremy Stein, Saskia Ter Ellen, Fabrice Tourre, Annette Vissing-Jorgensen, and seminar and conference participants at the AFA meeting in Chicago, the Bank of Canada, the Bank of England, the Bank for International Settlements, Berkeley, Chicago, the European Central Bank, the Federal Reserve Board, the Federal Reserve Bank at Dallas, the Federal Reserve Bank of Philadelphia, the Federal Reserve Bank of San Francisco, Harvard, the International Monetary Fund, MIT Sloan, the NBER Summer Institute, Northwestern, UNC Chapel Hilll, Wharton, Vanderbilt, and Washington University for comments and suggestions. All remaining errors are our own. The paper previously circulated under the title "Cross-currency Basis."

NBER working papers are circulated for discussion and comment purposes. They have not been peer-reviewed or been subject to the review by the NBER Board of Directors that accompanies official NBER publications.

(C) 2017 by Wenxin Du, Alexander Tepper, and Adrien Verdelhan. All rights reserved. Short sections of text, not to exceed two paragraphs, may be quoted without explicit permission provided that full credit, including $\odot$ notice, is given to the source. 
Deviations from Covered Interest Rate Parity

Wenxin Du, Alexander Tepper, and Adrien Verdelhan

NBER Working Paper No. 23170

February 2017

JEL No. F31,G15

\section{ABSTRACT}

We find that deviations from the covered interest rate parity condition (CIP) imply large, persistent, and systematic arbitrage opportunities in one of the largest asset markets in the world. Contrary to the common view, these deviations for major currencies are not explained away by credit risk or transaction costs. They are particularly strong for forward contracts that appear on the banks' balance sheets at the end of the quarter, pointing to a causal effect of banking regulation on asset prices. The CIP deviations also appear significantly correlated with other fixed-income spreads and with nominal interest rates.

Wenxin Du

Federal Reserve Board

Division of International Finance

20th Street and Constitution Avenue NW

Washington, DC 20551

wenxin.du@frb.gov

Alexander Tepper

Columbia University

Graduate School of Architecture,

Planning and Preservation

1172 Amsterdam Ave

New York, NY 10027

at3065@columbia.edu
Adrien Verdelhan

MIT Sloan School of Management

100 Main Street, E62-621

Cambridge, MA 02142

and NBER

adrienv@mit.edu 


\section{Introduction}

The foreign exchange forward and swap market is one of the largest and most liquid derivative markets in the world with a total notional amount outstanding equal to $\$ 61$ trillion and an average daily turnover equal to $\$ 3$ trillion (Bank of International Settlements, 2013, 2014). The cornerstone of currency forward and swap pricing, presented in all economics and finance textbooks and taught in every class in international finance, is the covered interest rate parity (CIP) condition. In this paper, we document deviations from the CIP post crisis and investigate their causes.

We show that the CIP condition is systematically and persistently violated among G10 currencies, leading to significant arbitrage opportunities in currency and fixed income markets since the 2008 global financial crisis. Our findings are a puzzle for all no-arbitrage models in macroeconomics and finance. Since the arbitrage opportunities exist at very short horizon, such as overnight or one-week, our findings are also a puzzle for the classic limitsof-arbitrage models that rely on long-term market risk à la Shleifer and Vishny (1997). The systematic patterns of the CIP violations point to the key interaction between costly financial intermediation and international imbalances in funding supply and investment demand across currencies in the new, post-crisis regulatory environment. In particular, we provide evidence of the impact of post-crisis regulatory reforms on CIP arbitrage.

The intuition for the CIP condition relies on a simple no-arbitrage condition. For example, an investor with U.S. dollars in hand today may deposit her dollars for one month, earning the dollar deposit rate. Alternatively, the investor may also exchange her U.S. dollars for some foreign currency, deposit the foreign currency and earn the foreign currency deposit rate for one month. At the same time, the investor can enter into a one-month currency forward contract today, which would convert the foreign currency earned at the end of the month into U.S. dollars. If both U.S. and foreign currency deposit rates are default-free and the forward contract has no counterparty risk, the two investment strategies are equivalent and should thus deliver the same payoffs. Therefore, the difference between U.S. dollar and 
foreign currency deposit rates should be exactly equal to the cost of entering the forward contract, i.e. the log difference between the forward and the spot exchange rates, with all rates observed at the same date.

The cross-currency basis measures the deviation from the CIP condition. It is the difference between the direct dollar interest rate from the cash market and the synthetic dollar interest rate from the swap market obtained by swapping the foreign currency into U.S. dollars. A positive (negative) currency basis means that the direct dollar interest rate is higher (lower) than the synthetic dollar interest rate. When the basis is zero, CIP holds. Before the global financial crisis, the log difference between the forward and the spot rate was approximately equal to the difference in London interbank offer rates (Libor) across countries (Frenkel and Levich, 1975; Akram, Rime, and Sarno, 2008). In other words, the Libor cross-currency basis was very close to zero. As is by now well-known, large bases appeared during the height of the global financial crisis and the European debt crisis, as the interbank markets became impaired and arbitrage capital was limited.

We show that Libor bases persist after the global financial crisis among G10 currencies and remain large in magnitude. Our sample includes the most liquid currencies, with a total daily turnover above $\$ 2$ trillion (Bank of International Settlements, 2013): the Australian dollar, the Canadian dollar, the Swiss franc, the Danish krone, the euro, the British pound, the Japanese yen, the Norwegian krone, the New Zealand dollar, and the Swedish krona. The average annualized absolute value of the basis is 24 basis points at the three-month horizon and 27 basis points at the five-year horizon over the 2010-2016 sample. These averages hide large variations both across currencies and across time. In the current economic environment, the cross-currency basis can be of the same order of magnitude as the interest rate differential. For example, the five-year basis for the Japanese yen was close to -90 basis points at the end of 2015, which was even greater in magnitude than the difference (of about -70 basis points) between the five-year Libor interest rate in Japan and in the United States. 
We show that credit risk in the Libor market and the indicative nature of Libor cannot explain away the persistence of the cross-currency basis. A common explanation for CIP deviations is that interbank panels have different levels of credit worthiness (e.g., Tuckman and Porfirio, 2004). If, for example, interbank lending in yen entails a higher credit risk (due to the average lower credit quality of yen Libor banks) than interbank lending in U.S. dollars, the lender should be compensated for the credit risk differential between yen Libor and dollar Libor, and thus the cross-currency basis needs not be zero. ${ }^{1}$ Studying the credit default spreads of banks on interbank panels in different currencies, we do not find much support for this explanation of the CIP deviations.

More crucially, we document that the currency basis exists even in the absence of any credit risk difference across countries and for actual interest rate quotes. To do so, we turn first to general collateral repurchase agreements (repo) and then to Kreditanstalt für Wiederaufbau (KfW) bonds issued in different currencies. Repo contracts are fully collateralized and thus do not exhibit any credit risk. KfW bonds are fully backed by the German government and thus exhibit very minimal credit risk, without differences in credit risk across currencies. Repo and forward contracts highlight the CIP deviations at the short-end of the yield curves, while KfW bonds and swaps focus on longer maturities. We find that the repo currency basis is persistently and significantly negative for the Japanese yen, the Swiss franc and the Danish krone, and that the KfW basis is also significantly different from zero for the euro, the Swiss Franc and the Japanese yen, even after taking into account transaction costs.

The CIP deviations thus lead to persistent arbitrage opportunities free from exchange rate and credit risks. A long-short arbitrageur may for example borrow at the U.S. dollar repo rate or short U.S. dollar-denominated KfW bonds and then earn risk-free positive profits by investing in repo rates or KfW bonds denominated in low interest rate currencies, such

\footnotetext{
1"Libor" rates are supposed to measure the interest rates at which Libor panel banks borrow from each other. We use the term "Libor" loosely to refer to the benchmark unsecured interbank borrowing rate, which can be determined by local interbank panels rather than the British Banker Association (now Intercontinental Exchange) Libor panels.
} 
as the euro, the Swiss franc, the Danish krone or the yen, while hedging the foreign currency risk using foreign exchange forwards or swaps. The net arbitrage profits range from 9 to 20 basis points on average in annualized values. The averages may appear small, but again they hide large time variations: the standard deviation of the net arbitrage profits range from 5 to 23 basis points. Moreover, the conditional volatility of each investment opportunity is naturally zero and Sharpe ratios are thus infinite for the fixed investment horizon of the strategy.

After documenting the persistence of CIP deviations and formally establishing arbitrage opportunities, we turn to their potential explanations. We hypothesize that persistent CIP deviations can be explained by the combination of the increased cost of financial intermediation post-crisis and persistent international imbalances in investment demand and funding supply across currencies. If financial intermediaries were unconstrained, the supply of currency hedging should be perfectly elastic, and any CIP deviations would be arbitraged away. Similarly, if the global funding and investment demand were balanced across currencies, there would be no client demand for FX swaps to transform funding liquidity or investment opportunities across currencies, and thus the cross-currency basis would also be zero regardless of the supply of currency hedging. Costly financial intermediation can explain why the basis is not arbitraged away post crisis. The imbalances in savings and investment across currencies can explain the systematic relationship between the basis and nominal interest rates.

Consistent with our two-factor hypothesis, we find that the CIP deviations exhibit four main characteristics. First, CIP deviations increase towards the quarter ends, as banks face tighter balance sheet constraints and renewed investors' attention due to quarterly regulatory filings. We find that the one-month CIP deviation increases exactly one month before the quarter ends, at the time when a one-month forward contract has to appear on the quarterend balance sheet. Likewise, the one-week CIP deviation increases exactly one week before the quarter ends. Meanwhile, a three-month CIP trade, which has to appear on a quarter-end 
report regardless of when it is executed, does not exhibit any particular dynamics. In this example, the one-month or the one-week forward contracts that cross the quarter ends are the "treated" assets, subject to higher balance sheet costs due to regulatory filings, while the three-month forward contract is the "non-treated" asset. Our simple difference-in-difference experiments exploits different lags before the quarter ends and different horizons of the forward contracts. The term structure of short-term CIP deviations suggest that banking regulations have a causal impact on asset prices.

Second, we find that a proxy for the shadow costs of banks' balance sheet accounts for about one third to one half of the CIP deviations. Our proxy is the spread between the interest rates on excess reserves (IOER) paid by the Fed and the Fed Funds or the U.S. Libor rate. In the absence of balance sheet costs, banks should borrow at the Fed Funds/U.S. Libor rate and invest risk-free at the IOER, until the Fed Funds/Libor rate increases and both rates are equal. Yet, a significant spread persists, and we interpret it as a proxy for the shadow cost of leverage. Furthermore, by taking into account the better liquidity of central bank reserve balances over private money market instruments, in part codified by the liquidity coverage ratio requirement under Basel III, the CIP deviations can be further reduced by comparing IOERs across major central banks.

Third, in the cross section and time series, the cross-currency basis is positively correlated with the level of nominal interest rates. In the cross section, high interest rate currencies tend to exhibit positive basis while low interest rate currencies tend to exhibit negative ones. An arbitrageur should thus borrow in high interest rate currencies and lend in low interest currencies while hedging the currency risk - this is the opposite allocation to the classic currency carry trade. In the time series, the cross-currency basis tends to increase with interest rate shocks, as measured in an event study of yield changes around monetary policy announcements of the European Central Bank.

Fourth, the cross-currency basis is correlated with other liquidity spreads, especially the KfW over German bund basis and the U.S. Libor tenor basis, the price of swapping the 
one-month in exchange of the three-month U.S. Libor rates. The co-movement in bases measured in different markets points to the role of financial intermediaries and correlated demand shocks for dollar funding and other forms of liquidity.

We turn now to a short review of the existing relevant work. A large literature tests the CIP condition before the global financial crisis and documents large CIP deviations during the crisis. Our work focuses on the post-crisis period and is closely related to a large literature that departs from the frictionless asset pricing benchmark. ${ }^{2}$ On the theory side, Garleanu and Pedersen (2011) build a margin-based asset pricing model and use it to study the deviations from CIP during the crisis. Gabaix and Maggiori (2015) provide a tractable and elegant model of exchange rate determination in the presence of moral hazard. A variant of their model, presented in their Appendix, encompasses CIP deviations. Our evidence on the impact of banking regulation points towards models of intermediary-based asset pricing, as those of He and Krishnamurthy $(2012,2013)$ and Brunnermeier and Sannikov (2014) in the tradition of Bernanke and Gertler (1989) and Holmstrom and Tirole (1997). But many other

\footnotetext{
${ }^{2}$ An early exposition of the CIP condition appears in Lotz (1889) and much more clearly in Keynes (1923). A large literature in the 70s and 80s tests the CIP condition, notably Frenkel and Levich (1975, 1977), Deardorff (1979), Dooley and Isard (1980), Callier (1981), Mohsen Bahmani-Oskooee (1985) and Clinton (1988). Up to the recent global financial crisis, the consensus was that the CIP condition holds in the data. Several papers study the failure of the CIP condition during the global financial crisis and the European debt crisis (see, e.g., Baba, Packer, and Nagano, 2008; Baba, McCauley, and Ramaswamy, 2009; Coffey, Hrung, and Sarkar, 2009; Griffolli and Ranaldo, 2011; Bottazzi, Luque, Pascoa, and Sundaresan, 2012; and Ivashina, Scharfstein, and Stein, 2015). All these papers focus on CIP deviations based on short-term money market instruments. The large cross-currency basis during the crisis appears to be linked to a severe dollar funding shortage in the presence of limits to arbitrage. The establishment of the Fed swap lines with various foreign central banks, which alleviated the dollar shortage, significantly reduced the magnitude of the cross-currency basis (Baba and Packer, 2009; Goldberg, Kennedy, and Miu, 2011; and McGuire and von Peter, 2012). Building on our work, CIP deviations after the crisis have become an area of active research. In on-going work, Advijev, Du, Koch and Shin (2016) studies the relationship between the strength of the dollar spot exchange rate and CIP deviations. Amador, Bianchi, Bicola and Perri (2016) model exchange rate policy at the zero-lower bound and relate it to CIP deviations. Liao (2016) examines the implications of corporate funding cost arbitrage on CIP deviations. Rime, Schrimpf and Syrstad (2016) focuses on the role of money market segmentation on CIP deviations. Sushko, Borio, McCauley and McGuire (2016) link the estimated dollar hedging demand (quantities) for major currencies to the variation in CIP deviations (prices).
} 
friction-based models could potentially be relevant. ${ }^{3}$ To the best of our knowledge, however, there is no model so far that can replicate our four main facts on CIP deviations. On the empirical side, Adrian, Etula and Muir (2014) and He, Kelly and Manela (2015) show that shocks to the equity capital ratio of financial intermediaries account for a large share of the cross-sectional variation in expected returns in different asset classes. Siriwardane (2016) shows that limited investment capital impacts pricing in the credit default swap market. Our work is also closely related to recent papers on the interaction between the new U.S. monetary policy implementation framework and banking regulations, as discussed in Duffie and Krishnamurthy (2016), Klee, Senyuz, and Yoldas (2016), and Benegas and Tase (2016), and window dressing activities in repo markets on financial reporting dates (Munyan, 2015).

The paper is organized as follows. Section 2 defines and documents precisely the CIP condition and its deviations at the short- and long-end of the yield curves. Section 3 shows that the cross-currency basis exists in the absence of credit risk, for repo rates and KfW bonds, leading to clear arbitrage opportunities. Section 4 sketches a potential explanation of the CIP deviations centered on the capital constraints of financial intermediaries and global imbalances. Consistent with such potential explanation, Section 5 presents four characteristics of the currency basis: its surge at the end of the quarters post-crisis, its high correlation with other liquidity-based strategies in different fixed-income markets, its relationship with the IOER, and finally its cross-sectional and time-series links with interest rates. Section 6 concludes.

\footnotetext{
${ }^{3}$ The large theoretical literature on limits-to-arbitrage, surveyed in Grombs and Vayanos (2011), provides useful frameworks, with the caveat that CIP arbitrages exist over very short time horizons over which market risk and collateral constraints are very limited. Focusing on the U.S. swap market, Jermann (2016) proposes a novel and attractive limits-to-arbitrage model based on the regulation-induced increased cost of holding Treasuries. Likewise, models of market and funding liquidity, as in Brunnermeier and Pedersen (2009), or models of preferred habitat, as in Vayanos and Vila (2009) and Greenwood or Vayanos (2014), are potential theoretical frameworks to account for the CIP deviations. Our findings are also related to models of the global imbalances in safe assets, as studied in the pioneer work of Caballero, Farhi, and Gourinchas (2008, 2016).
} 


\section{CIP Condition and Cross-Currency Basis}

In this section, we review the CIP condition and define the cross-currency basis as the deviation from the CIP condition. We then document the persistent failure of the textbook CIP condition based on Libor.

\subsection{Covered Interest Rate Parity}

Let $y_{t, t+n}^{\$}$ and $y_{t, t+n}$ denote the $n$-year risk-free interest rates in U.S. dollars and foreign currency, respectively. The spot exchange $S_{t}$ rate is expressed in units of foreign currency per U.S. dollar: an increase in $S_{t}$ thus denotes a depreciation of the foreign currency and an appreciation of the U.S. dollar. Likewise, $F_{t, t+n}$ denotes the $n$-year outright forward exchange rate in foreign currency per U.S. dollar at time $t$. The CIP condition states that the forward rate should satisfy:

$$
\left(1+y_{t, t+n}^{\$}\right)^{n}=\left(1+y_{t, t+n}\right)^{n} \frac{S_{t}}{F_{t, t+n}}
$$

In logs, the forward premium, $\rho_{t, t+n}$, is equal to the interest rate difference between interest rates in the two currencies:

$$
\rho_{t, t+n} \equiv \frac{1}{n}\left(f_{t, t+n}-s_{t}\right)=y_{t, t+n}-y_{t, t+n}^{\$}
$$

The intuition behind the CIP condition is simple: an investor with one U.S. dollar in hand today would own $\left(1+y_{t, t+n}^{\$}\right)^{n}$ U.S. dollars $n$ years from now by investing in U.S. dollars. But the investor may also exchange her U.S. dollar for $S_{t}$ units of foreign currency and invest in foreign currency to receive $\left(1+y_{t, t+n}\right)^{n} S_{t}$ units of foreign currency $n$ years from now. A currency forward contract signed today would convert the foreign currency earned into $\left(1+y_{t, t+n}\right)^{n} S_{t} / F_{t, t+n}$ U.S. dollars. If both domestic and foreign notes are risk-free aside from the currency risk and the forward contract has no counterparty risk, the two investment 
strategies are equivalent and should thus deliver the same payoffs. All contracts are signed today. The CIP condition is thus a simple no-arbitrage condition. ${ }^{4}$

\subsection{Definition of the Cross-Currency Basis}

We define the cross-currency basis, denoted $x_{t, t+n}$, as the deviation from the CIP condition:

$$
\left(1+y_{t, t+n}^{\$}\right)^{n}=\left(1+y_{t, t+n}+x_{t, t+n}\right)^{n} \frac{S_{t}}{F_{t, t+n}} .
$$

Equivalently, in logs, the currency basis is equal to:

$$
x_{t, t+n}=y_{t, t+n}^{\$}-\left(y_{t, t+n}-\rho_{t, t+n}\right) .
$$

When CIP holds, the comparison of Equations (1) and (3) immediately implies that the currency basis is zero. The cross-currency basis measures the difference between the direct U.S. dollar interest rate, $y_{t, t+n}^{\$}$, and the synthetic dollar interest rate, $y_{t, t+n}-\rho_{t, t+n}$, obtained by converting the foreign currency interest rate in U.S. dollars using currency forward contracts. A negative currency basis suggests that the direct U.S. dollar interest rate is lower than the synthetic dollar interest rate by swapping the foreign currency interest rate into dollars.

As already noted, CIP holds in the absence of arbitrage. As soon as the basis is not zero, arbitrage opportunities theoretically appear. The cash flow diagram of this CIP arbitrage strategy is summarized in Figure 1. In the case of a negative basis, $x<0$, the dollar arbitrageur can earn risk-free profits equal to an annualized $|x|$ percent of the trade notional by borrowing at the direct dollar risk-free rate, investing at the foreign currency risk-free

\footnotetext{
${ }^{4}$ In the presence of transaction costs, the absence of arbitrage is characterized by two inequalities: arbitrage must be impossible either by borrowing the domestic currency and lending the foreign currency, or doing the opposite, hedging the currency risk with the forward contract in both cases (see Bekaert and Hodrick, 2012, for a textbook exposition). As a result, the bid and ask forward rates satisfy:

$$
\frac{F_{t, t+n}^{a s k}}{S_{t}^{\text {bid }}} \geq \frac{\left(1+y_{t, t+n}^{b i d}\right)^{n}}{\left(1+y_{t, t+n}^{\$, a s k}\right)^{n}} \text { and } \frac{F_{t, t+n}^{b i d}}{S_{t}^{a s k}} \leq \frac{\left(1+y_{t, t+n}^{a s k}\right)^{n}}{\left(1+y_{t, t+n}^{\$, b i d}\right)^{n}}
$$
}


rate and signing a forward contract to convert back the foreign currency into U.S dollars. In the case of a positive basis, the opposite arbitrage strategy of funding in the synthetic dollar risk-free rate and investing in the direct dollar risk-free rate would also yield an annualized risk-free profit equal to $x$ percent of the trade notional. With these definitions in mind, we turn now to a preliminary look at the data.

\subsection{Failure of Textbook Libor-Based Covered Interest Parity}

Textbook tests of the CIP condition usually rely on Libor rates. ${ }^{5}$ We document persistent failure of Libor-based CIP after 2007 for G10 currencies at short and long maturities. As we just saw, at short maturities less than one year, CIP violations can be computed using Libor rates and currency forward and spot rates. At the longer maturities (typically one year or greater), CIP violations based on Libor are directly quoted as spreads on Libor cross-currency basis swaps.

\subsubsection{Short-Term Libor Cross-Currency Basis}

We define the Libor basis as equal to:

$$
x_{t, t+n}^{\text {Libor }} \equiv y_{t, t+n}^{\$, \text { Libor }}-\left(y_{t, t+n}^{\text {Libor }}-\rho_{t, t+n}\right),
$$

where the generic dollar and foreign currency interest rates of Equation (4) are replaced with Libor rates. We obtain daily spot exchange rates and forward points from Bloomberg using London closing rates for G10 currencies. ${ }^{6}$ Mid-rates (average of bid and ask rates) are used for benchmark basis calculations. Daily Libor/interbank fixing rates are also obtained

\footnotetext{
${ }^{5}$ Eurocurrency deposit rates based in London have long been used as benchmark interest rates to test the CIP condition, starting with the work of Frenkel and Levich (1975), because eurocurrency deposits are highly fungible and avoid many barriers to the free flow of capital, such as differential domestic interest rate regulations, tax treatments, and reserve regulations. Akram, Rime, and Sarno (2008) confirm the high-degree of validity of the CIP condition using bank deposit rates in the early 2000s sample.

${ }^{6}$ In practice, since forward points are often quoted with a higher level of precision that outright forwards, we compute the forward premium $\rho_{t, t+n}$ directly from forward points, defined as $F_{t, t+n}=S_{t}+F P_{t, t+n}$. Thus, the forward premium is: $\rho_{t, t+n} \approx(1 / n) F P_{t, t+n} / S_{t}$.
} 
from Bloomberg. Figure 2 presents the three-month Libor basis for G10 currencies between January 2000 and September 2016.

The three-month Libor basis was very close to zero for all G10 currencies before 2007. As is well-known, during the global financial crisis (2007-2009), there were large deviations from Libor CIP, especially around the Lehman bankruptcy announcement, with some bases reaching -200 basis points. But the deviations from Libor CIP did not disappear when the crisis abated. In the aftermath of the crisis, since 2010, the three-month Libor basis has been persistently different from zero. Panel A of Table 1 summarizes the mean and standard deviation of the three-month Libor cross-currency basis across three different periods: 2000-2006, 2007-2009, and 2010-2016. Pre-crisis, the Libor basis was not significantly different from zero; post-crisis, it is. Moreover, a clear cross-sectional dispersion in the level of the basis appears among G10 currencies. The Australian dollar (AUD) and the New Zealand dollar (NZD) exhibit on average a positive basis of 4 and 11 basis points at the three-month horizon, while the Swiss franc (CHF), Danish krone (DKK), euro (EUR), Japanese yen (JPY), Norwegian krone (NOK), and Swedish krona (SEK) exhibit on average negative bases all below -20 basis points. Among the G10 currencies, the Danish krone has the most negative three-month Libor basis post crisis, with an average of -61 basis points, a stark contrast to its pre-crisis average of one basis point. ${ }^{7}$

\subsubsection{Long-Term Libor Cross-Currency Basis}

At long maturities, the long-term CIP deviation based on Libor is given by the spread on the cross-currency basis swap. A cross-currency basis swap involves an exchange of cash flows linked to floating interest rates referenced to interbank rates in two different currencies, as well as an exchange of principal in two different currencies at the inception and the maturity of the swap. Let us take a simple example. Figure 3 describes the cash flow diagram for

\footnotetext{
${ }^{7}$ The Danish central bank maintains a peg of its currency to the euro. Yet, the CIP deviations are larger for the Danish krone than for the euro, in part reflecting the risk of a sudden break of the peg, similar to the Swiss franc experience in January 2015.
} 
the yen/U.S. dollar cross-currency swap on $\$ 1$ notional between Bank A and Bank B. At the inception of the swap, Bank A receives $\$ 1$ from Bank $\mathrm{B}$ in exchange of $¥ S_{t}$. At the $j$-th coupon date, Bank A pays a dollar floating cash flow equal to $y_{t+j}^{L i b o r, \$}$ percent on the $\$ 1$ notional to Bank B, where $y_{t+j}^{L i b o r, \$}$ is the three-month U.S. dollar Libor at time $t+j$. In return, Bank A receives from Bank B a floating yen cash flow equal to $\left(y_{t+j}^{L i b o r, ¥}+x_{t, t+n}^{x c c y}\right)$ on the $¥ S_{t}$ notional, where $y_{t+j}^{L i b o r, ¥}$ is the three-month yen Libor at time $t+j$, and $x_{t, t+n}^{x c c y}$ is the cross-currency basis swap spread, which is pre-determined at date $t$ at the inception of the swap transaction. When the swap contract matures, Bank B receives $\$ 1$ from Bank A in exchange of $¥ S_{t}$, undoing the initial transaction.

The spread on the cross-currency basis swap, $x_{t, t+n}^{x c c y}$, is the price at which swap counterparties are willing to exchange foreign currency floating cash flows against U.S. cash flows. In the case of the yen/U.S dollar cross-currency swap over the recent period, $x_{t, t+n}^{x c c y}$ is often negative. Let us assume for simplicity that Bank B is able to lend risk-free in yen at the three-month yen Libor rate, $y_{t+j}^{\text {Libor, } ¥}$. Then, according to the cross-currency basis swap contract, Bank B has to pay to Bank A the yen cash flows $\left(y_{t+j}^{\text {Libor, } ¥}+x_{t, t+n}^{x c c y}\right)$, which is clearly less than the yen Libor rate $y_{t+j}^{\text {Libor, } ¥}$ that Bank B collects by investing the yen it received originally from Bank A. In this example, Bank B pockets a sure profit by lending U.S. dollars to Bank A. In other words, if both banks can borrow and lend risk-free at Libor rates, then the cross-currency basis should be zero. As soon as the cross-currency basis swap is not zero, one counterparty seems to benefit from the swap, hinting at potential deviations from the CIP condition at the long end of the yield curve.

More formally, to see how the cross-currency basis swap directly translates into deviations from the long-term Libor-based CIP condition, let us focus on the case of zero-coupon fixedfor-fixed cross-currency swap contracts. Such contracts are similar to the swap contract described above and in Figure 3, but no coupon payments are exchanged at the intermediary dates. Intuitively, an investor can take three steps to swap fixed foreign currency cash flows into fixed U.S. dollar cash flows. First, she pays the foreign currency interest rate swap, $y_{t, t+n}^{I R S}$, 
to swap fixed foreign currency cash flows into floating foreign currency Libor cash flows. Second, she pays the cross-currency basis swap, $x_{t, t+n}^{x c c y}$, to swap floating foreign currency Libor into U.S. dollar Libor cash flows. Third, she receives the U.S. interest rate swap, $y_{t, t+n}^{\$, I R S}$, to swap floating dollar U.S. Libor cash flows into fixed U.S. dollar cash flows. As Figure 4 illustrates, the combination of the three steps eliminate all floating cash flows, and only exchanges of fixed cash flows in two different currencies at the inception and maturity of the swap remain.

In this synthetic agreement, an investors pays $\$ 1$ in exchange of $S_{t}$ yen at the start of the swap period, receives $\left(1+y_{t, t+n}^{\$, I R S}\right)^{n}$ U.S. dollars at the maturity of the contract and pays $\left(1+y_{t, t+n}^{I R S}+x_{t, t+n}^{x c c y}\right)^{n} S_{t}$ yen at the end of the contract, worth $\left(1+y_{t, t+n}^{I R S}+x_{t, t+n}^{x c c y}\right)^{n} S_{t} / F_{t, t+n}$ U.S. dollars at that time. The cross-currency basis swap rates are priced such that:

$$
\left(1+y_{t, t+n}^{\$, I R S}\right)^{n}=\left(1+y_{t, t+n}^{I R S}+x_{t, t+n}^{x c c y}\right)^{n} \frac{S_{t}}{F_{t, t+n}}
$$

Equivalently, the long-term forward premium to hedge a foreign currency against the U.S. dollar is implicitly given by:

$$
\rho_{t, t+n} \equiv \frac{1}{n}\left(f_{t, t+n}-s_{t}\right)=y_{t, t+n}^{I R S}+x_{t, t+n}^{x c c y}-y_{t, t+n}^{\$, I R S}
$$

The cross-currency basis swap rate, $x_{t, t+n}^{x c c y}$, thus measures deviations from the CIP condition where interest rates are Libor interest rate swap rates.

Data on cross-currency basis swaps come from Bloomberg. Figure 5 shows the five-year Libor basis for G10 currencies between January 2001 and September 2016, while the Panel B of Table 1 reports averages and standard deviations by sub-periods. Before 2007, the fiveyear Libor basis was slightly positive for Australian, Canadian, and New Zealand dollars and negative for all the other currencies, but all bases were very close to zero. The five-year Libor bases started diverging away from zero in 2008, and reached their sample peak during the European debt crisis in 2012. The Libor bases narrowed in 2013 and early 2014, but 
started widening again in the second half of 2014. In the post-crisis sample, the Australian dollar and the New Zealand dollar exhibit the most positive bases, equal to 25 and 31 basis points on average, respectively, while the Japanese yen and the Danish krone exhibit the most negative bases, equal to -62 and -47 basis points on average, respectively. The Swiss franc and the euro also experience very negative bases.

At short and long horizons, CIP deviations abound post-crisis. But the textbook treatment of these deviations point to potential transaction costs and default risk, not necessarily to arbitrage opportunities.

\section{CIP-Based Arbitrage Opportunities}

In this section, we start with a short description of the main issues of a Libor-based investment strategy and then address those issues using repo contracts and bonds issued by KfW and other multi-currency issuers. We demonstrate that the existence of the repo and KfW basis implies CIP arbitrage opportunities free from currency and credit risk, even after taking into account transaction costs.

\subsection{Credit Risk in the Libor CIP Arbitrage}

A potential arbitrageur, noticing for example a negative Libor CIP basis on the yen/dollar market, would need to borrow in U.S. dollars at the dollar Libor rate, invest in yen at the yen Libor rate and enter a forward contract to convert back yen into U.S dollars at the end of her investment period. The investment strategy raises immediately three questions. First, can the arbitrageur really borrow and lend at the Libor rates? Libor rates are only indicative and do not correspond to actual transactions. The actual borrowing rate in U.S. dollars of the arbitrageur may thus be higher than the indicative Libor rate, even in the absence of any manipulation. More generally, transaction costs exist for both spot and derivative contracts and may lower the actual returns. Second, is the arbitrageur taking on credit risk when 
lending at the yen Libor rate? Libor rates are unsecured: if the arbitrageur faces a risk of default on her loan, she should be compensated by a default risk premium, which may then account for the CIP deviations. Third, is the arbitrageur taking on counterparty risk when entering an exchange rate forward contract? This last concern can be ruled out, as the impact of counterparty risk on the pricing of forwards and swaps is negligible due to the high degree of collateralization. As specified in the Credit Support Annex of the International Swap and Derivative Association, the common market practice is to post variation margins in cash with the amount equal to the mark-to-market value of the swap. Initial margins are also posted to cover the gap risk not covered by the variation margins. In the event of a counterparty default, the collateral is seized by the other counterparty to cover the default cost. $^{8}$

The indicative nature of Libor and the potential default risk are valid concerns. Default risk appears indeed as the recent leading explanation of the CIP deviations in the literature (e.g., Tuckman and Porfirio, 2004). Formally, the default risk explanation of CIP deviations relies on cross-country differences in credit worthiness of different Libor panel banks. Let us assume that the mean credit spread for the yen Libor panel is given by $s p_{t}^{J P Y}$ and the mean credit spread for the U.S. dollar Libor panel is given by $s p_{t}^{U S D}$. Let $y_{t}^{* J P Y}$ and $y_{t}^{* U S D}$ be the true risk-free rates in yen and U.S. dollars and assume that CIP holds for risk-free rates. Starting from the definition of the basis in Equation (4) and replacing each interest by the sum of the risk-free rate and the credit spread leads to:

$$
\begin{aligned}
x_{t}^{J P Y / U S D, \text { Libor }} & =\left(y_{t}^{* U S D}+s p_{t}^{U S D}\right)-\left(y_{t}^{* J P Y}+s p_{t}^{J P Y}-\rho_{t}^{J P Y / U S D}\right), \\
& =\left[y_{t}^{* U S D}-\left(y_{t}^{* J P Y}-\rho_{t}^{J P Y / U S D}\right)\right]+\left(s p_{t}^{U S D}-s p_{t}^{J P Y}\right) .
\end{aligned}
$$

\footnotetext{
${ }^{8}$ Direct empirical estimates for the magnitude of counterparty risk is available for the credit default swap (CDS) market, where counterparty risk is a more serious concern due to the possibility of losing the full notional of the trade. Consistent with high degree of collateralization, Arora, Gandhi, and Longstaff (2011) find that a 645 basis point increase in the seller's CDS spreads translates only to a one basis point reduction in the quoted CDS premium using actionable quote data. Using real CDS transaction data, Du, Gadgil, Gordy, and Vega (2016) obtain estimates of similar magnitude.
} 
In the absence of CIP deviations for risk-free rates, the term inside brackets is zero. In this case, the Libor-based currency basis of the yen/dollar is given by the difference between credit risk in dollar and yen Libor panels:

$$
x_{t}^{J P Y / U S D, \text { Libor }}=s p_{t}^{U S D}-s p_{t}^{J P Y} .
$$

Therefore, the yen basis can be negative if the yen Libor panel is riskier than the U.S. Libor panel. We test this hypothesis by regressing changes in the Libor basis $\Delta x_{t}^{i, L i b o r}$ for currency $i$ on changes in the mean credit default swap spreads (CDS) between banks on the interbank panel of currency $i$ and the dollar panel:

$$
\Delta x_{t}^{i, L i b o r}=\alpha^{i}+\beta \Delta\left(c d s_{t}^{i}-c d s_{t}^{U S D}\right)+\epsilon_{t}^{i}
$$

We use weekly changes in five-year Libor cross-currency basis swaps and five-year CDS of banks since 2007. The list of banks on the interbank panels included in our study is in Appendix A. If CDS measure credit spreads perfectly, Equation (8) suggests a slope coefficient of -1 and an $R^{2}$ of 1 . Table 2 reports the regression results from January 2007 to September 2016. In the pooled panel regression with currency fixed effects reported in the first column, the coefficient on the CDS spread differential is negligible, statistically not different from zero. Results based on individual currencies in the following columns show that the slope coefficient is only significantly negative for the Swiss franc and euro. In all the other cases, the slope coefficient are either insignificant or positive. Even in the case of the Swiss franc and the euro, the negative coefficients on the CDS differential are far from being equal to -1 . In all cases, $R^{2}$ are tiny. Assuming that bank CDS proxy for the credit risk of potential CIP arbitrageurs, there is therefore some doubt that the credit spread 
differential is the most important driver for the Libor cross-currency basis of G10 currencies in the post-crisis period. ${ }^{9}$ We rule out credit risk by turning to repo contracts.

\subsection{Repo Basis}

At short maturities, one way to eliminate the credit risk associated with Libor-based CIP is to use secured borrowing and lending rates from the repo markets. We thus use general collateral (GC) repo rates in U.S. dollars and foreign currencies to construct an alternative currency basis measure.

A GC repo is a repurchase agreement in which the cash lender is willing to accept a variety of Treasury and agency securities as collateral. Since GC assets are of high quality and very liquid, GC repo rates are driven by the supply and demand of cash, as opposed to the supply and demand of individual collateral assets.

Given the U.S. dollar GC repo rate $y_{t, t+n}^{\$, R e p o}$ and the foreign currency GC repo rate $y_{t, t+n}^{\text {Repo }}$, the general definition of the basis in Equation (4) leads to the following repo basis:

$$
x_{t, t+n}^{\text {Repo }}=y_{t, t+n}^{\$, R e p o}-\left(y_{t, t+n}^{\text {Repo }}-\rho_{t, t+n}\right) .
$$

Since the bulk of repo transactions are concentrated at very short maturities, we focus on the repo basis at the one-week horizon. ${ }^{10}$

\footnotetext{
${ }^{9}$ The credit spread differential, however, has a much more significant effect on the cross-currency basis of emerging market currencies.

${ }^{10}$ We can obtain similar results for the overnight tenor. However, since overnight forward premium needs to be annualized (i.e., multiplied by $360 /$ actual days) to obtain the annual forward premium, any measurement errors or unaccounted holidays would have very large impacts on the basis. We focus on the one-week horizon to lower measurement errors.
} 
Our data cover the Swiss, Danish, Euro, Japanese, and U.S. repo markets. ${ }^{11}$ Figure 6 reports the one-week Libor and repo basis for these markets since 2009. The repo basis tracks the Libor basis very closely for the Swiss Franc and the yen, and remains negative throughout the sample. For the Danish krone and the euro, the repo basis was closer to zero than the Libor basis during the peak of the European debt crisis, but it tracks the Libor basis very closely overall. Most of the time, the Libor- and repo-based deviations from CIP are undistinguishable from each other.

The first two columns of Table 3 report the annualized mean and standard deviation of Libor- and repo-based bases during the January 2009 to September 2016 period. The Danish krone exhibits the most negative mean repo basis, equal to -41 basis points if Libor-based and -34 basis points if repo-based. The euro exhibits the least negative mean repo basis equal to -20 basis points with repo rates and -16 with Libor rates. For the Swiss franc, the Libor and repo rates deliver similar basis: -21 and -25 basis points. For the yen, the repo basis is larger in magnitude for repo than for Libor rates: -27 vs -23 basis points. Clearly, CIP deviations exist even for interest rates that are free of credit risk. The third column of Table 3 reports the same summary statistics but conditional on a negative basis. The repo basis is negative $99 \%$ of the days for the swiss franc, $96 \%$ for the euro and the Danish krone and $100 \%$ for the yen. As a result, the conditional and unconditional average basis are close, ranging from -16 basis points for the euro to -36 basis points for the Danish krone.

A negative basis entices the arbitrageur to borrow at the U.S. dollar GC repo rate and invest in the foreign currency GC repo rate, while paying the forward premium to hedge the foreign currency exposure. A positive basis suggests the opposite strategy, borrowing at

\footnotetext{
${ }^{11}$ U.S. bid and ask repo rates come from the Thomson Reuters Tick History database. The mid rates are very close to the daily GC repo quotes from JP Morgan (obtained from Morgan Markets), one of the only two clearing banks to settle tri-party U.S. repo markets. The euro mid repo data based on German bunds as collateral are obtained from Bloomberg. Similar series from JP Morgan are very close the Bloomberg series, but shorter. Swiss franc mid repo and Danish krone bid and ask repo rates also come from Bloomberg. The Japanese repo rates come from the Bank of Japan and the Japan Securities and Dealer Association. Bid and ask rates on euro repos are available from Thomson Reuters Eikon. We do not use the Thomson Reuters Eikon GC euro rates in our baseline calculation because eligible collateral also includes sovereign bonds in other European countries besides the German bunds. Thomson Reuters Eikon GC repo rates are persistently higher than the Bloomberg rates, and thus imply larger arbitrage profits than the reported results.
} 
the foreign currency rate, receiving the forward premium, and investing in the U.S. dollar rate. The arbitrage profits under the negative and positive arbitrage strategies, denoted by $\pi^{\text {Repo- }}$ and $\pi^{\text {Repo+ }}$, are thus:

$$
\begin{aligned}
\pi_{t, t+n}^{\text {Repo- }} & \equiv\left[y_{t, t+n, \text { Bid }}^{\text {Repo }}-(1 / n) \times F P_{t, t+n, A s k} / S_{t, \text { Bid }}\right]-y_{t, t+n, \text { Ask }}^{\$, \text { Repo }}, \\
\pi_{t, t+n}^{\text {Repo+ }} & \equiv y_{t, t+n, \text { Bid }}^{\$, \text { Repo }}-\left[y_{t, \text { Ask }}^{\text {Repo }}-(1 / n) \times F P_{t, t+n, \text { Bid }} / S_{t, t+n, A s k}\right] .
\end{aligned}
$$

We assume that the transaction cost for each step of the arbitrage strategy is equal to one half of the posted bid-ask spread. We take into account bid-ask spreads on all forward and spot contracts and a conservative bid-ask spread for the U.S. dollar repo. The average bidask spread for U.S. repo used in our calculation is about 9 basis points, which is significantly higher than the 4 basis points bid-ask spread quoted on Tullett Prebon. Transaction costs for Danish repos are also taken into account with significantly wider average bid-ask spreads equal to 19 basis points. The Bloomberg series used in our repo basis calculations do not contain bid-ask spreads for the euro, Swiss franc and yen. In the case of euro repos, data from Thomson Reuters Eikon suggest that the average bid-ask spread is about 6 basis points. We do not have bid-ask spreads information available for the Swiss franc and the yen.

The fourth column of Table 3 reports the net profits obtained from the negative basis arbitrage strategy, which is implemented provided that the ex-ante profits are positive. The average annualized profits range from 11 to 19 basis points after taking into transaction costs. The profits vary over time, with standard deviations ranging from 13 basis points to 27 basis points. The arbitrage profits are positive for the majority of the sample window. The conditional volatility of each arbitrage strategy is again naturally zero, and the conditional Sharpe ratio is infinite.

The magnitude of the arbitrage profits is significant given the sheer size of repo markets in the United States, Europe and Japan. In 2015, the total size of the U.S. repo market is estimated to be around $\$ 2.2$ trillion with $\$ 1.5$ trillion of repos based on GC collateral. 
(Baklanova, Copeland, and McCaughrin, 2015). In Japan, the total size of the repo market is about $\$ 1$ trillion with $\$ 0.5$ trillion GC repos (Sato, 2015). Survey results reported by the International Capital Markets Association (ICMA, 2016) suggest that the total size of the repo market in Europe is about $\$ 3$ trillion, of which the euro accounts for about $\$ 1.8$ trillion of the cash currency and government securities account for about $\$ 2.1$ trillion of collaterals. On the other hand, the Danish krone and Swiss franc repo markets are much smaller, with a combined size of less than $\$ 75$ billion.

Repo contracts are generally characterized by their lending rates and the haircut rates applied to the collateral. Yet, no haircuts are customary for GC repo contracts involving Treasuries in Japan and Switzerland. In the U.S., GC repos traded under the Fixed Income Clearing Corporation's (FICC) GCF services also have zero haircuts. Haircuts exist on U.S. tri-party repo contracts and euro GC repo contracts, but they appear stable and similar across countries. ${ }^{12}$ We do not have haircut rates for the Danish Krone, but for the other markets, the short-term CIP deviations do not appear linked to variations in haircut rates.

\subsection{KfW Basis}

We turn now to CIP deviations at the long end of the yield curves. GC repo contracts do not exist for long maturities, but we can construct an alternative long-term cross-currency basis free from credit risk by comparing direct dollar yields on dollar denominated debt and synthetic dollar yields on debt denominated in other currencies for the same risk-free issuer and the same maturity in years. To do so, we focus on bonds issued by the KfW, an AAA-rated German government-owned development bank, with all its liabilities fully

\footnotetext{
${ }^{12}$ In the U.S. tri-party repo market, haircuts have been very stable at $2 \%$ for any Treasury collateral. In the case of the euro GC repo market, the leading electronic trading platform EUREX applies haircuts set by the ECB in its refinancing operations. The ECB haircuts vary with the credit quality and maturity of the collateral. Throughout our sample period, the haircuts on German bund collateral changed only slightly once in 2013. Early in the sample, haircuts on German Treasury collateral for the remaining maturity brackets are $0.5 \%$ ( $0-1$ years), $1.5 \%$ (1-3 years), $2.5 \%$ ( $3-5$ years), $3 \%$ ( $5-7$ years), $4 \%$ ( $7-10$ years) and $5.5 \%$ ( $>10$ years). On July 17, 2013, the ECB changed haircuts on German Treasury collateral to $0.5 \%$ (0-1 years), 1 (1-3 years), $1.5 \%$ (3-5 years), $2 \%$ ( $5-7$ years), $3 \%$ (7-10 years) and $5 \%$ ( $>10$ years). Haircuts exist on German bunds with remaining maturities of 5 to 7 years are thus comparable to the $2 \%$ haircut rate in the U.S. tri-party repo market.
} 
backed by the German government. The KfW is a very large multi-currency issuer, with an annual issuance of around $\$ 70$ billion and $\$ 370$ billion of bonds outstanding. Schwartz (2015) provides more details on the KfW bonds, comparing them to German government bonds to study their liquidity premium. Instead, we compare KfW bonds of similar maturity issued in different currencies. ${ }^{13}$

For the simplicity of exposition, we consider a world with zero-coupon yield curves and swap rates. Detailed calculations involving coupon bearing bonds and additional data are reported in the Online Appendix. Following the general definition of the basis in Equation (2), the KfW cross-currency basis is the difference between the direct borrowing cost of KfW in U.S. dollars and the synthetic borrowing cost of KfW in a foreign currency $j$ :

$$
x_{t, t+n}^{K f W}=y_{t, t+n}^{\$, K f W}-\left(y_{t, t+n}^{j, K f W}-\rho_{t, t+n}^{j}\right)
$$

where $y_{t, t+n}^{\$, K f W}$ and $y_{t, t+n}^{j, K f W}$ denote the zero-coupon yields on KfW bonds denominated in U.S. dollars and foreign currency $j$.

The first column of Table 4 reports summary statistics on the KfW basis during the January 2009 to August 2016 period. The mean post-crisis KfW basis is very close to zero for the Australian dollar (0.1 basis points) but is significantly negative for the other three currencies: -24 basis points for the Swiss franc, -14 basis points for the euro, and -30 basis points for the yen. The second column of Table 4 reports similar summary statistics for the basis conditional on a positive basis for the Australian dollar and a negative basis for the other three currencies: while the Australian dollar basis is only positive $57 \%$ of the time, the other bases are negative at least $94 \%$ of the sample. As a result, the average conditional basis is 7 basis points for the Australian dollar, and close to their unconditional values for

\footnotetext{
${ }^{13}$ The euro and the U.S. dollar are the most important funding currencies for $\mathrm{KfW}$, followed by the British pound and the Australian dollar. Currently, there are about $\$ 170$ billion euro-denominated KfW bonds outstanding and $\$ 130$ billion dollar-denominated bonds outstanding. Very similar results can be obtained for the European Investment Bank, a AAA-rated supranational agency.
} 
the other currencies: -24 basis points for the Swiss franc, -15 basis points for the euro, and -31 basis points for the yen. These bases point to potential arbitrage strategies.

When the KfW basis is negative, a potential arbitrage strategy would be to invest in the KfW bond denominated in foreign currency, pay the cross-currency swap to swap foreign currency cash flows into U.S. dollars, and short-sell the KfW bond denominated in U.S. dollars. When the KfW basis is positive, the arbitrage strategy would be the opposite. Arbitrage profits under the negative and positive strategies, denoted by $\pi_{t, t+n}^{K f W-}$ and $\pi_{t, t+n}^{K f W+}$, are:

$$
\begin{aligned}
& \pi_{t, t+n}^{K f W-} \equiv\left[\left(y_{t, t+n, B i d}^{j, K f W}-y_{t, t+n, A s k}^{I R S, j}\right)-x_{t, t+n, A s k}^{x c c y, j}-\left(y_{t, t+n, A s k}^{\$, K f w}-y_{t, t+n, B i d}^{\$, I R S}\right)-f e e_{t, t+n}^{\$},\right. \\
& \pi_{t, t+n}^{K f W+} \equiv\left(y_{t, t+n, B i d}^{\$, K f w}-y_{t, t+n, A s k}^{\$, I R S}\right)-\left[\left(y_{t, t+n, A s k}^{j, K f W}-y_{t, t+n, B i d}^{I R S, j}\right)+x_{t, t+n, B i d}^{x c c y, j}\right]-f e e_{t, t+n}^{j} .
\end{aligned}
$$

where $f e e_{t, t+n}^{\$}$ and $f e e_{t, t+n}^{j}$ denote the short-selling fee of the dollar and foreign currency bonds. We obtain all bid and ask prices for bond and swap rates from Bloomberg. Since interest rate swaps and cross-currency swaps are very liquid derivatives for G10 currencies, the total swap transaction cost is on average about 5 basis points since 2009. We obtain KfW shorting costs from transaction-level data provided by Markit Securities Finance (formerly known as Data Explorer). ${ }^{14}$ Post crisis, the median shorting cost fluctuates around 15 basis points.

The last three columns of Table 4 describe the profits net of transaction costs for the positive Australian dollar arbitrage and the negative Swiss franc, euro, and Japanese yen arbitrages. The third column takes into account bid-ask spreads on swaps and bonds, but not the bond short selling costs. The negative basis arbitrage strategy yields positive profits for Swiss franc, euro, and Japanese yen for the majority of the sample, with averages ranging

\footnotetext{
${ }^{14}$ The Online Appendix reports the time series of the KfW basis by currency as well as the 25 percentile, median, and 75 percentile of shorting costs for U.S. dollar bonds issued by KfW. There is a significant crosssectional dispersion in terms of shorting costs across transactions. During the peak of the global financial crisis, the 25 percentile and median shorting costs were negative, which reflects demand for U.S. dollar cash or U.S. Treasury collateral.
} 
from 10 to 22 basis points. The positive arbitrage strategy of the Australian dollar yields positive profits only $10 \%$ of the sample. The fourth and fifth columns report similar profits taking also into account the cost of shorting KfW bonds. The fourth (fifth) column assumes that the costs are equal to the 25th (50th) percentile of the shorting costs for KfW bonds of the corresponding currency on the same trading date. The negative basis arbitrage strategy yields positive profits between $30 \%$ and $50 \%$ of the sample for the Swiss franc and the euro, and around $75 \%$ of the sample for the Japanese yen. The positive basis arbitrage only yields profits in less than $5 \%$ of the sample for the Australian dollar. While the Australian dollar does not exhibit significant arbitrage opportunities net of transaction costs, the Swiss franc, euro, and Japanese yen clearly do. Assuming that arbitrageurs incur the median shorting fees prevalent on the day of their transaction, average profits range from 8 to 20 basis points, with standard deviations ranging from 5 to 11 basis points. Again, the conditional volatility of such strategies is zero and the conditional Sharpe ratio is infinite for the fixed investment horizon of the bonds.

Can cross-country differences in the liquidity of KfW bonds explain the CIP deviations? The answer depends on the currency pairs. For the euro and the Australian dollar, differences in liquidity vis-a-vis the U.S. dollar cannot explain CIP deviations; for the yen and the Swiss franc, they may. On the one hand, the liquidity of euro-denominated KfW bonds is at least comparable to, if not better than, the liquidity of dollar-denominated bonds. Therefore, liquidity differences cannot explain the positive arbitrage profits of going long in the euro bonds and shorting the U.S. dollar bonds. Likewise, the Australian dollar market, with the amount outstanding around $\$ 21$ billion, is significantly less liquid than the U.S. dollar market. ${ }^{15}$ Thus, the lower liquidity in the KfW Australian market works against finding positive CIP arbitrage opportunities of going long in U.S. dollar-denominated KfW bonds and shorting Australian-dollar denominated KfW bonds.

\footnotetext{
${ }^{15}$ The Australian regulatory authority does not assign zero-risk weight to Australian-dollar-denominated KfW bonds, citing reasons for low secondary market liquidity.
} 
On the other hand, the Swiss franc and the Japanese yen markets are comparatively small with total amounts outstanding of less than $\$ 5$ billion. As a result, liquidity differential can be a potential factor in explaining the positive profits of going long in the more illiquid yen and Swiss franc KfW bonds and shorting the more liquid dollar KfW bonds.

Overall, deviations from CIP are present in many currency and fixed income markets, often leading to significant arbitrage opportunities. In the next section, we review the potential causes of such arbitrage opportunities.

\section{Potential Explanations}

Deviations from CIP are at odds with a frictionless financial market. In this section, we hypothesize that the persistent and systematic CIP deviations can be explained by a combination of two factors: (1) costly financial intermediation, which affects the supply of exchange rate forwards and swaps, and (2) international imbalances in investment demand and funding supply across currencies, which affect the demand for exchange rate forwards and swaps. The cross-currency basis measures the cost of currency hedging subject to supply and demand side shocks.

\subsection{Costly Financial Intermediation}

Before the global financial crisis, global banks actively arbitraged funding costs in the interbank markets across currencies and enforced the CIP condition. Since the crisis, a wide range of regulatory reforms has significantly increased the banks' balance sheet costs associated with arbitrage and market making activities. Bank regulations likely affect other non-regulated entities, such as hedge funds, increasing the cost of leverage for the overall financial market. We consider more specifically how the following banking regulations affect

the CIP arbitrages: (i) non-risk weighted capital requirements, or the leverage ratio, (ii) risk-weighted capital requirements, and (iii) other banking regulations, such as the restric- 
tions on proprietary trading and the liquidity coverage ratio. Finally, we also discuss limits to arbitrage facing other players, such as hedge funds, money market funds, FX reserve managers and corporate issuers.

Non-risk-weighted Capital Requirements First, non risk-weighted capital requirements are particularly relevant for short-term CIP arbitrage. The leverage ratio requires banks to hold a minimum amount of capital against all on-balance-sheet assets and offbalance-sheet exposure, regardless of their risk. Short-term CIP arbitrage trades have very little market risk, but still expand bank balance sheets since it involves borrowing and lending in the cash markets and therefore makes the leverage ratio requirement more binding. ${ }^{16}$

For foreign banks, the leverage ratio did not exist before the crisis; it is now equal to $3 \%$ under Basel III. ${ }^{17}$ For U.S. banks, even though the leverage ratio existed before the crisis, the ratio became more stringent after the crisis with the introduction of the supplementary leverage ratio, which equals 5-6\% for systematically important financial institutions. The leverage ratio requirement is likely to be acting as the constraint on the bank balance sheet (Duffie, 2016). If the leverage ratio is equal to $3 \%$ and binds, a simple back of the envelope approximation illustrates its impact: if we assume that banks need to hold $3 \%$ of their capital against the CIP arbitrage trades and that their overall objective in terms of rates of return on capital is around 10\%, then banks need at least a $3 \% \times 10 \%=30$ basis point cross-currency basis to engage in the trade. ${ }^{18}$ In a nutshell, many of the arbitrage opportunities that are

\footnotetext{
${ }^{16}$ Banks may arbitrage the CIP deviations as real money investors, selling dollar Treasury bills and purchasing an equivalent value of yen Treasury bills. Such trades change the composition of the assets without affecting the total size of the balance sheet, and thus have no effects on the leverage ratio.

${ }^{17}$ As noted by the Basel Committee on Banking Supervision (2014), "Implementation of the leverage ratio requirements has begun with bank-level reporting to national supervisors of the leverage ratio and its components from 1 January 2013, and will proceed with public disclosure starting 1 January 2015. The Committee will continue monitoring the impact of these disclosure requirements. The final calibration, and any further adjustments to the definition, will be completed by 2017, with a view to migrating to a Pillar 1 (minimum capital requirement) treatment on 1 January 2018." Even though there is no formal penalty during the observation period before the rule finally kicks on January 1, 2018. The leverage ratio has been a concern for European banks due to the close monitoring by the regulatory authority and public disclosure requirements.

${ }^{18}$ Even if the leverage ratio requirement does not bind, banks might prefer to maintain some buffer over the minimum leverage ratio requirement, so the leverage ratio would still matter.
} 
balance sheet intensive may not be attractive enough for banks: as balance sheet expansion becomes expensive due to the leverage ratio requirement, banks may limit or even shy away from CIP arbitrage.

The Basel Committee recommends the leverage ratio to be disclosed at minimum at the quarter end. The actual calculation method of the leverage ratio differs across jurisdictions. For European banks, effective in January 2015, the European Leverage Ratio Delegated Act switches the definition of this ratio from the average of the month-ends over a quarter to the point-in-time quarter-end ratio. For U.S. banks, the supplementary leverage ratio is calculated based on the daily average balances of the quarter. Furthermore, mandatory public disclosure of the Leverage Ratio for European banks began in January 2015. Since European banks play an important role intermediating U.S. dollars offshore, we expect the quarter-end dynamics to be particularly pronounced since January 2015.

Risk-weighted Capital Requirements Second, from the perspective of risk-weighted capital, global banks face significantly higher capital requirements since the global financial crisis. For example, for the eight U.S. globally systematically important banks (G-SIBs), the Tier 1 capital ratio increased from $4 \%$ pre-crisis to the $9.5 \%-13 \%$ range under Basel III, and the total capital ratio increased from $8 \%$ to the $11.5 \%-15 \%$ range. ${ }^{19}$ In addition to higher capital ratios against the risk-weighted assets (RWA), the estimation of the RWA itself also increased significantly due to more stringent capital rules and the higher volatility of the cross-currency basis.

The central component of the RWA calculation for a CIP trade is the 99\% Value-at-Risk (VaR) measure based on the 10-business-day holding period returns, typically calculated over a sample window that corresponds to the past calendar year. Since one-week arbitrage opportunities exhibit zero VaR, constraints about RWA only matter for long-term CIP arbitrages. Basel II.5 (effective January 2013 in the United States) introduced an additional

\footnotetext{
${ }^{19}$ The breakdown of the capital ratio under the U.S. implementation of Basel III is as follows: $4.5 \%$ minimum common equity Tier 1 (CET1) capital, $1.5 \%$ additional Tier 1 capital, $2 \%$ Tier 2 capital, $2.5 \%$ CET1 capital conservation buffer and $1 \%$ to $4.5 \%$ CET1 G-SIB surcharge.
} 
"stress-VaR" (SVaR) calibrated for the stress period. As Figure 5 shows, the cross-currency basis became significantly more volatile after the crisis, thus increasing the VaR on the CIP trade.

Table 5 illustrates the increase in capital charges against a five-year Libor CIP trade in recent years. For simplicity, we assume that only VaR and SVaR matter for RWA, while ignoring all other add-on risk charges, and we consider a CIP trade in isolation, ignoring the rest of the banks' portfolio. The first column reports the $99 \%$ VaR measure for the trade based on the 10-business-day holding period; the VaR is annualized (multiplied by 26). The VaR measure was below $5 \%$ before the crisis, but increased to $20 \%$ during the peak of the crisis and remained elevated after the crisis. The second column reports the SVaR, implemented in January 2013 in the United States under Basel II.5, which equals the VaR in 2009. The third column reports the minimum total capital ratio for U.S. banks. Finally, the fourth column presents the total capital charges against the CIP trade. It is obtained by multiplying the sum of VaR and SVaR by the minimum capital ratio and scaling by a factor of 12.5 times 3, as specified by the Basel rules. Capital charges against the five-year CIP trade increase dramatically from less than $0.4 \%$ before the crisis to more than $4 \%$ of the trade notional after both Basel II.5 and Basel III went into effect. In other words, banks engaging in CIP arbitrages could trade a volume equal to 250 times their equity before the crisis; now, they can only trade a volume equal to 25 times their equity. While the RWA is likely to be very small for short-term CIP arbitrage, it appears as a significant concern for long-term CIP arbitrage.

Other Banking Regulations Third, a host of other financial regulations have also reduced banks' willingness to engage in CIP arbitrage. For example, the Volcker Rule (a part of the Dodd-Frank Act) forbids banks to actively engage in proprietary trading activities. Proprietary trading in spot exchange rates is allowed, but not in exchange rate forwards and swaps. As a result, banks can only engage in market making or facilitate arbitrage activities 
of their clients in the exchange rate derivative markets. ${ }^{20}$ In addition, the over-the-counter derivatives market reform sets higher capital and minimum margin requirements for crosscurrency swaps, which are generally uncleared, further increasing the capital necessary to implement the CIP trade.

In addition to the new risk-weighted capital rules and the leverage ratio, the Basel III agreement also introduces the liquidity coverage ratio, which requires banks to hold High Quality Liquidity Assets (HQLA) against potential net cash outflows during a 30-day stress period. The expected net cash outflows are defined as expected cash outflows minus expected cash inflows. The expected inflows are at most equal to $75 \%$ of the expected outflows. When the $75 \%$ inflow cap is not binding, since the CIP trade goes long and short instruments of the same tenor, expected cash outflows and inflows exactly cancel, and the CIP trade has largely no effects on the liquidity coverage ratio. On the one hand, the CIP trade can deteriorate the liquidity coverage ratio when the $75 \%$ inflow cap is binding: in this case, outflows are added to the denominator of the liquidity coverage ratio without offsetting inflows, and thus lowering the ratio. On the other hand, the CIP trade can improve the liquidity coverage ratio if the trade involves investing in HQLAs, e.g. central bank reserves.

Limits to arbitrage facing other potential arbitrageurs We turn now to the other potential arbitrageurs, i.e., hedge funds, money market funds, reserve managers, and corporate issuers. For each category, we review rapidly their ability to profit from, and thus attenuate, the CIP deviations, along with their potential constraints. The persistence of CIP deviations suggests that these potential arbitrageurs take only limited positions.

The regulatory reforms on banks certainly have some spillover effects on the cost of leverage faced by non-regulated entities, such as hedge funds. This is because hedge funds need to obtain funding from their prime brokers, which are regulated entities. In order to sell the CIP arbitrage strategy to their clients, hedge funds would need to lever up the arbitrage strategy ten or twenty times to make it attractive. When borrowing large amounts, their

\footnotetext{
${ }^{20}$ In practice, however, the distinction between arbitrage and market making may be difficult to draw.
} 
borrowing costs may increase significantly as their positions show up in their prime brokers' balance sheets (making prime brokers' capital requirements more binding).

U.S. prime money market funds (MMFs) hold large amounts of commercial paper (CP) and certificates of deposits (CD) issued by foreign banks and act as an important alternative source of dollar funding to foreign banks. The recent MMF reform has significant impact on the intermediation capacity of the prime MMFs. The reform requires a floating Net Asset Value for prime MMFs and allows gates and fees to limit redemptions for prime funds, which led to large outflows of funds from prime MMFs to government MMFs. Government MMFs do not hold bank CDs or CPs. In the run-up to the MMF reform implementation (October 14, 2016), as dollar funding from U.S. prime MMFs became scarcer and more expensive, the cross-currency basis also widened notably.

In addition to MMFs, FX reserve managers with large dollar-denominated holdings may arbitrage CIP deviations. For example, the People's Bank of China reportedly increased their holdings of Japanese Treasury bills, which, on the swapped basis, quadrupled yields on U.S. Treasury bills (Bloomberg, August 21, 2016). There is, however, limited information on the central bank trading positions.

Last but not the least, corporate issuers and bank treasuries can also arbitrage longterm CIP deviations by issuing long-term debt in different currencies and then swapping into their desired currency. In the Online Appendix, we report additional evidence on the CIP condition for bond yields of the same risky issuer denominated in different currencies. Using a panel including global banks, multinational non-financial firms and supranational institutions, we show that the issuer-specific basis was close to zero pre-crisis but has been persistently different from zero post-crisis. Large differences in CIP bases appear post-crisis across issuers. Relative to the synthetic dollar rate obtained by swapping foreign currency interest rates, foreign banks generally borrow in U.S. dollars directly at higher costs, whereas U.S. banks and supranational institutions generally borrow in U.S. dollar directly at lower 
costs. As a result, the U.S. banks and supranational institutions are in the best position to arbitrage the negative cross-currency basis, especially during periods of financial distress.

Testable hypothesis In summary, the rules and the behavior of banks have changed since the crisis, offering a potential explanation of the CIP deviations and suggesting some simple predictions:

Prediction \#1: (i) CIP deviations are wider when the banks' balance sheet costs are higher, particularly towards quarter-end financial reporting dates; (ii) CIP deviations should be of similar magnitude as the balance sheet costs associated with wholesale dollar funding; and (iii) CIP deviations should be correlated with other near-risk-free fixed-income spreads.

Costly financial intermediation is a likely driver of the overall increase in CIP deviations post-crisis. In the absence of currency-specific trading costs though, frictions to financial intermediation would likely affect all currencies similarly. Yet, large cross-currency differences exist in the data, pointing to hedging demand arising from international imbalances in funding and investment opportunities across currencies.

\subsection{International Imbalances}

The second element of our two-factor hypothesis works as follows. Search-for-yield motives create a large customer demand for investments in high-interest-rate currencies, such as the Australian and New Zealand dollars, and a large supply of savings in low-interest-rate currencies, such as the Japanese yen and the Swiss franc. Japanese life insurance companies, for example, may look for high yields in the U.S. Treasury markets (instead of investing in the low yield, yen-based Treasuries). Part of such investments is certainly currency-hedged: e.g., Japanese life insurers sell dollars and buy yen forward to hedge their U.S. Treasury bond portfolios. Financial intermediaries, such as foreign exchange swap market makers, supply currency hedging, but do not want to bear the currency risk. To that effect, the 
financial intermediaries hedge the currency exposure of their forward and swap positions in the cash market by going long in low interest rate currencies and short in high interest rate currencies. The profit per unit of notional is equal to the absolute value of the cross-currency basis, compensating the intermediary for the cost of capital associated with the trade. This hypothesis leads to the following prediction:

Prediction \#2: The cross-currency basis is increasing in the nominal interest rate differential between the foreign currency and the dollar.

The intuition behind the prediction is that the lower the foreign currency interest rate compared to the U.S. interest rate, the higher the demand for U.S. dollar-denominated investment opportunity, which generates a greater currency hedging demand to sell U.S. dollars and buy foreign currencies in the forward or the swap market. Since providing these currency hedging contracts is costly for financial intermediaries, the cross-currency basis has to become more negative to justify the higher balance sheet costs associated with larger positions.

With the two-factor hypotheses in mind, we turn now to additional empirical evidence on CIP deviations.

\section{Characteristics of the Basis}

In this section, we characterize the systematic nature of the basis and test the two predictions outlined in the previous section, looking at (i) CIP deviations at quarter ends, (ii) a proxy for the cost of wholesale dollar funding, (iii) the correlation of the CIP deviations with other liquidity spreads, (iv) and the correlation with nominal interest rates.

\subsection{Quarter-End Dynamics}

We find that, since the 2007-2008 global financial crisis, one-week and one-month CIP deviations tend to increase at the quarter ends for contracts that would cross quarter-end 
reporting dates. The quarter-end anomalies become more exacerbated since January 2015, which coincides with the change in the leverage ratio calculation method and the beginning of the public disclosure of the leverage ratio for European banks. These findings are consistent with the view that tightened balance sheet constraints at quarter ends, due to banking regulation, translates into wider CIP deviations in the post-crisis period.

\subsubsection{Quarter-end Effects on the Level of CIP Deviations}

We test whether CIP deviations are more pronounced at the end of the quarters vs. any other point in time, and especially so since the global financial crisis and since 2015. Our simple difference-in-difference test for the one-week contract takes the following form:

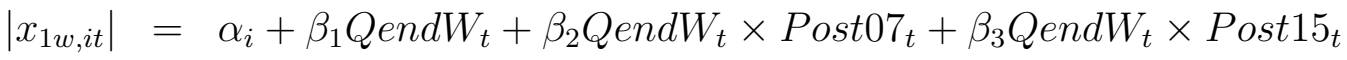

$$
\begin{aligned}
& +\gamma_{1} \operatorname{Post}_{07}+\gamma_{2} \operatorname{Post}_{1} 5_{t}+\epsilon_{i t}
\end{aligned}
$$

where $\left|x_{1 w, i t}\right|$ is the absolute value of the one-week basis for currency $i$ at time $t, \alpha_{i}$ is a currency fixed effect. POST07 $t$ is an indicator variable equal to one after January 1, 2007 and zero otherwise, and POST15 is an indicator variable equal to one after January 1, 2015 and zero otherwise. The variable $Q e n d W_{t}$ is an indicator variable that equals one if the settlement date for the contract traded at $t$ is within the last week of the current quarter and the maturity date is within the following quarter. ${ }^{21}$ These one-week contracts crossing the quarter ends would show up on the bank balance sheet on quarter-end reporting dates. The regression is estimated on the daily sample from $01 / 01 / 2000$ to $09 / 15 / 2016$ on one-week Libor, OIS and repo bases. Similarly, we also test the quarter-end effect for the monthly CIP deviation as follows:

$$
\begin{aligned}
\left|x_{1 m, i t}\right| & =\alpha_{i}+\beta_{1} \text { Qend }_{t}+\beta_{2} \text { Qend }_{t} \times \text { Post }_{0} 7_{t}+\beta_{3} \text { Qend }_{t} \times \text { Post }_{1} 5_{t} \\
& +\gamma_{1} \text { Post } 07_{t}+\gamma_{2} \text { Post }_{15_{t}}+\epsilon_{i t},
\end{aligned}
$$

\footnotetext{
${ }^{21} \mathrm{FX}$ forwards follow the $T+2$ settlement convention.
} 
where $Q e n d M_{t}$ is a binary variable indicating if the settlement date and maturity date of the monthly contract spans two quarters.

Table 6 reports the regression results. Columns 1 to 3 pertain to the one-week CIP deviations based on Libor, OIS, and repos. The slope coefficients $\beta_{2}$ and $\beta_{3}$ are positive and statistically significant across all three instruments. The quarter-end CIP deviation relative to the mean deviation in the rest of the quarter is on average 10 to 22 basis points higher in the post-2007 sample than over the pre-2007 sample for the one-week contracts. Furthermore, compared to the post-2007 sample, the quarter-end weekly CIP deviation increases by another 30-40 basis points on average since January 2015. Columns 4 to 6 pertain to the one-month CIP deviations. Again, we find that $\beta_{2}$ and $\beta_{3}$ are all significantly positive except in one case. For CIP deviation based on Libor and OIS rates, the month-end deviation relative to the rest of the quarter is on average 4 to 5 basis point higher post-crisis than the level pre-crisis and increases by another 8 basis point in the post-2015 sample. For one-month repo, even though $\beta_{3}$ is not significant, $\beta_{2}$ is highly significant and equals 13 basis points. Furthermore, we note that coefficients on $Q e n d W_{t}$ and $Q e n d M_{t}$ are very small and largely insignificant, suggesting that there is very little quarter end effect before 2007.

\subsubsection{Quarter-end Effects on the Term Structure of CIP Deviations}

Since a three-month forward contract always shows up in a quarterly report regardless of when it is executed within the quarter, we should not expect discrete price movement one week or one month prior to the quarter end. Therefore, the quarter-end balance sheet constraint has implications for the term structure of the basis. In particular, we expect the difference between three-month and one-month CIP deviation $\left(t s_{t, 3 M-1 M} \equiv\left|x_{t, 3 M}\right|-\left|x_{t, 1 M}\right|\right)$ to drop significantly once the one-month contract crosses the quarter-end. Meanwhile, the difference between one-month and one-week CIP deviation $\left(t s_{t, 1 M-1 W} \equiv\left|x_{t, 1 M}\right|-\left|x_{t, 1 W}\right|\right)$ should first increase significantly as the one-month contract crosses the quarter end and then decreases significantly once the one-week contract crosses the quarter end. 
Figure 7 illustrates the case for the yen starting in 2015. The blue shaded area denotes the dates for which one-week contracts cross quarter-end reporting dates. The grey area denotes the dates for which the one-month contract crosses quarter-end reporting dates, but one-week contracts stay within the quarter. The top figure plots one-week, one-month and three-month CIP deviations in levels, and the bottom figure plots the term spreads $t s_{t, 3 M-1 M}$ and $t s_{t, 1 M-1 W}$. We can see that once the one-month contract crosses the quarter end, $t s_{t, 3 M-1 M}$ decreases sharply and $t s_{t, 1 M-1 W}$ increases sharply due to spikes in the onemonth deviation. Once the one-week contract crosses the quarter end, $t s_{t, 1 M-1 W}$ drops significantly due to spikes in the one-week deviation.

Table 7 confirms these observations in panel regressions. Columns 1 to 3 report regression results using $t s_{t, 3 M-1 M}$ based on Libor, OIS and repo as follows, similar to Equation (17):

$$
\begin{aligned}
t s_{t, 3 M-1 M} & =\alpha_{i}+\beta_{1} \text { Qend }_{t}+\beta_{2} \text { Qend }_{t} \times \text { Post } 07_{t}+\beta_{3} \text { Qend }_{t} \times \text { Post }_{1} 5_{t} \\
& +\gamma_{1} \text { Post } 07_{t}+\gamma_{2} \text { Post } 15_{t}+\epsilon_{i t} .
\end{aligned}
$$

We find that $\beta_{1}$ is small and insignificant, and $\beta_{2}$ and $\beta_{3}$ are both significantly negative. Compared to the pre-crisis sample, $t s_{t, 3 M-1 M}$ is 2.4 basis point lower relative to its mean in the rest of the quarter when the one-month contract crosses the quarter ends in the postcrisis sample. In the post-2015 sample, the quarter-end effect corresponds to another 9.5 basis point reduction in $t s_{t, 3 M-1 M}$ compared to its post-crisis mean. Columns 4 to 6 report similar tests for $t s_{s, 1 M-1 W}$ :

$$
\begin{aligned}
& t s_{t, 1 M-1 W}=\alpha_{i}+\beta_{1} \mathbb{I}_{\text {Qend } M_{t}=1, Q e n d W_{t}=0}+\beta_{2} \mathbb{I}_{\text {Qend } M_{t}=1, \text { Qend } W_{t}=0} \times{\text { Post } 07_{t}}
\end{aligned}
$$

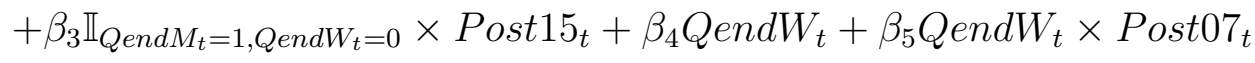

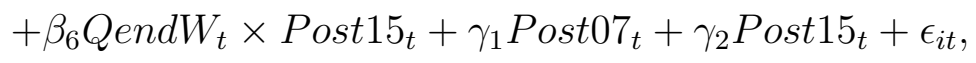


where $\mathbb{I}_{Q e n d M_{t}=1, Q e n d W_{t}=0}$ is an indicator variable that equals 1 if a one-month contract traded at $t$ crosses the quarter end, but the one-week contract traded at $t$ does not cross the quarter end. As expected, we find significantly positive $\beta_{2}$ and $\beta_{3}$ coefficients and significantly negative $\beta_{5}$ and $\beta_{6}$ coefficients, which suggests that the difference between one-month and one-week CIP deviation first increases as the once-month contract crosses the quarter end, but the one-week contract does not, and then decreases as the one-week contract crosses the quarter end. These quarter-end effects are again larger in the post-crisis period and especially since 2015 .

In summary, consistent with the key role of banks' balance sheets on quarter-end reporting dates, we find that CIP deviations are systematically higher for contracts that cross quarterend reporting dates post the crisis. We compare now a proxy for the banks balance sheet costs to the CIP deviations.

\subsection{CIP Arbitrage Based on Excess Reserves at Central Banks}

Under unconventional monetary policies implemented by major central banks since the global financial crisis, global depositary institutions have held large amounts of excess reserves at major central banks, currently including $\$ 2.4$ trillion at the Fed and $\$ 0.5$ trillion at the ECB. Excess reserves are remunerated at an interest rate set by the central bank, which is referred to as the interest rate on excess reserves (IOER).

One interesting feature of the IOER at the Fed is that it is often above interest rates paid on private money market instruments, for example, the Fed Funds rate. The main reason that the Fed funds rate stays persistently below the IOER in the United States is that government-sponsored enterprises (GSEs), such as Federal Home Loan Banks, do not have access to the IOER deposit facility and are willing to lend at rates below the IOER in the Fed funds market. This creates the well-known IOER-Fed funds arbitrage for depositary institutions with access to the IOER deposit facility, in which banks borrow in the Fed fund market from the GSEs and deposit the proceeds in the forms of excess reserves at the Fed, 
earning the IOER-Fed Funds spread. The trade is risk-free and central bank reserve balances dominates private money market instruments in terms of liquidity and fungibility.

Figure 8 shows the IOER, one-week OIS and Libor rates for the U.S. dollar since 2009. The IOER is always greater than the one-week OIS rate over the entire sample and is also greater than the one-week Libor rate starting in 2011. If borrowing funds at the Fed funds or Libor rate did not carry additional costs, banks would amass even more reserves at the Fed in order to profit from this arbitrage opportunity, and the interest rate gap between IOER and OIS would disappear. ${ }^{22}$

The spread earned on the IOER-Fed Fund arbitrage thus gives us a concrete measure of the cost of balance sheet expansion for depository institutions that engage in risk-free arbitrage opportunities. This cost includes at least two components. For U.S. and foreign banks, the cost of leverage, summarized in leverage ratios, is likely to be the most important factor since the trade is risk-free, but still expands the size of banks' balance sheet. For U.S. banks, an additional cost matters: the deposit insurance fees paid on wholesale funding, which mattered after the Federal Deposit Insurance Corporation (FDIC) widened the assessment base for deposit insurance fees to include wholesale funding in April 2011. In other words, the IOER is the opportunity cost of wholesale dollar funding for depository institutions, and the synthetic dollar interest rates by swapping foreign currency investments have to be higher than the IOER to attract banks to engage in CIP trades, instead of parking the dollars as excess reserves at the Fed.

Therefore, instead of using the Libor (or OIS) rates as the direct U.S. dollar funding costs when computing the cross-currency basis, we use the IOER as the dollar funding costs. This is equivalent to assuming, for example, that banks borrow at the Libor (or OIS) rates and that the difference between the IOER minus the Libor (or OIS) rate proxies for the banks' balance sheet costs. Table 8 shows the results for this alternative basis calculation.

\footnotetext{
${ }^{22}$ The gap between the IOER and the Fed Funds rate widens at quarter ends if we use the overnight Fed Fund rate, instead of the one-week OIS rate. This is because the IOER-Fed Fund arbitrage is typically done for the overnight horizon,
} 
Compared to the standard Libor basis reported in the first column, "funding" at the IOER reduces the magnitude of the Libor basis by 6 basis points on average, as shown in the second column. Similarly, compared to the standard OIS basis reported in the third column, the basis is 12 basis point narrower when using the IOER instead of the OIS as the direct dollar funding cost, as shown in the fourth column. Compared to the standard repo basis, the basis is 8 basis point narrower when using the IOER as the funding cost, as shown in the sixth column. Therefore, the gap between the IOER and OIS/Libor/repo in the U.S. can explain about one-third of the one-week CIP deviations.

The CIP arbitrage based on Libor, OIS and repo rates have neutral impact on the liquidity coverage ratio at best, but the IOER-Fed fund arbitrage can potentially improve the liquidity coverage ratio. ${ }^{23}$ Also, more generally, central bank balances are considered safer and more liquid than any private market alternatives even before being codified as the Level-1 HQLA by the Basel liquidity coverage ratio requirement. By taking into account the better liquidity of central bank balances, we assume that banks funds themselves at the U.S. IOER (as above) and invest at the foreign IOER. Summary statistics for the IOER basis are reported in the last column. The average IOER basis is -8 basis points, much closer to zero than the Libor and OIS basis at -26 and -28 basis points, respectively. ${ }^{24}$

Using the IOER-Libor spread as proxy for the banks' balance sheet costs and investing at the foreign central bank deposit facility significantly reduces the size of the CIP deviations, but it does not eliminate them. For the Danish krone, the Swiss franc, and the Japanese

\footnotetext{
${ }^{23}$ The IOER-Fed Funds arbitrage can improve the liquidity coverage ratio in two potential ways. First, the IOER-Fed Funds arbitrage increases the numerator and the denominator by the same amount, which leads to a mechanical increase in the ratio, especially for large positions. Second, if the bank were to be subject to the composition cap for eligible Level-2 HQLA (40\% of total HQLAs), adding reserve balances (Level-1 HQLA) may permit the inclusion of additional eligible level 2 assets in the LCR numerator.

${ }^{24}$ The Online Appendix reports the time-series of the IOER basis, together with the Libor basis and the modified Libor basis obtained by "funding" at the IOER. The bases based on the IOER can be positive, while the Libor basis is always negative. A positive IOER basis would lead U.S. banks to park excess reserves at the Fed, as opposed to lending out in U.S. dollars as suggested by a negative Libor basis. Increasing reserves at the Fed further reduces the bank flows to arbitrage the Libor basis.
} 
yen, the CIP deviations still range from -12 to -15 basis points on average. ${ }^{25}$ Such CIP deviations imply risk-free arbitrage opportunity for global depository institutions that can borrow U.S. dollars in wholesale cash funding market, and deposit at the foreign central bank deposit facility while hedging currency risk, even after proxying for their balance sheet costs. Banks are either factoring in higher shadow costs, or they are willing to forego some extra yields to hold Fed balances over swapped balances at the Bank of Japan, the Swiss National Bank or the Danish National Bank, even though these central bank reserve balances are all risk-free HQLAs. One potential explanation is that Fed balances are more desirable to fulfill banks dollar liquidity needs compared to swapped foreign central bank balances, even though there is no hardwired Liquidity Coverage Ratio imposed at the individual currency level.

In summary, by assuming that banks borrow and invest at the IOER, we proxy for the banks' balance sheet costs associated with the leverage ratio and take into account the liquidity advantage of central bank reserve balances over private money market instruments. These adjustments correspond approximately to two-thirds of the average CIP deviations. ${ }^{26}$

\subsection{Correlated Spreads in Other Markets}

Intermediary constraints, if present, would likely affect other asset classes beyond exchange rates. We thus compare the dynamics of the currency bases to other types of near-arbitrage fixed-income strategies, focusing on (1) the KfW-German Bund basis, (2) the one-versus

\footnotetext{
${ }^{25}$ In the euro area, since the EONIA is significantly higher than the ECB deposit rate (unlike in the U.S.), the CIP arbitrage involving euro borrowing and Fed deposits is rarely profitable despite the 8 basis point average IOER basis for the euro.

${ }^{26}$ In the online Appendix, we show an alternative proxy for banks' balance sheet costs due to the leverage ratio requirement given by the spread between the GCF and Tri-party repo rates backed by Treasury securities. As explained by Nelson (2016) "The GCF repo rate is a rate at which smaller or lower-rated dealers borrow from larger and higher-rated dealers and the GC repo rate is a rate at which larger dealers borrow from money funds. The spread is a measure of the premium larger dealer charge smaller dealers to borrow in the repo market via the larger dealers' balance sheet." The spread largely varies between 5-20 basis points outside quarter ends, and can reach 100 basis points at quarter ends. Same as the CIP deviations, the quarter-end spikes in the repo-GCF spreads become very pronounced since January 2015.
} 
three-month U.S. Libor tenor swap basis, (3) the CDS-CDX basis, and (4) the CDS and corporate bond (CDS-bond) basis. $^{27}$

Figure 9 plots the average of the absolute value of the five-year Libor currency basis for G10 currencies and the four other types of bases in four different panels. The currency basis appears highly correlated with the two liquidity-based bases, the KfW-German bund basis and the Libor tenor basis. They all increased during the recent global financial crisis and during the European debt crisis. Although there is no mechanical link between the CIP deviations and the KfW-bund and Libor tenor swap bases, their co-movement is striking.

The currency basis appears less correlated with the two credit bases, the CDS-CDX basis and the bond-CDS basis. The credit bases both increased significantly during the recent global financial crisis, together with the cross-currency basis, but they narrowed significantly after the crisis between 2010 and 2014, whereas the currency basis did not. In the past two years again, the credit and currency bases appear to move in sync.

We test the link across asset classes with a simple regression of the G10 average changes in the cross-currency bases on changes in the four other liquidity and credit bases for the 2005-2016 and the 2010-2016 samples. Table 9 reports the monthly regression results. In the

${ }^{27}$ We review these four spreads rapidly:

- The KfW-German bund basis is the spread of a five-year euro-denominated bond issued by KfW over the five-year German Bund yield, obtained from Bloomberg. The five-year KfW bond yield is estimated by the Nelson-Siegel methodology on individual KfW bond prices also obtained from Bloomberg. Since the KfW bonds are fully guaranteed by the German government, the KfW-German Bund spread should not contain any credit risk component. As previously noted, Schwartz (2015) uses that spread to measure the liquidity premium.

- The Libor tenor swap basis measures the premium that one party has to pay in order to receive the one-month floating U.S. Libor in exchange of the three-month floating U.S. Libor for the five-year duration of the contract. The tenor swap basis reflects a premium for more frequent payments or a higher desirability of short-term liquidity.

- The CDS-CDX basis measures the difference between the average five-year CDS spreads on the 125 constituent names of the North America investment grade credit default swap index (NA.IG.CDX) and the spread on the corresponding aggregate NA.IG.CDX index. All data on CDS and CDX spreads are obtained from Markit.

- The CDS-bond basis measures the difference between the asset swap spread on a corporate bond over the CDS spread on the same reference entity. We use the CDS-bond basis provided by Morgan Markets for investment-grade bonds. Both the CDS-CDX basis and CDS-bond basis lead to popular credit arbitrage strategies. 
full sample that includes the global financial crisis, CIP deviations co-move significantly with the four other spreads. In the post-crisis sample, CIP deviations still co-move significantly with the two liquidity spreads. The correlation with the two credit spreads remains positive but is no longer significant. Overall, the correlation between the CIP deviations and other near-arbitrage strategies, especially the KfW-German bund basis and the Libor tenor basis, is consistent with a key role for liquidity-providing intermediaries.

\subsection{Cross-Currency Basis and Nominal Interest Rates}

Consistent with Prediction \#2, we find that CIP deviations are highly correlated with nominal interest rates in the cross section and in the time series.

\subsubsection{Cross Section of CIP Deviations and Interest Rates}

We first document a robust cross-sectional relationship between nominal interest rates and various types of cross-currency basis. We find that low interest rate currencies tend to have most negative bases and high interest rate currencies tend to have less negative bases or positive bases. The cross-sectional pattern holds across Libor, OIS, Treasuries, KfW and other multinational bonds.

Figure 10 reports the mean cross-currency basis on the vertical axis as a function of the average nominal interest rates between 2010 and 2015 on the horizontal axis. The first two panels show that the Libor cross-currency basis is positively correlated with Libor rates at short and long maturities. The relationship is particularly strong at long maturities, with the correlation between five-year Libor bases and Libor rates equal to 89 percent for G10 currencies. $^{28}$ By contrast, the mean CDS spread of the interbank panel exhibits a correlation of -33 percent with the five-year Libor basis.

Therefore, for a long-short arbitrageur, there exist arbitrage opportunities for going long in low interest rate currencies, short in high interest rate currencies with the currency risk

\footnotetext{
${ }^{28}$ Similarly, as shown in the Online Appendix, we obtain a very high correlation between the average level of interest rates and the CIP deviations measured on bonds issued by KfW and other multinationals.
} 
hedged using exchange rate swaps. The direction of the arbitrage trade is exactly the opposite of the conventional unhedged carry trade of going long in high interest rate currencies and short in low interest rate currencies. ${ }^{29}$ This finding has clear implications for carry trade investors and multinational issuers.

For carry trade investors, the CIP deviations make the carry trade more profitable on the forward than on the cash markets. The unhedged currency excess return is:

$$
\begin{aligned}
f_{t}-s_{t+1} & =f_{t}-s_{t}+s_{t}-s_{t+1} \\
& =y_{t}-y_{t}^{\$}-\Delta s_{t+1}+x_{t}
\end{aligned}
$$

For any investor who borrows in U.S. dollars (or yen) and invest in Australian (or New Zealand) dollar, the CIP basis is positive $\left(x_{t}>0\right)$. As a result, the carry trade excess return obtained through forward contracts, equal to $f_{t}-s_{t+1}$, is larger than the excess return obtained on the cash markets, equal to $y_{t}-y_{t}^{\$}-\Delta s_{t+1}$.

For multinational issuers, the cross-sectional pattern has a robust funding cost implication that on the currency-hedged basis, currencies with high nominal interest rates are cheaper funding currencies, and currencies with higher nominal interest rates are more expensive funding currencies.

We find evidence that supranational organizations do take advantage of this funding cost arbitrage. Figure 11 plots the ratio of total issuance by KfW and supranational issuers over total issuance by other non-financial issuers during the sample 2010-2015 period against the mean Libor cross-currency basis. ${ }^{30}$ Data come from Dealogic. Relative to the universe of non-financial issuers, supranational issuers issue more in high-basis and high-interest-rate currencies, such as the Australian and New Zealand dollars, and issue less in low-basis and

\footnotetext{
${ }^{29}$ Note that the average CIP deviations and average carry trade excess returns differ by an order of magnitude: less than 50 basis points for the CIP deviations, and more than 500 basis points for average carry trade excess returns.

${ }^{30}$ Issuances in U.S. dollars and in euros are excluded from Figure 11 because some benchmark issues often need to be maintained even though it might be economically costly to do so.
} 
low-interest-rate currencies, such as the Swiss franc, the Danish Krone, and the Japanese yen.

\subsubsection{Time Series of CIP Deviations and Interest Rates}

Consistent with the cross-sectional pattern, the nominal interest rate differential between two currencies is also a significant driver of the cross-currency basis in the time series. We establish the time series relationship between the basis and the nominal interest rate using a high-frequency event study of a narrow window around the ECB monetary policy announcements. The event-study approach allows us to study the effect of unexpected shocks to the interest rate differential on the cross-currency basis. Assuming that the monetary policy is exogenous to the basis - a reasonable assumption prior to our work, this eventstudy measures the causal impact of monetary policy on the cross-currency basis.

Our event study focuses on changes in the dollar/euro basis and changes in the yield differential between German Bunds and U.S. Treasuries. The event window starts five minutes before the release of the monetary decision, usually at 1:45 pm Central European Time (CET), and ends 105 minutes after the release of the statement, thus including the one-hour press conference that usually takes place between 2:30 pm CET and 3:30 pm CET. By choosing such a narrow event window, the movements in the currency basis and government yields can be attributed to monetary policy shocks from the ECB. Intraday data come from the Thomson Reuters Tick History database. The currency basis corresponds to OTC quotes, from a major European bank, for an Euribor/U.S. Libor one-year maturity basis contract. ${ }^{31}$ The event-study focuses on the ECB announcements because quotes on the currency basis are available at high frequency for the euro.

We regress the changes in the currency basis around the $i$-th monetary policy announcement $\left(\Delta x_{i}\right)$ on the changes in the German bund and U.S. Treasury two-year benchmark

\footnotetext{
${ }^{31}$ Cross-currency bases at tenors longer than one year are not quoted frequently enough for our event study. The three-month cross-currency basis was not actively traded as a separate derivative product until 2012. Our results, however, are robust to using the three-month basis since it became separately quoted.
} 
yield differentials around the same event window $\left(\Delta y_{i}^{G E}-\Delta y_{i}^{U S}\right)$ :

$$
\Delta x_{i}=\alpha+\beta\left(\Delta y_{i}^{G E}-\Delta y_{i}^{U S}\right)+\epsilon_{i}
$$

In the cross-section, as we saw, the currency basis tends to increase with the interest rate

differential. A similar behavior would imply a positive slope coefficient, $\beta>0$. As Figure 12 shows, this is clearly the case: in the time-series too, the currency basis tends to increase with the interest rate differential. The slope coefficient on the interest rate differential in Equation (20) is equal to 0.15 with a $t$-statistic equal to 5.88 . Therefore, a 10 basis point reduction in the German/U.S. Treasury two-year yield differential due to an accommodative ECB monetary policy shock leads to 1.5 basis point reduction in the one-year euro/dollar Libor CIP deviations. A more accommodative-than-expected monetary policy by the ECB thus results in a more negative cross-currency-basis for the euro, implying that the synthetic dollar rate increases compared to the direct dollar rate, making the indirect dollar funding of European banks more expensive than before the announcement.

\section{Conclusion}

In this paper, we examine the persistent and systematic failures of the CIP condition in the post crisis period. After formally establishing CIP arbitrage opportunities based on repo rates and KfW bonds, we argue that these arbitrage opportunities can be rationalized by the interaction between costly financial intermediation and international imbalances in funding supply and investment demand across currencies. Consistent with this two-factor hypothesis, we report four empirical characteristics of the CIP deviations. First, CIP deviations increase at the quarter ends post crisis, especially for contracts that appear in banks' balance sheets. Second, proxies for the banks' balance sheet costs account for two-thirds of the CIP deviations. Third, CIP deviations co-move with other near-risk-free fixed income spreads. 
Fourth, CIP deviations are highly correlated with nominal interest rates in the cross section and time series.

Looking beyond our paper, we expect a large literature to investigate further the CIP deviations. The deviations occur in one of the largest and most liquid markets in the world after the crisis in the absence of financial distress, suggesting that other arbitrage opportunities exist elsewhere. While trading in exchange rate derivatives is a zero-sum game, the CIP deviations may have large welfare implications because of the implied deadweight cost borne by firms seeking to hedge their cash flows.Furthermore, the existence of CIP deviation introduces wedges between the interest rates in the cash and swap markets, which affects the external transmission of monetary policy. The welfare cost of the CIP deviation is behind the scope of this paper; it would necessitate a general equilibrium model. Yet, even without such model, the CIP condition is a clean laboratory to test the impact of financial frictions in a very general framework. In this spirit, we present the first international evidence on the causal impact of recent banking regulation on asset prices. We expect more research in this direction in the future. 


\section{References}

Adrian, T., E. Etula, And T. Muir (2014): "Financial Intermediaries and the CrossSection of Asset Returns," Journal of Finance, 69(6), 2557-2596.

Akram, Q. F., D. Rime, and L. Sarno (2008): "Arbitrage in the Foreign Exchange Market: Turning on the Microscope," Journal of International Economics, 76, 237-253.

Amador, M., J. Bianchi, L. Bocola, and F. Perri (2016): "Exchange Rate Policies at the Zero Lower Bound," Working Paper.

Arora, N., P. Gandhi, and F. A. Longstaff (2011): "Counterparty credit risk and the credit default swap market," Journal of Financial Economics, 103(280-293).

Avdjiev, S., W. Du, C. Koch, And H. S. Shin (2016): "The dollar, bank leverage and the deviation from covered interest parity," BIS Working Paper No. 592.

Baba, N., R. N. McCauley, and S. Ramaswamy (2009): "US Dollar Money Market Funds and Non-US Banks," BIS Quarterly Review, pp. 65-81.

BABA, N., And F. PACKer (2009): "Interpreting Deviations from Covered Interest Parity During the Financial Market Turmoil of 2007-08," Journal of Banking and Finance, 33, 1953-1962.

Baba, N., F. Packer, and T. Nagano (2008): "The Spillover of Money Market Turbulence to FX Swap and Cross-Currency Swap Markets," BIS Quarterly Review, pp. 73-86.

Baklanova, V., A. Copeland, and R. MCCaughrin (2015): "Reference Guide to U.S. Repo and Securities Lending Markets," Federal Reserve Bank of New York Staff Report No. 740.

Banegas, A., And M. TAse (2016): "Reserve Balances, the Federal Funds Market and Arbitrage in the New Regulatory Framework," Finance and Economics Discussion Series 2016-079, Federal Reserve Board.

Bekaert, G., And R. J. Hodrick (2012): International financial management. Pearson Prentice Hall Upper Saddle River, New Jersey, NJ.

Bernanke, B., And M. Gertler (1989): "Agency Costs, Net Worth, and Business Fluctuations," American Economic Review, pp. 14-31.

BIS (2013): "Triennial Central Bank Survey of Foreign Exchange and Derivatives Market Activity in 2013," Discussion paper, Bank for International Settlements.

_ (2014a): "Basel III leverage ratio framework and disclosure requirements," Discussion paper, Bank for International Settlements.

(2014b): "Detailed Tables on Semiannual OTC Derivatives Statistics at EndDecember 2014," Discussion paper, Bank for International Settlements. 
Bloomberg (August 21, 2016): "World's Biggest Bond Traders Undeterred by Negative Yields," .

Bottazzi, J.-M., J. Luque, M. PascoA, and S. M. Sundaresan (2012): "Dollar Shortage, Central Bank Actions, and the Cross Currency Basis," Working Paper.

Brunnermeier, M. K., And L. H. Pedersen (2009): "Market Liquidity and Funding Liquidity," Review of Financial studies, 22(6), 2201-2238.

Brunnermeier, M. K., And Y. SAnnikov (2014): "A Macroeconomic Model with a Financial Sector," American Economic Review, 104(2), 379-421.

Buraschi, A., M. Menguturk, and E. Sener (2015): "The Geography of Risk Capital," Review of Financial Studies, 28, 1103-1152.

Caballero, R. J., E. Farhi, and P.-O. Gourinchas (2008): "An Equilibrium Model of "Global Imbalances" and Low Interest Rates," The American Economic Review, 98(1), $358-393$.

(2016): "Global Imbalances and Currency Wars at the ZLB," Working Paper, Harvard University.

Callier, P. (1981): "One Way Arbitrage, Foreign Exchange and Securities Markets: A Note," The Journal of Finance, 36(5), 1177-1186.

Clinton, K. (1988): "Transactions Costs and Covered Interest Arbitrage: Theory and Evidence," Journal of Political Economy, 96(2), 358-370.

Coffey, N., W. B. Hrung, and A. Sarkar (2009): "Capital Constraints, Counterparty Risk, and Deviations from Covered Interest Rate Parity," Federal Reserve Bank of New York Staff Report 393.

DeardorfF, A. V. (1979): "One-Way Arbitrage and Its Implications for the Foreign Exchange Markets," Journal of Political Economy, 87(2), 351-364.

Dooley, M. P., And P. IsArd (1980): "Capital Controls, Political Risk, and Deviations from Interest-Rate Parity," Journal of Political Economy, pp. 370-384.

Du, W., S. Gadgil, M. B. Gordy, and C. Vega (2016): "Counterparty risk and counterparty choice in the credit default swap market," Working Paper, Federal Reserve Board.

Du, W., And J. Schreger (Forthcoming): "Local Currency Sovereign Risk," Journal of Finance.

Duffie, D. (2016): "Why Are Big Banks Offering Less Liquidity To Bond Markets?," Forbes, March.

Duffie, D., And A. Krishnamurthy (2016): "Passthrough Efficiency in the Fed's New Monetary Policy Setting," Jackson Hole Symposium of the Federal Reserve Bank of Kansas City. 
FREnkel, J. A., AND R. M. LeVich (1975): "Covered Interest Arbitrage: Unexploited Profits?," Journal of Political Economy, 83, 325-338.

Gabaix, X., And M. Maggiori (2015): "International Liquidity and Exchange Rate Dynamics," Quarterly Journal of Economics, 130(3), 1369-1420.

Garleanu, N., and L. Pedersen (2011): "Margin-Based Asset Pricing and Deviations from the Law of One Price," Review of Financial Studies, 24, 1980-2022.

GoldberG, L. S., C. Kennedy, and J. Miu (2011): "Central Bank Dollar Swap Lines and Overseas Dollar Funding Costs," Federal Reserve Bank of New York Economic Policy Review, May.

Greenwood, R., And D. Vayanos (2014): "Bond Supply and Excess Bond Returns," Review of Financial Studies, 27, 663-713.

Griffolli, M. T., And A. Ranaldo (2011): "Limits to Arbitrage during the Crisis: Funding Liquidity Constraints and Covered Interest Parity," Working Paper.

Gromb, D., and D. Vayanos (2010): "Limits of arbitrage," Annual Review of Financial Economics, 2(1), 251-275.

He, Z., B. T. Kelly, and A. Manela (2015): "Intermediary Asset Pricing: New Evidence from Many Asset Classes," Working Paper, University of Chicago.

He, Z., and A. Krishnamurthy (2012): "A Model of Capital and Crises," The Review of Economic Studies, 79(2), 735-777.

He, Z., and A. Krishnamurthy (2013): "Intermediary Asset Pricing," American Economic Review, 103(2), 732-770.

Holmstrom, B., And J. Tirole (1997): "Financial Intermediation, Loanable Funds, and the Real Sector," Quarterly Journal of economics, pp. 663-691.

ICMA (2016): "European Repo Market Survey Number 30," International Capital Market Association.

Ivashina, V., D. S. Scharfstein, And J. C. Stein. (2015): "Dollar Funding and the Lending Behavior of Global Banks," Quarterly Journal of Economics, 130(3), 1241-1281.

Jacob A. Frenkel, R. M. L. (1977): "Transaction Costs and Interest Arbitrage: Tranquil versus Turbulent Periods," Journal of Political Economy, 85(6), 1209-1226.

Jermann, U. J. (2016): "Negative Swap Spreads and Limited Arbitrage," Available at $S S R N$.

Keynes, J. M. (1923): A Tract on Monetary Reform. Macmillan.

Klee, E., Z. Senyuz, and E. Yoldas (2016): "Effects of Changing Monetary and Regulatory Policy on Overnight Money Markets," Finance and Economics Discussion Series 2016-084, Federal Reserve Board. 
LiAO, G. Y. (2016): "Credit Migration and Covered Interest Rate Parity," Working Paper, Harvard Business School.

Lotz, W. (1889): Die Währungsfrage in Österreich-Ungarn und ihre wirtschaftliche und politische Bedeutung. Duncker \& Humblot.

McGuire, P., And G. von Peter (2012): "The Dollar Shortage in Global Banking and the International Policy Response," International Finance, 15(2), 155-178.

Mohsen Bahmani-Oskooee, S. P. D. (1985): "Transaction Costs and the Interest Parity Theorem," Journal of Political Economy, 93(4), 793-799.

Munyan, B. (2015): "Regulatory Arbitrage in Repo Markets," Working Paper.

Nelson, B. (2016): "Money Market Developments and Bank Regulation," TheClearingHouse Blog.

Rime, D., A. Schrimpf, and O. Syrstad (2016): "Segmented Money Markets and Covered Interest Parity Arbitrage," Working Paper.

SATO, T. (2015): "Toward Further Development of the Tokyo Financial Market: Issues on Repo Market Reform," Keynote Speech at the Futures Industry Association Japan Financial Market Conference 2015 in Tokyo.

Schwartz, K. (2015): "Mind the Gap: Disengtangling Credit and Liquidity in Risk Spreads," Working Paper.

Shleifer, A., And R. W. Vishny (1997): "The Limits of Arbitrage," Journal of Finance, $52(1), 35-55$.

Siriwardane, E. N. (2016): "Concentrated Capital Losses and the Pricing of Corporate Credit Risk," Harvard Business School Working Paper.

Tuckman, B., And P. Porfirio (2004): "Interest Rate Parity, Money Market Basis Swaps, and Cross-Currency Basis Swaps," Lehman Brothers Fixed Income Liquid Markets Research.

VAyanos, D., And J.-L. Vila (2009): "A Preferred-Habitat Model of the Term Structure of Interest Rates," Working Paper.

Vladyslav Sushko, Claudio Borio, R. N. M., and P. McGuire (2016): "The failure of covered interest parity: FX hedging demand and costly balance sheets," BIS Working Papers No 590. 


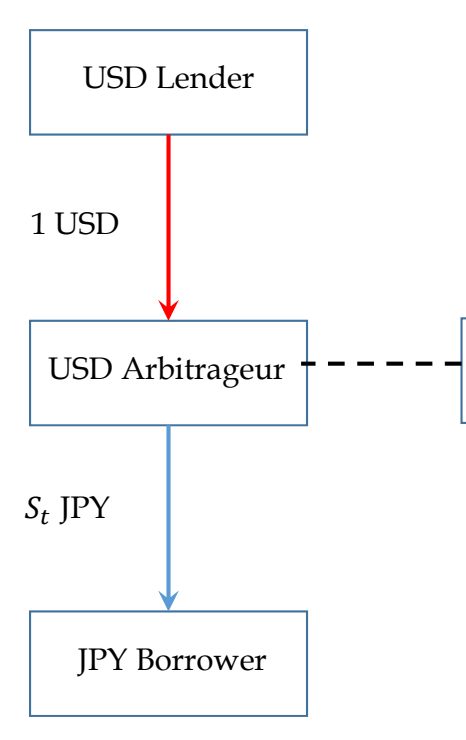

Time $t$

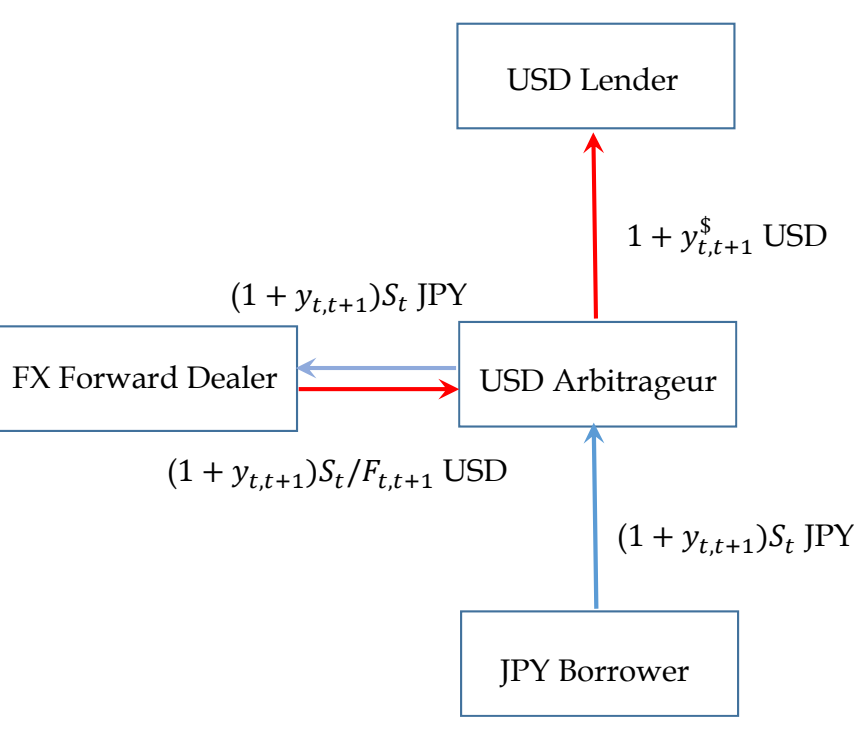

Time $t+n$

Net Cash Flow 0 USD

$$
-\left(1+y_{t, t+1}^{\$}\right)+\left(1+y_{t, t+1}\right) S_{t} / F_{t, t+1} \approx-x_{t, t+1}>0 \text { USD }
$$

Figure 1: Cash Flow Diagram for CIP Arbitrage with a Negative Basis $\left(x_{t, t+1}<0\right)$ : This figure plots the cash flow exchanges of an arbitrageur profiting from a negative crosscurrency basis between the Yen and the U.S. dollar. To arbitrage the negative cross-currency basis, the USD arbitrageur borrows 1 U.S. dollar at the interest rate $y_{t, t+n}^{\$}$, convert it into $S_{t}$ yen, lends in yen at the interest rate $y_{t, t+n}$, and finally signs a forward contract at date $t$. There is no cash flow at date $t$. At date $t+n$, the arbitrageur receives $\left(1+y_{t, t+n}\right)^{n} S_{t}$ yen, and convert that into $\left(1+y_{t, t+n}\right)^{n} S_{t} / F_{t, t+n}$ U.S. dollars thanks to the forward contract. The arbitrageur reimburses her debt in U.S. dollars and is left with a profit equal to the negative of the cross-currency basis $x_{t, t+1}$. In essence, the arbitrageur is going long in JPY and short in USD, with the JPY cash flow fully hedged by a forward contract. 


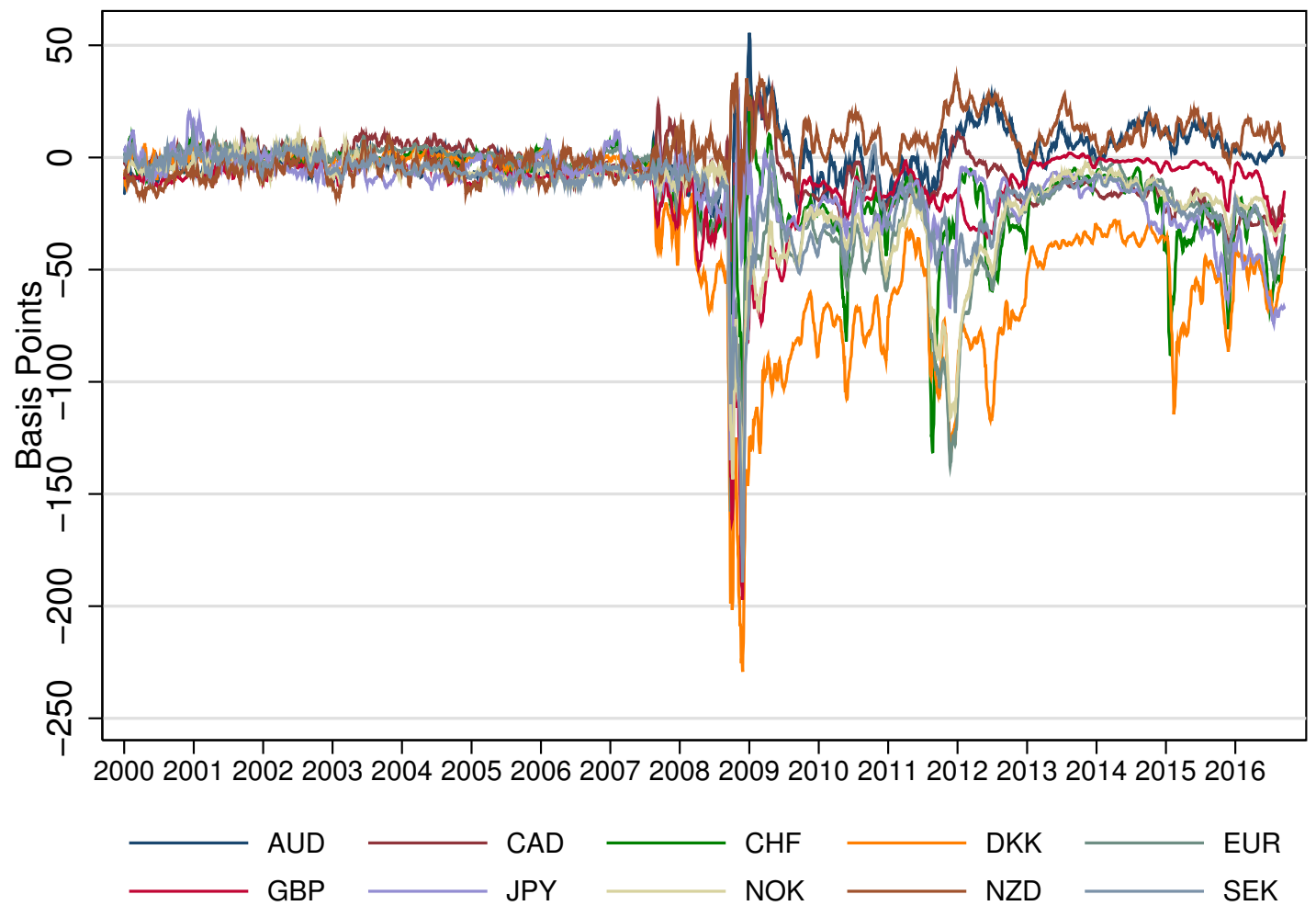

Figure 2: Short-Term Libor-Based Deviations from Covered Interest Rate Parity: This figure plots the 10-day moving averages of the three-month Libor cross-currency basis, measured in basis points, for G10 currencies. The covered interest rate parity implies that the basis should be zero. One-hundred basis points equal one percent. The Libor basis is equal to $y_{t, t+n}^{\$, \text { Libor }}-\left(y_{t, t+n}^{\text {Libor }}-\rho_{t, t+n}\right)$, where $n=$ three months, $y_{t, t+n}^{\$, \text { Libor }}$ and $y_{t, t+n}^{\text {Libor }}$ denote the U.S. and foreign three-month Libor rates, and $\rho_{t, t+n} \equiv \frac{1}{n}\left(f_{t, t+n}-s_{t}\right)$ denotes the forward premium obtained from the forward $f_{t, t+n}$ and spot $s_{t}$ exchange rates. 


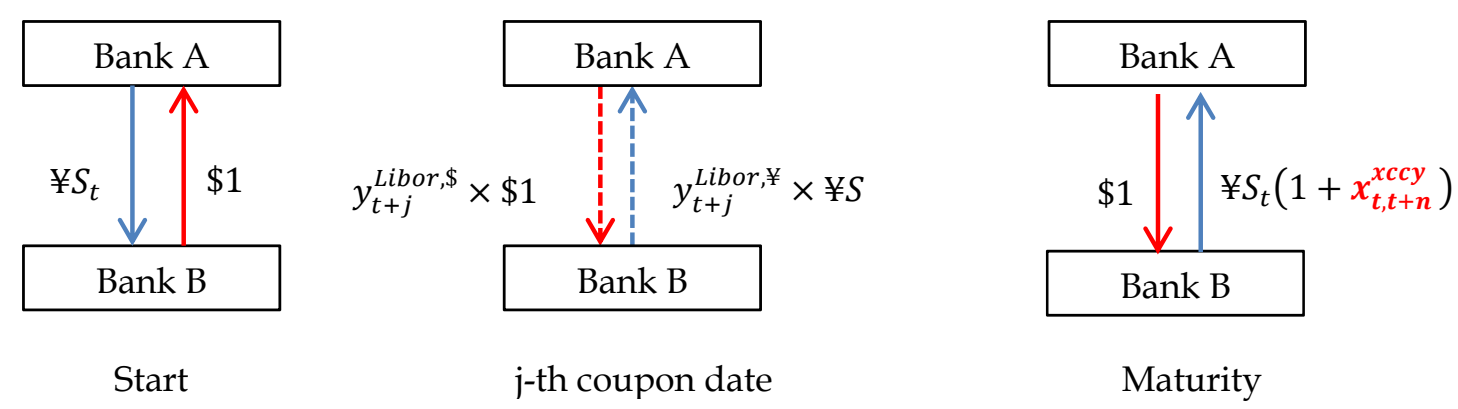

Figure 3: Cash Flow Diagram for JPY/USD Cross-Currency Basis Swap: This figure shows the cash flow exchanges of a standard yen/dollar cross-currency basis swap. At the inception of the swap, Bank A receives $\$ 1$ from Bank B in exchange of $¥ S_{t}$. At the $j$-th coupon date, Bank A pays a dollar floating cash flow equal to $y_{t+j}^{L i b o r, \$}$ percent on the $\$ 1$ notional to Bank B, where $y_{t+j}^{L i b o r, \$}$ is the three-month U.S. dollar Libor at time $t+j$. In return, Bank A receives from Bank B a floating yen cash flow equal to $\left(y_{t+j}^{L i b o r, ¥}+x_{t, t+n}^{x c c y}\right)$ on the $¥ S_{t}$ notional, where $y_{t+j}^{\text {Libor } ¥}$ is the three-month yen Libor at time $t+j$, and $x_{t, t+n}^{x c c y}$ is the cross-currency basis swap spread, which is pre-determined at date $t$ at the inception of the swap transaction. When the swap contract matures, Bank B receives $\$ 1$ from Bank A in exchange of $¥ S_{t}$, undoing the initial transaction. 


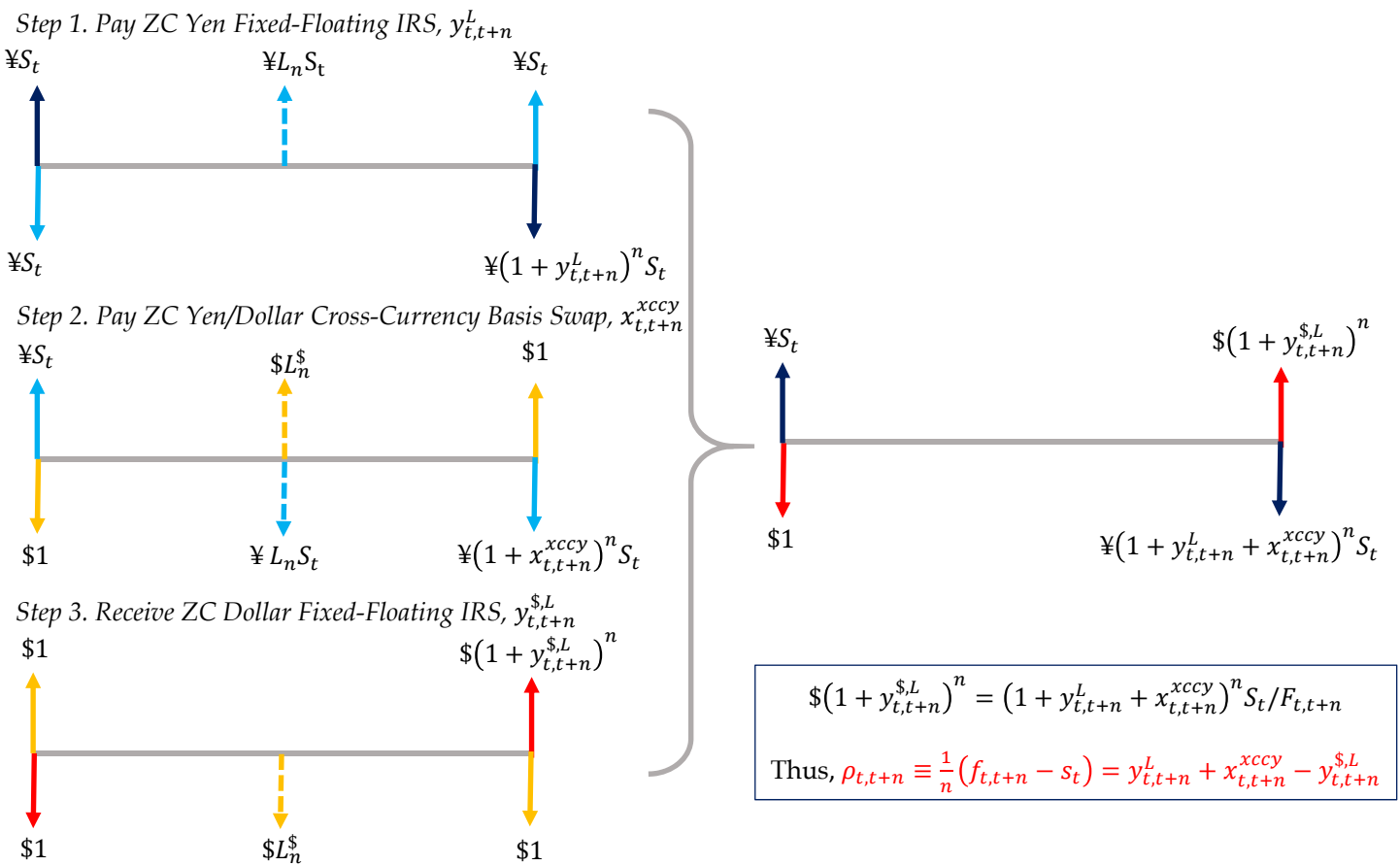

Figure 4: Cash Flow Diagram for Long-Term Forward Premium: This figure shows that the long-term forward premium is equal to the zero fixed-for-fixed cross-currency swap rate. The zero-coupon fixed-for-fixed cross-currency swap can be constructed using the following three steps: (1) paying a zero-coupon foreign currency fixed for floating interest rate swap indexed to the foreign currency Libor; (2) paying a zero-coupon foreign currencyLibor for USD-Libor cross-currency basis swap; and (3) receiving a USD fixed for floating interest rate swap. By summing up cash flows of the three steps, all floating cash flows are canceled and we are left exchanges of fixed cash flows at the inception and maturity of the swap in two currencies. 


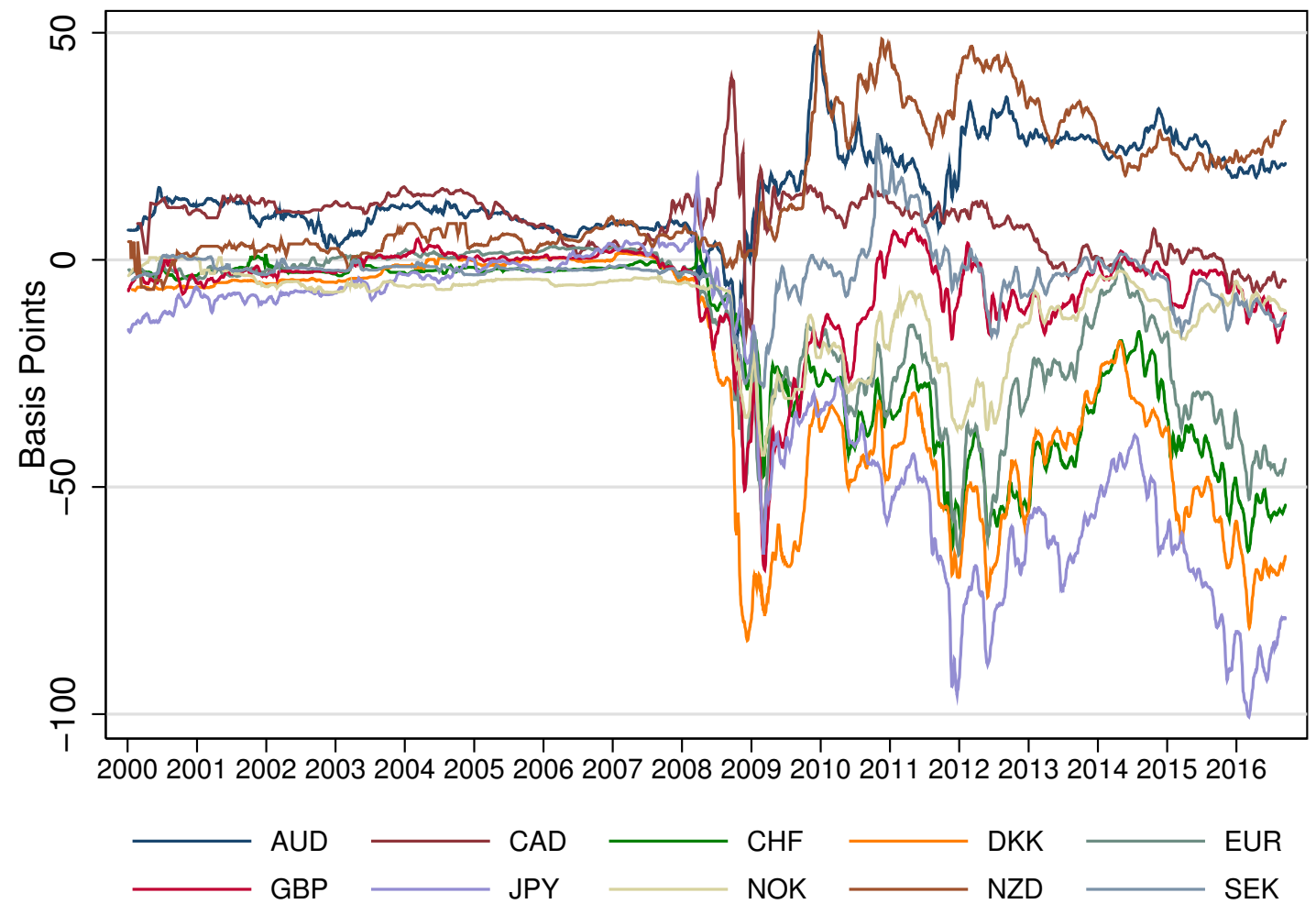

Figure 5: Long-Term Libor-Based Deviations from Covered Interest Rate Parity: This figure plots the 10-day moving averages of the five-year Libor cross-currency basis, measured in basis points, for G10 currencies. The covered interest rate parity implies that the basis should be zero. One-hundred basis points equal one percent. 

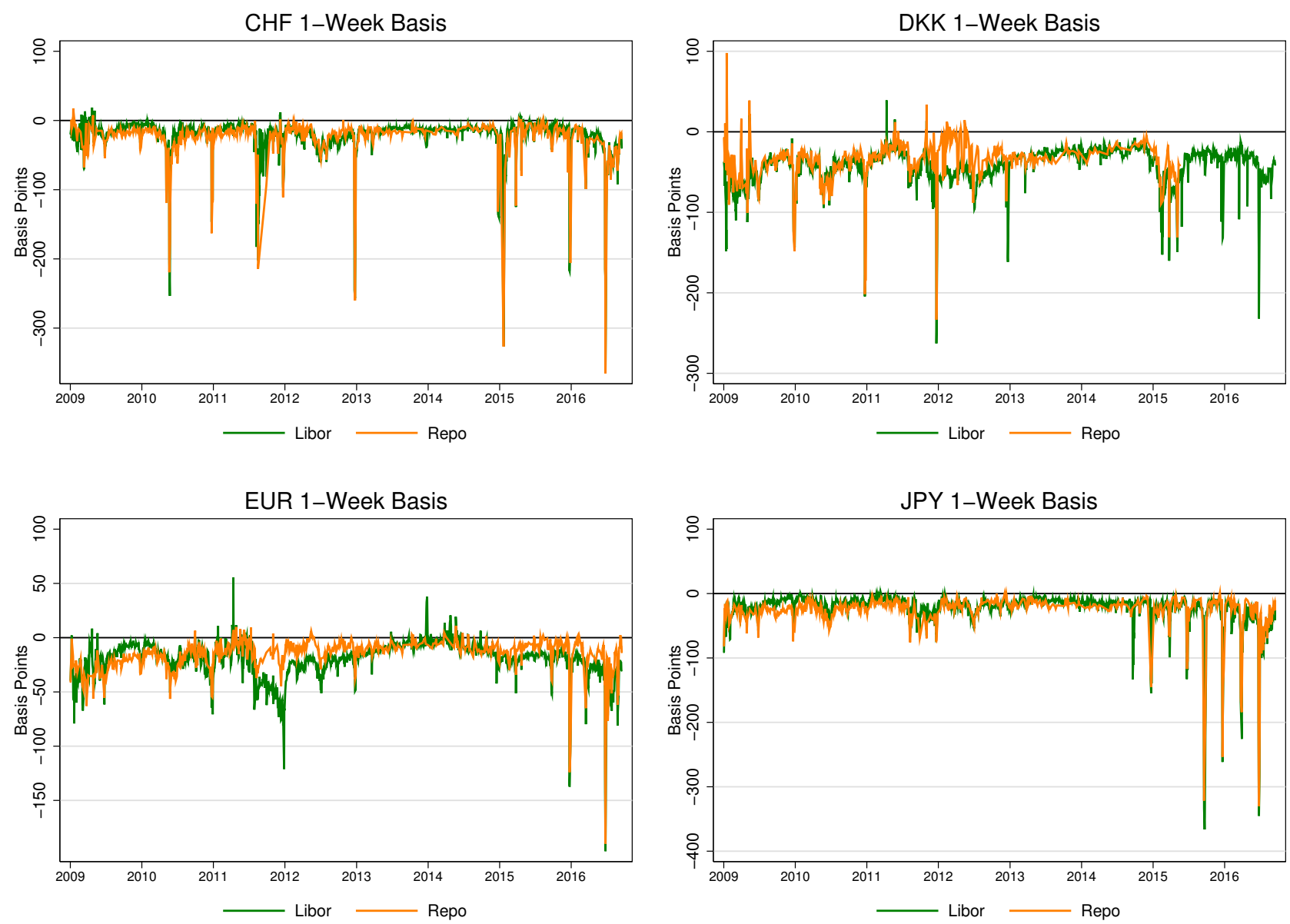

Figure 6: One-week Repo- and Libor-based CIP Deviations: The green line plots the one-week Libor cross-currency basis and the orange line plots the one-week repo crosscurrency basis for the Swiss Franc (CHF), the Danish Krone (DKK), the euro (EUR) and the yen (JPY). 


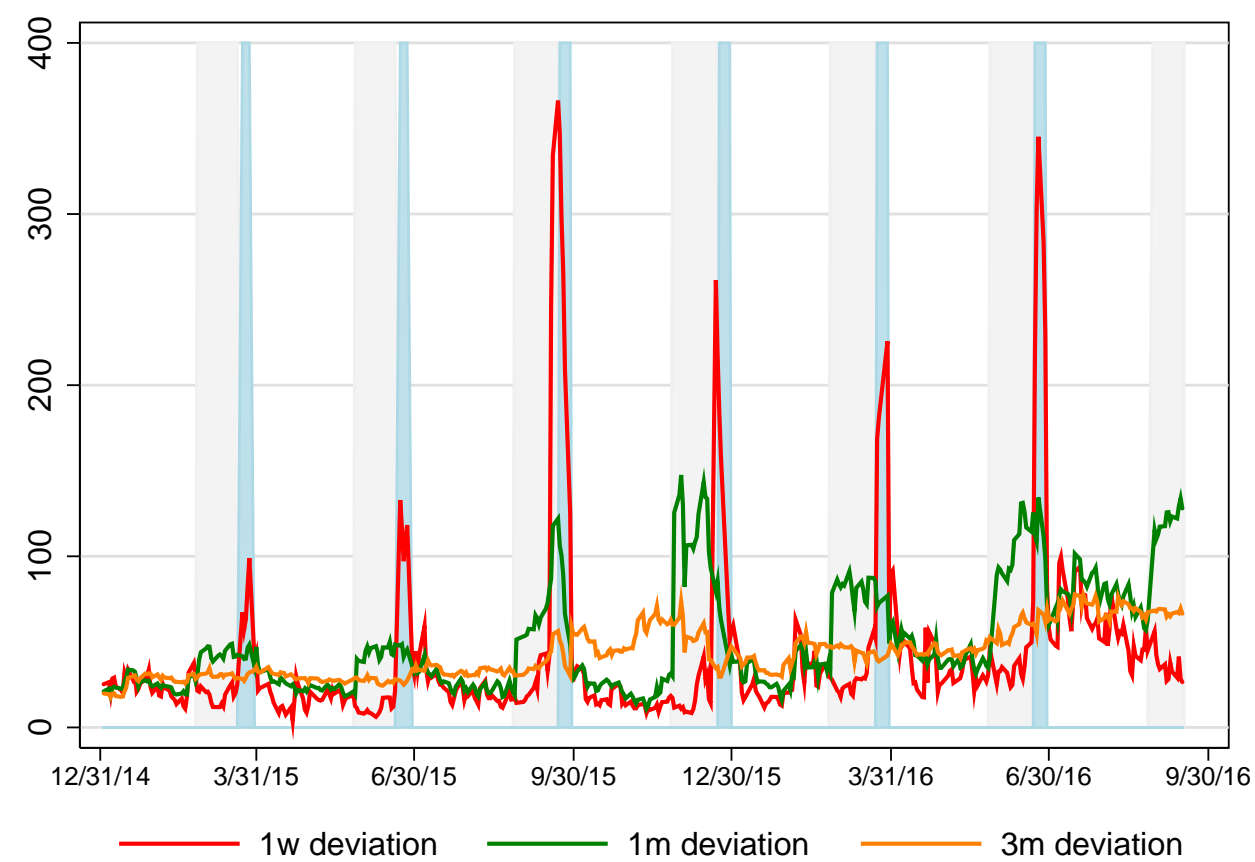

(a) Level of Yen CIP Deviations

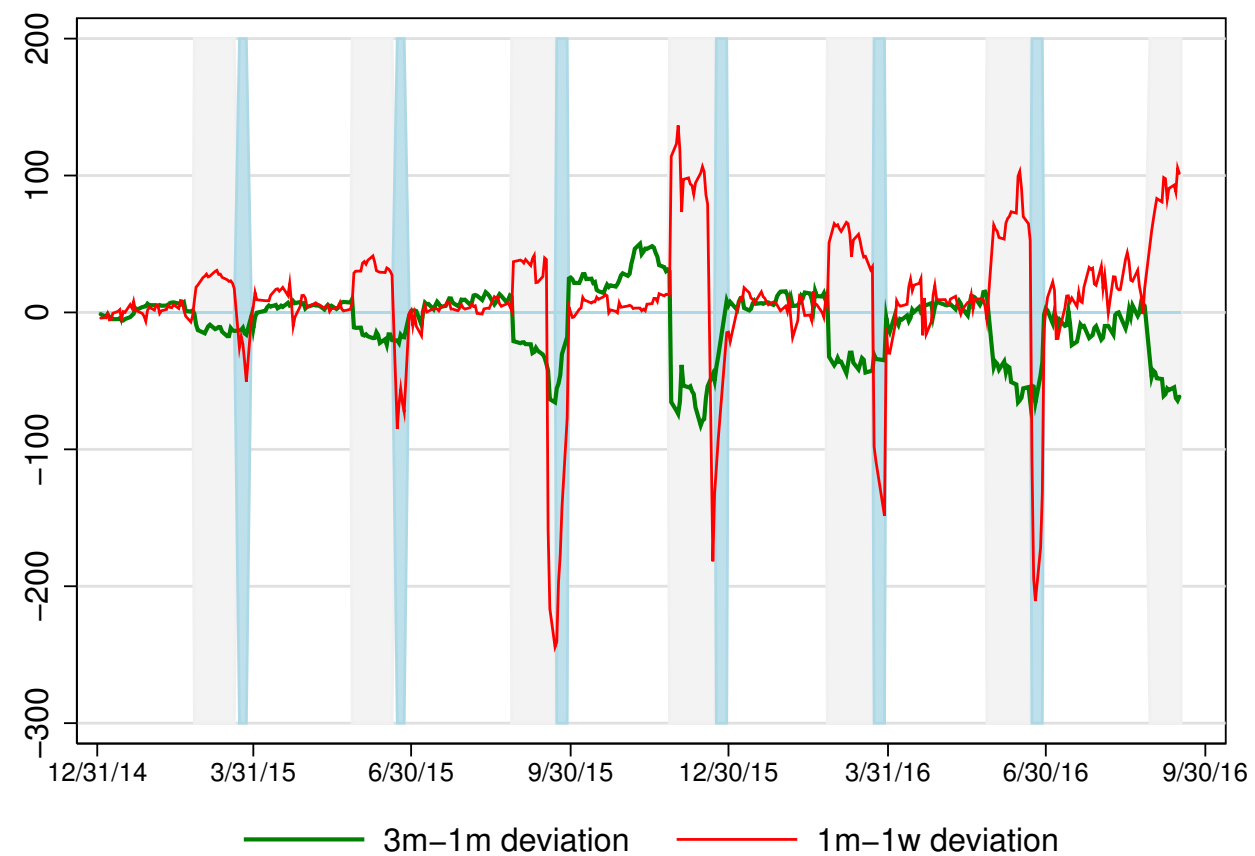

(b) Term Structure of Yen CIP Deviations

Figure 7: Illustration of Quarter-End Dynamics for the Term Structure of CIP Deviations: In both figures, the blue shaded area denotes the dates for which the settlement and maturity of a one-week contract spans two quarters. The grey shaded area denotes the dates for which the settlement and maturity dates of a one-month contract spans two quarters, and excludes the dates in the blue shaded area. The top figure plots one-week, one-month and three-month CIP Libor CIP deviations for the yen in red, green and orange, respectively. The bottom figure plots the difference between 3-month and 1-month Libor CIP deviation for the yen in green and between 1-month and 1-week Libor CIP deviation for the yen in red. 


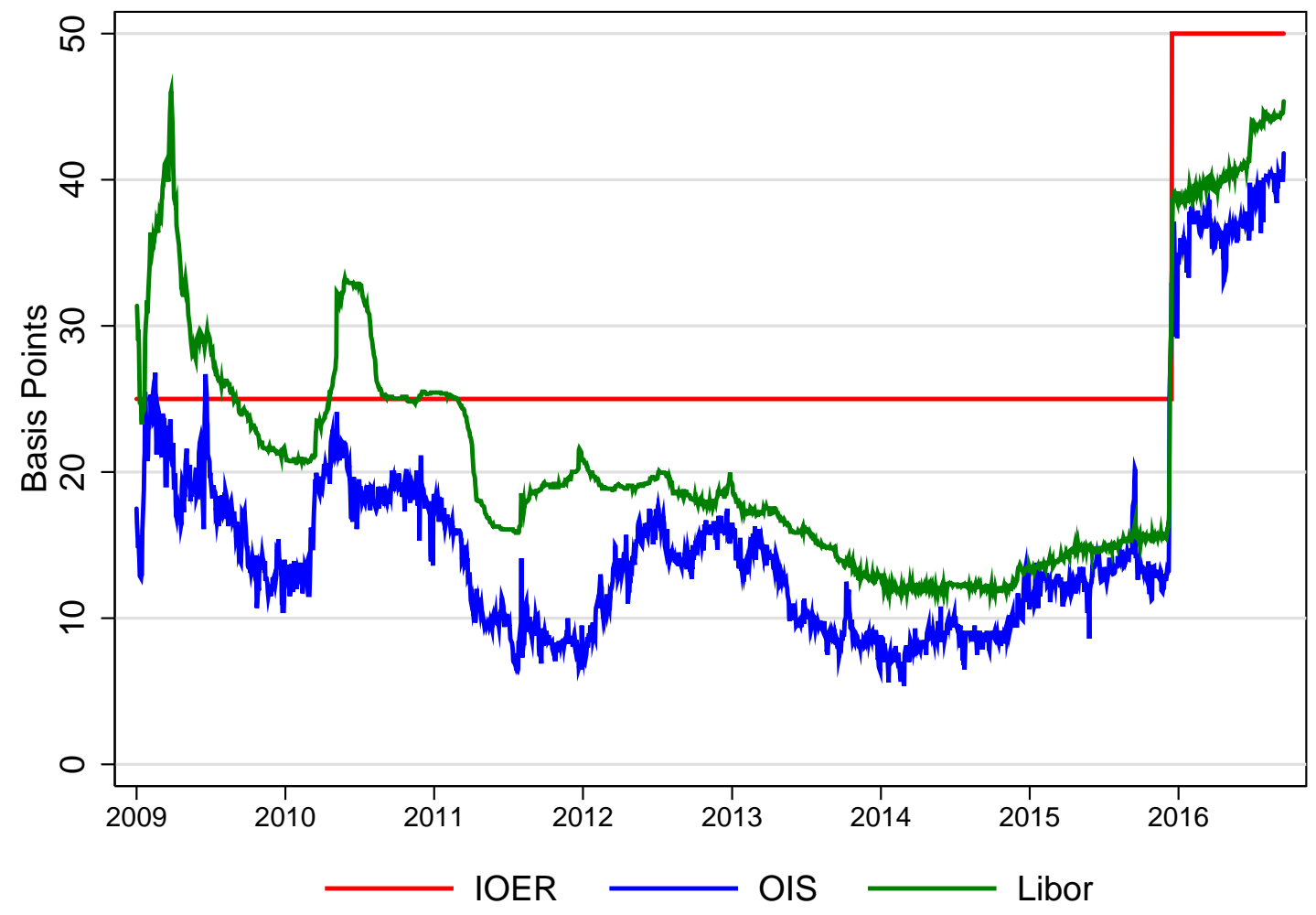

Figure 8: IOER, OIS and Libor rates for the U.S. Dollar: This figure the one-week interest on excess reserves (IOER), overnight interest swap (OIS), and Libor rates for the U.S. dollar from $1 / 1 / 2009$ to $09 / 15 / 2016$. 

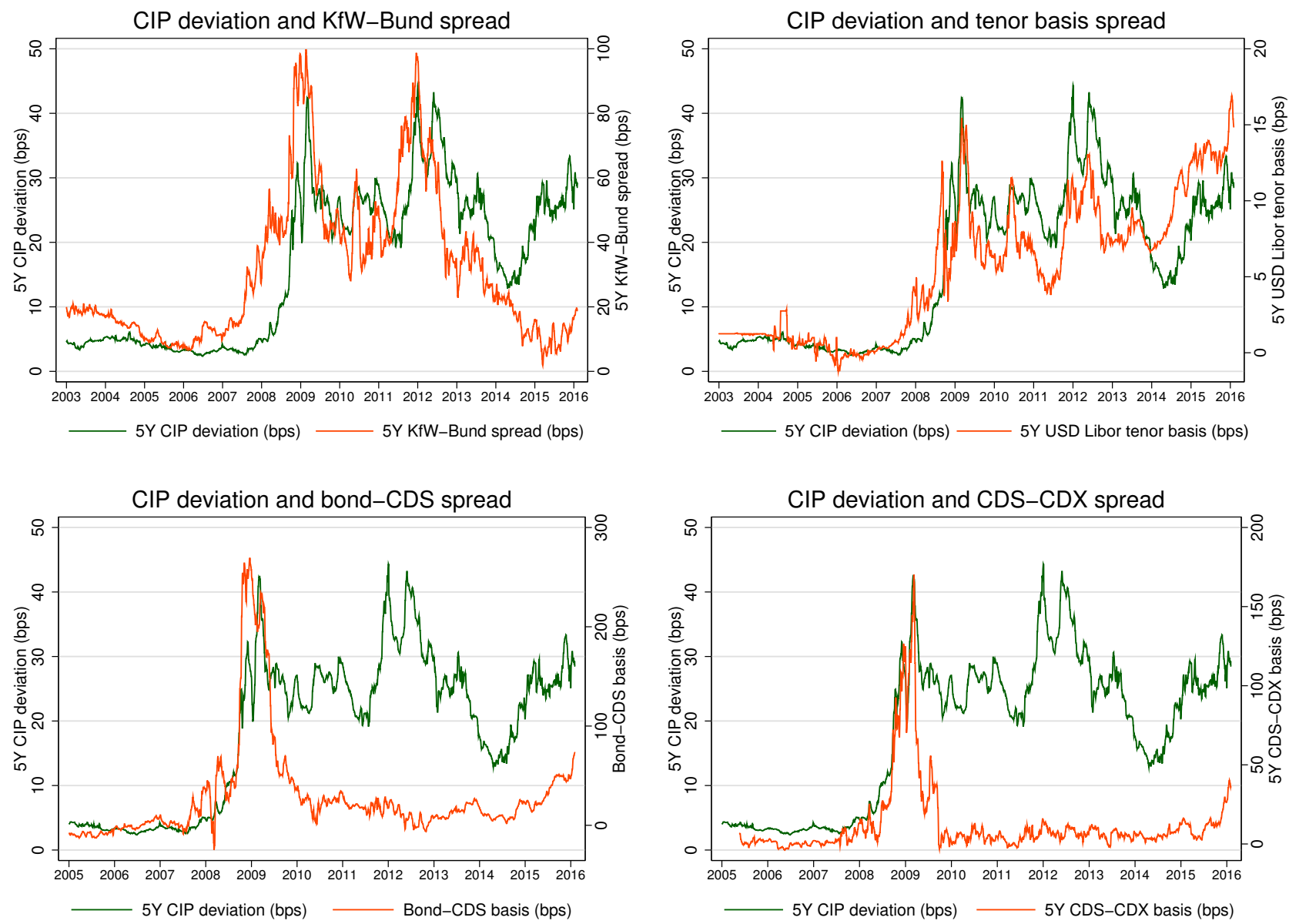

Figure 9: The Cross-Currency Basis and Other Near-Riskfree Arbitrages Each panel compares the time-series of the average currency basis to the time-series of other fixed-income spreads. The average currency basis corresponds to the average of the absolute value of the five-year Libor cross-currency bases of G10 currencies; its scale in basis points is reported on the left-hand side. The scale of the other fixed-income spreads, also expressed in basis points, is reported on the right-hand side of each panel. The other fixed-income spreads include: (1) the KfW-Bund spread, defined as the spread of a five-year euro-denominated KfW bonds over a five-year German Bund, obtained from Bloomberg, (2) the U.S. dollar Libor tenor basis spread, defined as the five-year spread of exchanging one-month U.S. dollar Libor against three-month U.S. dollar Libor, obtained from Bloomberg, (3) the bond-CDS spread for investment grade firms, obtained from Morgan Markets, and (4) the CDS-CDX spread, defined as difference between the average five-year CDS spreads on the 125 constituents of the NA.IG.CDX index and the spread on the NA.IG.CDX index, obtained from Markit. 

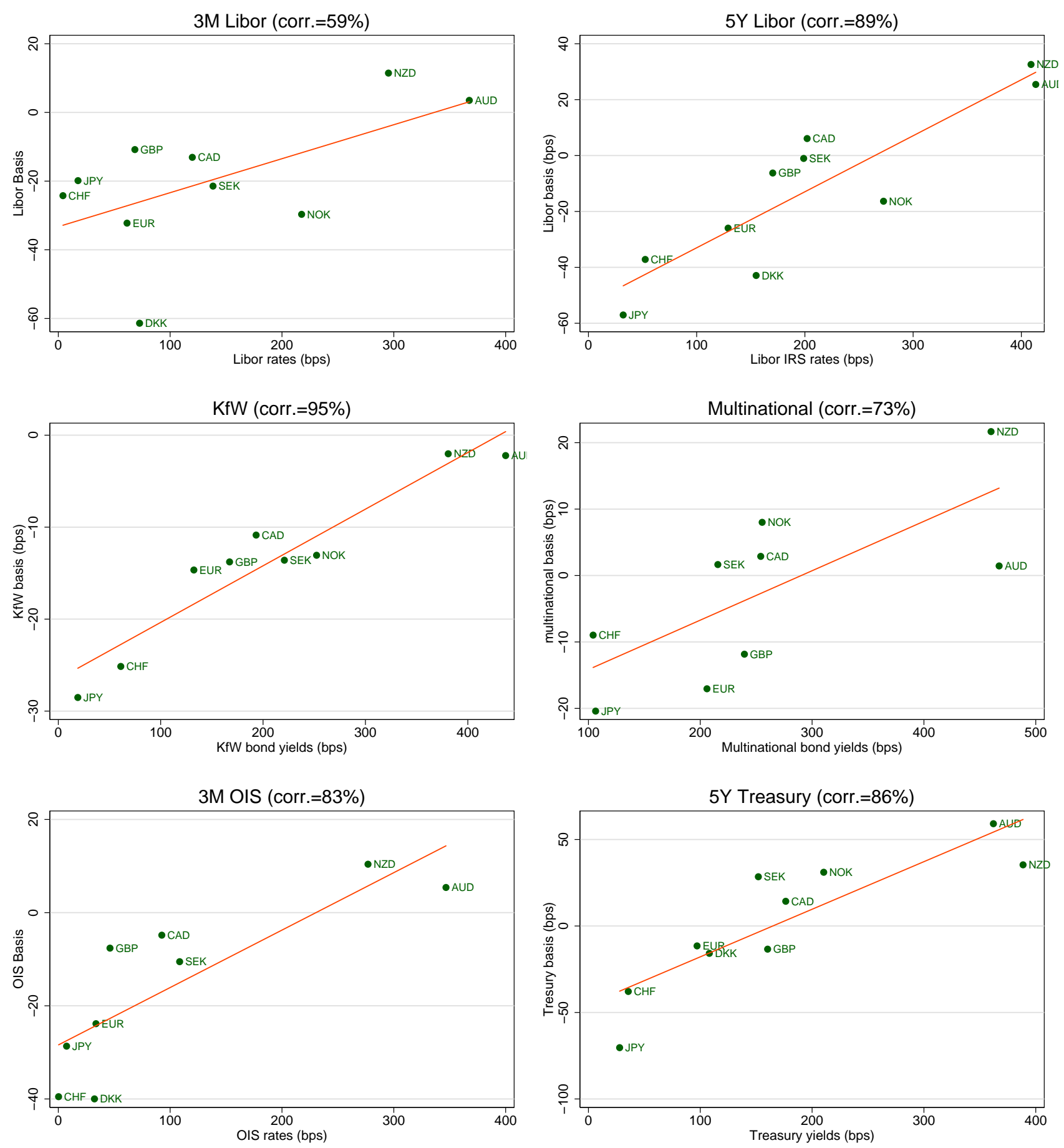

Figure 10: Cross-Sectional Variations in Currency Basis (2010-2015): This figure shows the cross-currency relationship between various cross-currency bases on the y-axis and nominal interest rates on the x-axis. The top two panels plot the relationship for Libor at 3-month and 5-year. The middle two panels plot the relationship for KfW and average multinational issuers. The bottom two panels plot the relationship for 3-month OIS rates and 5-year Treasuries. The correlation between cross-currency bases and nominal interest rates for each interest rate instrument are indicated in the title of each panel. 


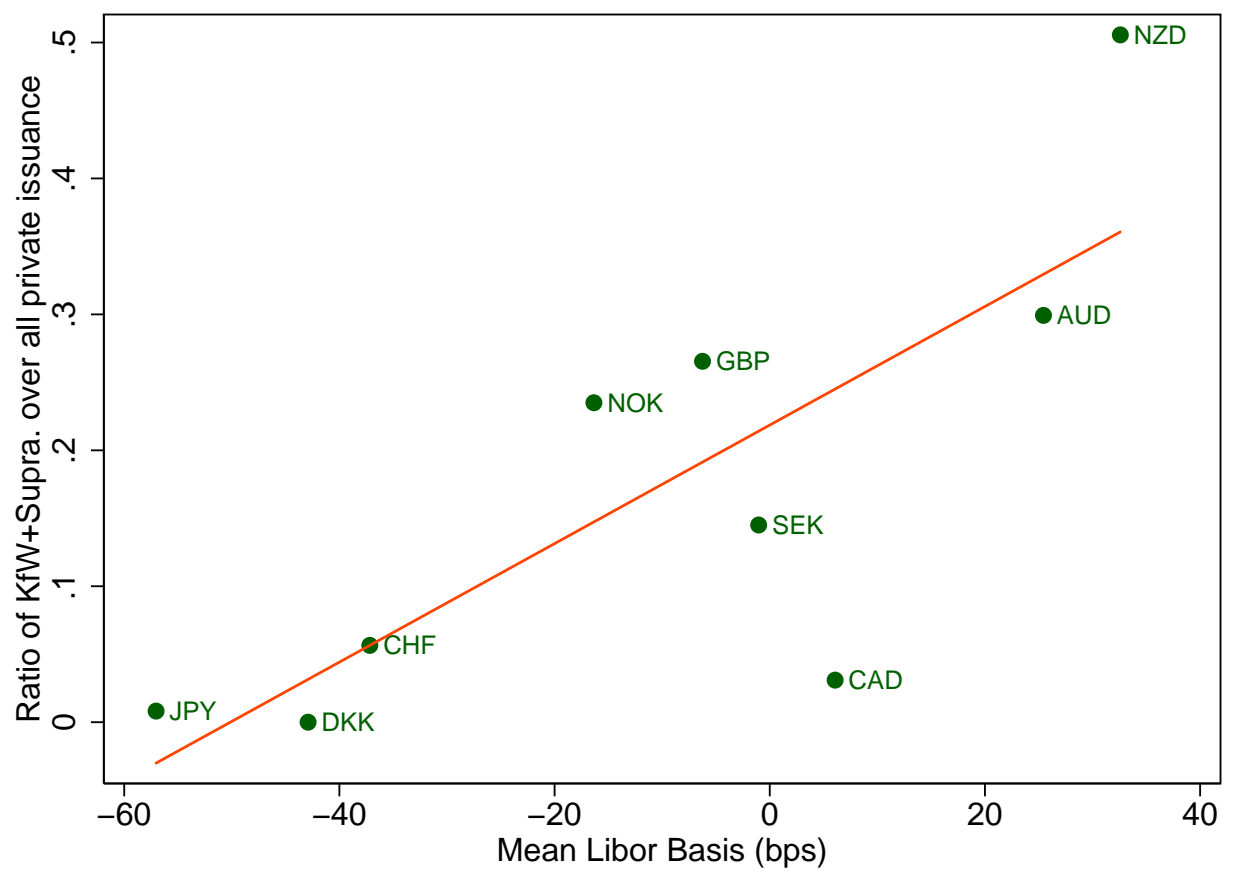

Figure 11: SSA Relative Issuance and the Libor Cross-Currency Basis: On the vertical axis, we plot the ratio of total issuance by KfW and suprantional issuers over the total issuance by all non-financial firms across currencies. On the horizontal, we plot the mean Libor cross-currency basis. The issuance data are from Dealogic and the sample period is $2010-2015$. 


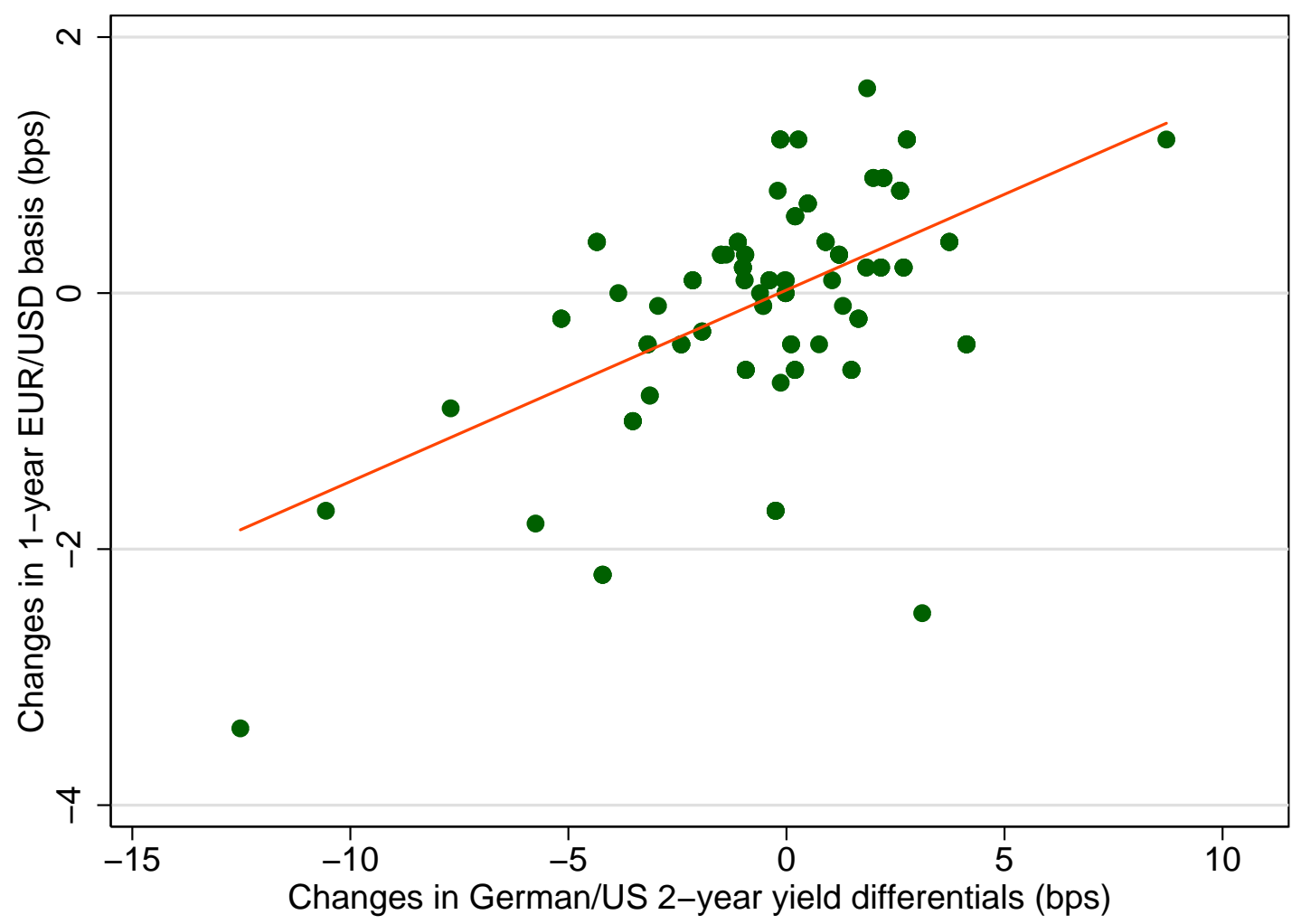

Figure 12: Monetary Policy Shocks and Deviations from CIP: This figure plots intraday changes in the two-year German bund and U.S. Treasury yield differential around the ECB monetary policy announcements on the horizontal axis and intraday changes in the one-year euro/dollar cross-currency basis around the same time on the vertical axis. All intraday data are from Thomson Reuters Tick History. The sample period is from 1/1/2010 to $10 / 30 / 2015$. 
Table 1: Summary Statistics for Libor-based Covered Interest Parity Deviations

\begin{tabular}{|c|c|c|c|c|c|c|c|}
\hline \multirow{2}{*}{ Currency } & \multirow[b]{2}{*}{ Benchmark } & \multicolumn{3}{|c|}{ Panel A: 3-month } & \multicolumn{3}{|c|}{ Panel B: 5-year } \\
\hline & & $2000-06$ & $2007-09$ & $2010-16$ & $2000-06$ & 2007-09 & 2010-16 \\
\hline \multirow[t]{2}{*}{ AUD } & BBSW & -3.7 & -2.5 & 3.9 & 9.5 & 9.3 & 24.6 \\
\hline & & $(4.8)$ & $(20.5)$ & $(10.7)$ & $(2.8)$ & $(11.8)$ & $(5.5)$ \\
\hline \multirow[t]{2}{*}{ CAD } & CDOR & 1.7 & -3.8 & -16.1 & 10.7 & 10.9 & 4.4 \\
\hline & & $(5.2)$ & $(16.6)$ & $(9.4)$ & (3.7) & $(9.5)$ & $(6.2)$ \\
\hline \multirow[t]{2}{*}{$\mathrm{CHF}$} & Libor & -0.4 & -17.9 & -26.7 & -2.2 & -12.9 & -39.8 \\
\hline & & $(4.5)$ & $(27.7)$ & $(20.3)$ & $(0.9)$ & $(12.8)$ & $(12.0)$ \\
\hline \multirow[t]{2}{*}{ DKK } & Cibor & -1.0 & -62.8 & -60.5 & -2.6 & -30.2 & -46.7 \\
\hline & & $(4.6)$ & $(54.6)$ & $(23.3)$ & (2.4) & $(30.2)$ & $(14.1)$ \\
\hline \multirow[t]{2}{*}{ EUR } & Euribor & 1.8 & -27.8 & -31.7 & 0.1 & -15.0 & -28.6 \\
\hline & & $(3.9)$ & $(32.4)$ & $(25.3)$ & $(2.0)$ & $(16.2)$ & $(13.5)$ \\
\hline \multirow[t]{2}{*}{ GBP } & Libor & -6.7 & -35.1 & -10.9 & -0.9 & -17.2 & -6.6 \\
\hline & & $(3.8)$ & $(36.8)$ & $(9.8)$ & (2.3) & $(18.1)$ & $(6.6)$ \\
\hline \multirow[t]{2}{*}{ JPY } & Libor & -3.7 & -15.7 & -25.5 & -5.3 & -13.5 & -62.0 \\
\hline & & $(7.0)$ & $(23.9)$ & $(16.1)$ & $(4.2)$ & $(20.1)$ & $(17.3)$ \\
\hline \multirow[t]{2}{*}{ NOK } & Nibor & -4.1 & -29.1 & -28.1 & -4.7 & -14.8 & -15.1 \\
\hline & & $(6.5)$ & $(33.7)$ & $(21.5)$ & (1.9) & $(12.3)$ & $(9.0)$ \\
\hline \multirow[t]{2}{*}{ NZD } & BKBM & -5.3 & 4.7 & 11.4 & 3.6 & 7.9 & 31.0 \\
\hline & & $(6.8)$ & $(15.0)$ & (8.5) & $(2.9)$ & (8.6) & $(8.2)$ \\
\hline \multirow[t]{2}{*}{ SEK } & Stibor & -3.8 & -26.5 & -23.3 & -1.8 & -7.2 & -2.7 \\
\hline & & $(5.7)$ & $(33.5)$ & $(12.5)$ & (1.0) & (7.9) & $(8.2)$ \\
\hline \multirow[t]{2}{*}{ Average } & & -2.5 & -21.6 & -20.6 & 0.6 & -8.3 & -14.1 \\
\hline & & $(6.0)$ & $(36.4)$ & $(25.3)$ & (6.0) & $(20.5)$ & $(30.7)$ \\
\hline
\end{tabular}

Notes: This table reports the mean Libor basis for G10 currencies for three different periods in basis points. The periods are $1 / 1 / 2000-12 / 31 / 2006,1 / 1 / 2007-12 / 31 / 2009$, and $1 / 1 / 2010-09 / 15 / 2016$. Standard deviations are shown in the parentheses. Panel A focuses on the three-month currency basis, while Panel B focuses on the five-year currency basis. The three-month Libor basis is equal to: $y_{t, t+n}^{\$, \text { Libor }}-\left(y_{t, t+n}^{\text {Libor }}-\rho_{t, t+n}\right)$, where $y_{t, t+n}^{\$, L i b o r}$ and $y_{t, t+n}^{\text {Libor }}$ denote the U.S. and foreign three-month Libor rates and $\rho_{t, t+n} \equiv \frac{1}{n}\left(f_{t, t+n}-s_{t}\right)$ denotes the forward premium obtained from the forward $f_{t, t+n}$ and spot $s_{t}$ exchange rates. The five-year currency basis is obtained from cross-currency basis swap contracts. The countries and currencies are denoted by their usual abbreviations: Australia (AUD), Canada (CAD), Switzerland (CHF), Denmark (DKK), euro area (EUR), U.K. (GBP), Japan (JPY), Norway (NOK), New Zealand (NZD) and Sweden (SEK). For each currency, the table reports the precise benchmark interest rates used to compute the basis. 
Table 2: Credit Spread Differentials and Libor-based Covered Interest Parity Deviations

\begin{tabular}{lcccccc}
\hline & Pooled & AUD & CAD & CHF & DKK & EUR \\
\hline \multirow{2}{*}{$\left(c d s^{i}-c d s^{U S D}\right)$} & -0.00786 & -0.0253 & -0.00714 & $-0.184^{* * *}$ & -0.0199 & $-0.0662^{* *}$ \\
& $(0.0107)$ & $(0.0420)$ & $(0.0369)$ & $(0.0537)$ & $(0.0299)$ & $(0.0316)$
\end{tabular}

\begin{tabular}{ccccccc} 
Observations & 4,891 & 505 & 346 & 505 & 505 & 505 \\
R-squared & 0.000 & 0.005 & 0.000 & 0.016 & 0.002 & 0.023 \\
\hline & & GBP & JPY & NOK & NZD & SEK \\
\hline
\end{tabular}

$\begin{array}{lccccc}\Delta\left(c d s^{i}-c d s^{U S D}\right) & -0.0714 & 0.159^{*} & 0.0117 & 0.0267^{*} & 0.0284^{* *} \\ & (0.116) & (0.0855) & (0.0112) & (0.0151) & (0.0120)\end{array}$

$\begin{array}{llllll}\text { Observations } & 505 & 505 & 505 & 505 & 505\end{array}$

$\begin{array}{llllll}\text { R-squared } & 0.002 & 0.010 & 0.002 & 0.011 & 0.013\end{array}$

Notes: This table shows the regression results of weekly changes in the five-year Libor crosscurrency basis of currency $i$ on weekly changes in mean five-year CDS spreads differential between the interbank panel of currency $i$ and U.S. dollar Libor panel. The sample period is $01 / 01 / 2007$ to $09 / 15 / 2016$. Newey-West standard errors with 13 -week lag are shown in the parentheses, and one, two, and three stars denote significance levels at 10, 5, and 1 percent confidence levels. 
Table 3: One-week Libor- and Repo-based Basis and Repo CIP Arbitrage

\begin{tabular}{cccccc}
\hline & & $\begin{array}{c}\text { Libor Basis } \\
\text { Full Sample }\end{array}$ & $\begin{array}{c}\text { Repo Basis } \\
\text { Full Sample }\end{array}$ & $\begin{array}{c}\text { Repo Basis } \\
\text { Conditional neg. }\end{array}$ & $\begin{array}{c}\text { Repo Arbitrage } \\
\text { Profits }\end{array}$ \\
\hline CHF & Mean & -21.4 & -25.2 & -25.5 & 16.3 \\
& S.D. & $(28.6)$ & $(32.0)$ & $(32.0)$ & $(27.4)$ \\
& \% sample & & & $99 \%$ & $84 \%$ \\
\hline DKK & Mean & -41.3 & -33.8 & -35.6 & 19.3 \\
& S.D. & $(22.7)$ & $(25.2)$ & $(23.5)$ & $(23.7)$ \\
& \% sample & & & $96 \%$ & $67 \%$ \\
\hline EUR & Mean & -19.8 & -15.5 & -16.3 & 11.5 \\
& S.D. & $(16.6)$ & $(14.7)$ & $(14.5)$ & $(13.7)$ \\
& \% sample & & & $96 \%$ & $81 \%$ \\
\hline JPY & Mean & -22.3 & -26.6 & -26.7 & 17.8 \\
& S.D. & $(28.7)$ & $(29.1)$ & $(29.1)$ & $(22.8)$ \\
& \% sample & & & $100 \%$ & $93 \%$
\end{tabular}

Notes: The first two columns report the annualized mean and annualized standard deviation for one-week Libor and GC repo basis by currency during the 01/01/2009-09/15/2016 period. The next column reports the same summary statistics conditional on observing a negative repo basis. For each currency, the last row of the panel reports the percentage of observations with a negative basis. The last column reports the arbitrage profits for the negative basis repo arbitrage provided that the arbitrage profits are positive after taking into account the transaction costs on the forward and spot exchange rates. Transaction costs are taken into accounts for the U.S. and Danish krone repo rates, but not for the Swiss franc, euro, and yen repo rates. 
Table 4: KfW Basis and KfW CIP Arbitrage

\begin{tabular}{ccccccc}
\hline & & Basis & Basis & Pos. Profits & Pos. Profits & Pos. Profits \\
& & full sample & conditional & ex. shorting fee & 25 pct fee & median fee \\
\hline AUD & Mean & 0.1 & 6.9 & 4.3 & 6.1 & 5.8 \\
& S.D. & $(11.5)$ & $(6.1)$ & $(4.2)$ & $(3.1)$ & $(3.4)$ \\
& \% sample & & $57 \%$ & $10 \%$ & $4 \%$ & $2 \%$ \\
\hline CHF & Mean & -23.5 & -24.3 & 15.0 & 5.6 & 15.2 \\
& S.D. & $(15.7)$ & $(15.0)$ & $(10.7)$ & $(10.0)$ & $(8.9)$ \\
& \% sample & & $97 \%$ & $72 \%$ & $50 \%$ & $33 \%$ \\
\hline \multirow{2}{*}{ EUR } & Mean & -13.6 & -14.7 & 9.3 & 2.5 & 8.7 \\
& S.D. & $(9.7)$ & $(8.8)$ & $(6.7)$ & $(6.9)$ & $(5.4)$ \\
& $\%$ sample & & $94 \%$ & $68 \%$ & $34 \%$ & $23 \%$ \\
\hline JPY & Mean & -30.2 & -30.8 & 21.6 & 13.1 & 20.2 \\
& S.D. & $(15.2)$ & $(14.6)$ & $(13.5)$ & $(13.1)$ & $(11.3)$ \\
& \% sample & & $98 \%$ & $90 \%$ & $75 \%$ & $63 \%$
\end{tabular}

Notes: The first column reports the annualized mean, annualized standard deviation, and number of observations for the KfW basis by currency during the $1 / 1 / 2009-08 / 31 / 2016$ period. The second column reports similar statistics, conditional on observing a positive KfW basis for the Australian Dollar (AUD) and a negative KfW basis for the Swiss franc $(\mathrm{CHF})$, the euro (EUR), and the Japanese yen (JPY). The third column reports summary statistics for the arbitrage profits. The arbitrages (a positive basis arbitrage strategy for the Australian Dollar and a negative basis arbitrage strategy for Swiss franc, the euro, and the Japanese yen) are implemented provided that the profits remain positive after taking into account the bid-ask spreads of bonds and swaps. The last two columns report similar profits taking also into account the cost of shorting KfW bonds. The fourth (fifth) column assumes that the costs are equal to the 25th (50th) percentile of the shorting costs for KfW bonds of the corresponding currency on the same trading date. 
Table 5: An Illustration of U.S. Banks Capital Charges Against a Five-year Libor CIP Trade

\begin{tabular}{ccccc}
\hline Year & VaR & SVaR & Capital Ratio & $\begin{array}{c}\text { Capital Charge } \\
\text { (\% of notional) }\end{array}$ \\
\hline 2000 & $4.87 \%$ & & $8 \%$ & $0.56 \%$ \\
2001 & $3.34 \%$ & & $8 \%$ & $0.39 \%$ \\
2002 & $3.65 \%$ & & $8 \%$ & $0.42 \%$ \\
2003 & $3.64 \%$ & & $8 \%$ & $0.42 \%$ \\
2004 & $3.12 \%$ & & $8 \%$ & $0.36 \%$ \\
2005 & $2.07 \%$ & & $8 \%$ & $0.24 \%$ \\
2006 & $1.92 \%$ & & $8 \%$ & $0.22 \%$ \\
2007 & $3.26 \%$ & & $8 \%$ & $0.38 \%$ \\
2008 & $19.21 \%$ & & $8 \%$ & $2.22 \%$ \\
2009 & $20.28 \%$ & & $8 \%$ & $2.34 \%$ \\
2010 & $12.03 \%$ & & $8 \%$ & $1.39 \%$ \\
2011 & $12.78 \%$ & & $8 \%$ & $1.47 \%$ \\
2012 & $14.39 \%$ & & $8 \%$ & $1.66 \%$ \\
2013 & $8.94 \%$ & $20.28 \%$ & $8 \%$ & $3.37 \%$ \\
2014 & $6.43 \%$ & $20.28 \%$ & $11.50 \%$ & $4.44 \%$ \\
2015 & $9.20 \%$ & $20.28 \%$ & $11.50 \%$ & $4.88 \%$ \\
\hline
\end{tabular}

Notes: This table illustrates the capital charges against a five-year Libor CIP trade. The first column reports the $99 \%$ Value-at-Risk (VaR) measure for the trade by year. The VaR are obtained using 10-day rolling windows and annualized (multiplied by 26). The second column reports the 99\% Stress Value-at-Risk (SVaR), which is equal to the VaR in 2009. The third column reports the minimum total capital ratio over time. The fourth column computes the capital charges as $(\mathrm{VaR}+\mathrm{SVaR}) / 26 \times 12.5 \times 3 \times$ capital ratio. 
Table 6: Quarter-End Effects of the Level of CIP Deviations (2000-2016)

\begin{tabular}{|c|c|c|c|c|c|c|}
\hline Panel A & $\begin{array}{c}(1) \\
\text { 1w Libor }\end{array}$ & $\begin{array}{c}(2) \\
1 \mathrm{w} \text { OIS }\end{array}$ & $\begin{array}{c}(3) \\
1 \mathrm{w} \text { Repo }\end{array}$ & $\begin{array}{c}(4) \\
1 \mathrm{~m} \text { Libor }\end{array}$ & $\begin{array}{c}(5) \\
1 \mathrm{~m} \text { OIS }\end{array}$ & $\begin{array}{c}(6) \\
1 \mathrm{~m} \text { Repo }\end{array}$ \\
\hline Qend $W_{t}$ & $\begin{array}{l}1.585^{*} \\
(0.963)\end{array}$ & $\begin{array}{c}2.446 \\
(2.851)\end{array}$ & $\begin{array}{l}6.624^{* *} \\
(2.675)\end{array}$ & & & \\
\hline QendW $W_{t} \times{\text { Post } 07_{t}}_{t}$ & $\begin{array}{c}9.545^{* * *} \\
(1.297)\end{array}$ & $\begin{array}{c}11.23^{* * *} \\
(3.191)\end{array}$ & $\begin{array}{c}22.42^{* * *} \\
(3.864)\end{array}$ & & & \\
\hline Qend $W_{t} \times{\text { Post } 15_{t}}_{t}$ & $\begin{array}{c}37.30^{* * *} \\
(2.257)\end{array}$ & $\begin{array}{c}31.35^{* * *} \\
(3.406)\end{array}$ & $\begin{array}{c}38.48^{* * *} \\
(7.014)\end{array}$ & & & \\
\hline Qend $M_{t}$ & & & & $\begin{array}{l}-0.523 \\
(0.598)\end{array}$ & $\begin{array}{l}-0.397 \\
(1.407)\end{array}$ & $\begin{array}{c}0.331 \\
(1.928)\end{array}$ \\
\hline 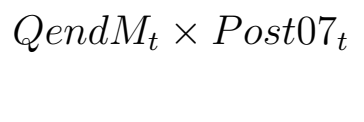 & & & & $\begin{array}{c}4.748^{* * *} \\
(0.822)\end{array}$ & $\begin{array}{c}4.419^{* *} \\
(1.748)\end{array}$ & $\begin{array}{c}13.01^{* * *} \\
(2.689)\end{array}$ \\
\hline QendM $M_{t} \times{\text { Post } 15_{t}}$ & & & & $\begin{array}{c}7.561^{* * *} \\
(1.371)\end{array}$ & $\begin{array}{c}8.154^{* * *} \\
(2.493)\end{array}$ & $\begin{array}{c}1.792 \\
(5.620)\end{array}$ \\
\hline${\text { Post } 07_{t}}$ & $\begin{array}{c}11.00^{* * *} \\
(1.036)\end{array}$ & $\begin{array}{c}18.33^{* * *} \\
(2.737)\end{array}$ & $\begin{array}{c}21.71^{* * *} \\
(2.301)\end{array}$ & $\begin{array}{c}12.64^{* * *} \\
(1.062)\end{array}$ & $\begin{array}{c}13.55^{* * *} \\
(2.057)\end{array}$ & $\begin{array}{c}22.00^{* * *} \\
(2.587)\end{array}$ \\
\hline Post $15_{t}$ & $\begin{array}{c}4.344^{* * *} \\
(1.602)\end{array}$ & $\begin{array}{l}4.838^{*} \\
(2.554)\end{array}$ & $\begin{array}{c}-8.259^{* *} \\
(4.000)\end{array}$ & $\begin{array}{c}6.228^{* * *} \\
(1.706)\end{array}$ & $\begin{array}{c}5.795^{* *} \\
(2.828)\end{array}$ & $\begin{array}{c}3.026 \\
(5.449)\end{array}$ \\
\hline Observations & 32,102 & 22,664 & 9,921 & 41,577 & 31,765 & 9,262 \\
\hline R-squared & 0.168 & 0.101 & 0.112 & 0.200 & 0.129 & 0.162 \\
\hline
\end{tabular}

Notes:This table reports regression results of the absolute value of the daily one-week and one-month Libor, OIS and GC repo bases. Qend $M_{t}$ is an indicator variable that equals 1 if the one-month contract traded at $t$ crosses quarter ends and equals 0 if otherwise. QendW $W_{t}$ is an indicator variable that equals 1 if the one-week contract traded at $t$ crosses quarter ends and equals 0 if otherwise. Post 07 is an indicator variable that equals 1 if the trading date $t$ is on or after $01 / 01 / 2007$ and equals 0 if other wise. Post 15 is an indicator variable that equals 1 if the trading date $t$ is on or after $01 / 01 / 2015$ and equals 0 if other wise. All regressions include currency fixed effects. Newey-West standard errors are used with 90-day lags and one, two, and three stars denote significance levels at 10, 5, and 1 percent confidence levels. The sample period is $1 / 1 / 2000-09 / 15 / 2016$. 
Table 7: Quarter-End Effects on the Term Structure of CIP Deviations (2007-2016)

\begin{tabular}{|c|c|c|c|c|c|c|}
\hline & $\begin{array}{c}(1) \\
t s_{3 M-1 M}^{L i b o r}\end{array}$ & $\begin{array}{c}(2) \\
t s_{3 M-1 M}^{O I S}\end{array}$ & $\begin{array}{c}(3) \\
t s_{3 M-1 M}^{\text {Repo }} \\
\end{array}$ & $\begin{array}{c}(4) \\
t s_{1 M-1 W}^{L i b o r}\end{array}$ & $\begin{array}{c}(5) \\
t s_{1 M-1 W}^{O I S}\end{array}$ & $\begin{array}{c}(6) \\
t s_{1 M-1 W}^{\text {Repo }}\end{array}$ \\
\hline QendM $M_{t}$ & $\begin{array}{c}0.565 \\
(0.414)\end{array}$ & $\begin{array}{c}0.565 \\
(0.414)\end{array}$ & $\begin{array}{c}0.565 \\
(0.414)\end{array}$ & & & \\
\hline 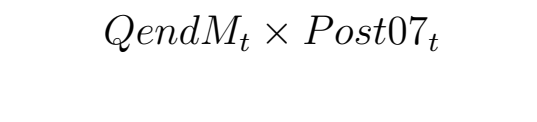 & $\begin{array}{c}-2.390^{* * *} \\
(0.567)\end{array}$ & $\begin{array}{c}-2.390^{* * *} \\
(0.567)\end{array}$ & $\begin{array}{c}-2.390^{* * *} \\
(0.567)\end{array}$ & & & \\
\hline QendM $M_{t} \times \operatorname{Post}_{1} 5_{t}$ & $\begin{array}{c}-9.476^{* * *} \\
(0.934)\end{array}$ & $\begin{array}{c}-9.476^{* * *} \\
(0.934)\end{array}$ & $\begin{array}{c}-9.476^{* * *} \\
(0.934)\end{array}$ & & & \\
\hline $\mathbb{I}_{Q e n d M_{t}=1, Q e n d W_{t}=0}$ & & & & $\begin{array}{l}-0.625 \\
(0.577)\end{array}$ & $\begin{array}{c}0.543 \\
(1.315)\end{array}$ & $\begin{array}{c}0.827 \\
(1.020)\end{array}$ \\
\hline $\mathbb{I}_{Q e n d M_{t}=1, Q e n d W_{t}=0} \times$ Post $07_{t}$ & & & & $\begin{array}{c}4.242^{* * *} \\
(0.773)\end{array}$ & $\begin{array}{c}2.392 \\
(1.466)\end{array}$ & $\begin{array}{c}8.270^{* * *} \\
(1.505)\end{array}$ \\
\hline $\mathbb{I}_{\text {Qend }_{t}=1, \text { Qend } W_{t}=0} \times$ Post $15_{t}$ & & & & $\begin{array}{c}12.76^{* * *} \\
(1.226)\end{array}$ & $\begin{array}{c}11.05^{* * *} \\
(1.426)\end{array}$ & $\begin{array}{c}19.84^{* * *} \\
(3.635)\end{array}$ \\
\hline$Q e n d W_{t}$ & & & & $\begin{array}{c}-3.217^{* * *} \\
(0.809)\end{array}$ & $\begin{array}{c}-3.782^{* *} \\
(1.743)\end{array}$ & $\begin{array}{c}-5.618^{* * *} \\
(1.525)\end{array}$ \\
\hline 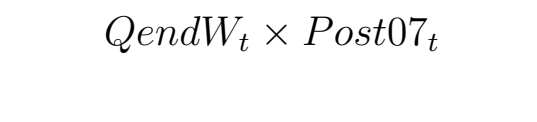 & & & & $\begin{array}{l}-1.404 \\
(1.085)\end{array}$ & $\begin{array}{c}-5.725^{* * *} \\
(1.950)\end{array}$ & $\begin{array}{c}-8.307^{* * *} \\
(2.353)\end{array}$ \\
\hline 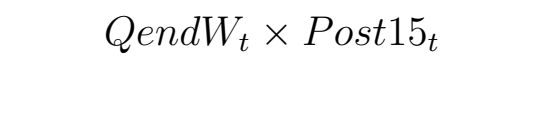 & & & & $\begin{array}{c}-33.39 * * * \\
(1.849)\end{array}$ & $\begin{array}{c}-25.22^{* * *} \\
(2.057)\end{array}$ & $\begin{array}{c}-77.10^{* * *} \\
(6.177)\end{array}$ \\
\hline Post $07_{t}$ & $\begin{array}{c}5.925^{* * *} \\
(0.553)\end{array}$ & $\begin{array}{c}5.925^{* * *} \\
(0.553)\end{array}$ & $\begin{array}{c}5.925^{* * *} \\
(0.553)\end{array}$ & $\begin{array}{c}0.843 \\
(0.657)\end{array}$ & $\begin{array}{l}-0.524 \\
(1.097)\end{array}$ & $\begin{array}{c}1.087 \\
(0.912)\end{array}$ \\
\hline Post $15_{t}$ & $\begin{array}{c}-2.591^{* * *} \\
(0.890)\end{array}$ & $\begin{array}{c}-2.591^{* * *} \\
(0.890)\end{array}$ & $\begin{array}{c}-2.591^{* * *} \\
(0.890)\end{array}$ & $\begin{array}{c}0.444 \\
(1.022)\end{array}$ & $\begin{array}{c}1.594 \\
(1.030)\end{array}$ & $\begin{array}{l}5.516^{* *} \\
(2.160)\end{array}$ \\
\hline Observations & 41,553 & 41,553 & 41,553 & 32,045 & 22,491 & 7,337 \\
\hline R-squared & 0.104 & 0.104 & 0.104 & 0.095 & 0.091 & 0.131 \\
\hline
\end{tabular}

Notes:This table reports regression results of the absolute value of the daily one-week and one-month Libor, OIS and GC repo bases. Qend $M_{t}$ is an indicator variable that equals 1 if the one-month contract traded at $t$ crosses quarter ends and equals 0 if otherwise. Qend $W_{t}$ is an indicator variable that equals 1 if the one-week contract traded at $t$ crosses quarter ends and equals 0 if otherwise. $\mathbb{I}_{\text {QendM }}=1$,Qend $W_{t}=0$ is an indicator variable that equals 1 if Qend $M_{t}=1$ and Qend $W_{t}=0$ and equals 0 if otherwise. Post07 is an indicator variable that equals 1 if the trading date $t$ is on or after 01/01/2007 and equals 0 if other wise. Post 15 is an indicator variable that equals 1 if the trading date $t$ is on or after 01/01/2015 and equals 0 if other wise. All regressions include currency fixed effects. Newey-West standard errors are used with 90-day lags and one, two, and three stars denote significance levels at 10, 5, and 1 percent confidence levels. The sample period is $1 / 1 / 2000-09 / 15 / 2016$. 
Table 8: One-Week Deviations from CIP and Interest Rates on Excess Reserves

\begin{tabular}{cccccccc}
\hline & $(1)$ & $(2)$ & $(3)$ & $(4)$ & $(5)$ & $(6)$ & $(7)$ \\
Currency & Libor basis & IOER-Libor & OIS basis & IOER-OIS & Repo basis & IOER-Repo & IOER basis \\
\hline CHF & -21.4 & -15.5 & -36.8 & -24.8 & -25.2 & -16.5 & -13.2 \\
& $(28.6)$ & $(29.5)$ & $(36.9)$ & $(37.4)$ & $(32.0)$ & $(34.0)$ & $(30.3)$ \\
\multirow{2}{*}{ DKK } & -41.3 & -35.4 & -29.1 & -16.1 & -33.8 & -24.4 & -12.0 \\
& $(22.7)$ & $(25.6)$ & $(23.6)$ & $(24.4)$ & $(25.2)$ & $(26.2)$ & $(25.7)$ \\
\multirow{2}{*}{ EUR } & -19.8 & -13.9 & -22.9 & -11.1 & -15.5 & -7.1 & 8.8 \\
& $(16.6)$ & $(19.1)$ & $(15.8)$ & $(17.2)$ & $(14.7)$ & $(17.3)$ & $(23.6)$ \\
\multirow{2}{*}{ JPY } & -22.3 & -16.4 & -26.5 & -14.3 & -26.6 & -18.2 & -15.6 \\
& $(28.7)$ & $(29.1)$ & $(30.7)$ & $(30.9)$ & $(29.1)$ & $(30.9)$ & $(29.4)$ \\
\hline \multirow{2}{*}{ Total } & -26.1 & -20.2 & -28.3 & -16.1 & -24.7 & -16.0 & -7.9 \\
& $(26.2)$ & $(27.6)$ & $(27.8)$ & $(28.4)$ & $(26.7)$ & $(28.4)$ & $(29.1)$ \\
\hline
\end{tabular}

Notes: This table shows the means and standard deviations of the one-week cross-currency basis for the Swiss franc (CHF), the Danish Krone (DKK), the euro (EUR), and the Japanese yen (JPY). Column 1, denoted "Libor basis," refers to the Libor cross-currency basis. Column 2, denoted "IOER-Libor," refers to the basis obtained by borrowing at the U.S. dollar interest rate on excess reserves (IOER) and investing at the foreign currency Libor rate and hedging the exchange rate risk. Column 3, denoted "OIS basis," refers to the overnight interest rate swap (OIS) cross-currency basis. Column 4, denoted "IOER-OIS," refers to the basis obtained by borrowing in U.S. dollars at the IOER and investing in foreign currency at the OIS rate. Column 5, denoted "Repo basis", refers to the repo cross-currency basis. Column 6 , denoted "IOER-repo," refers to the basis obtained by borrowing in U.S. dollars at the IOER and investing in foreign currency at the repo rate. The seventh column, denoted "IOER basis," refers to the IOER cross-currency basis. The sample starts in 01/01/2009 and ends in $09 / 15 / 2016$. 
Table 9: Currency Basis and Other Fixed-Income Near-Arbitrages

Panel A: 2005-2015

Panel B: 2010-2015

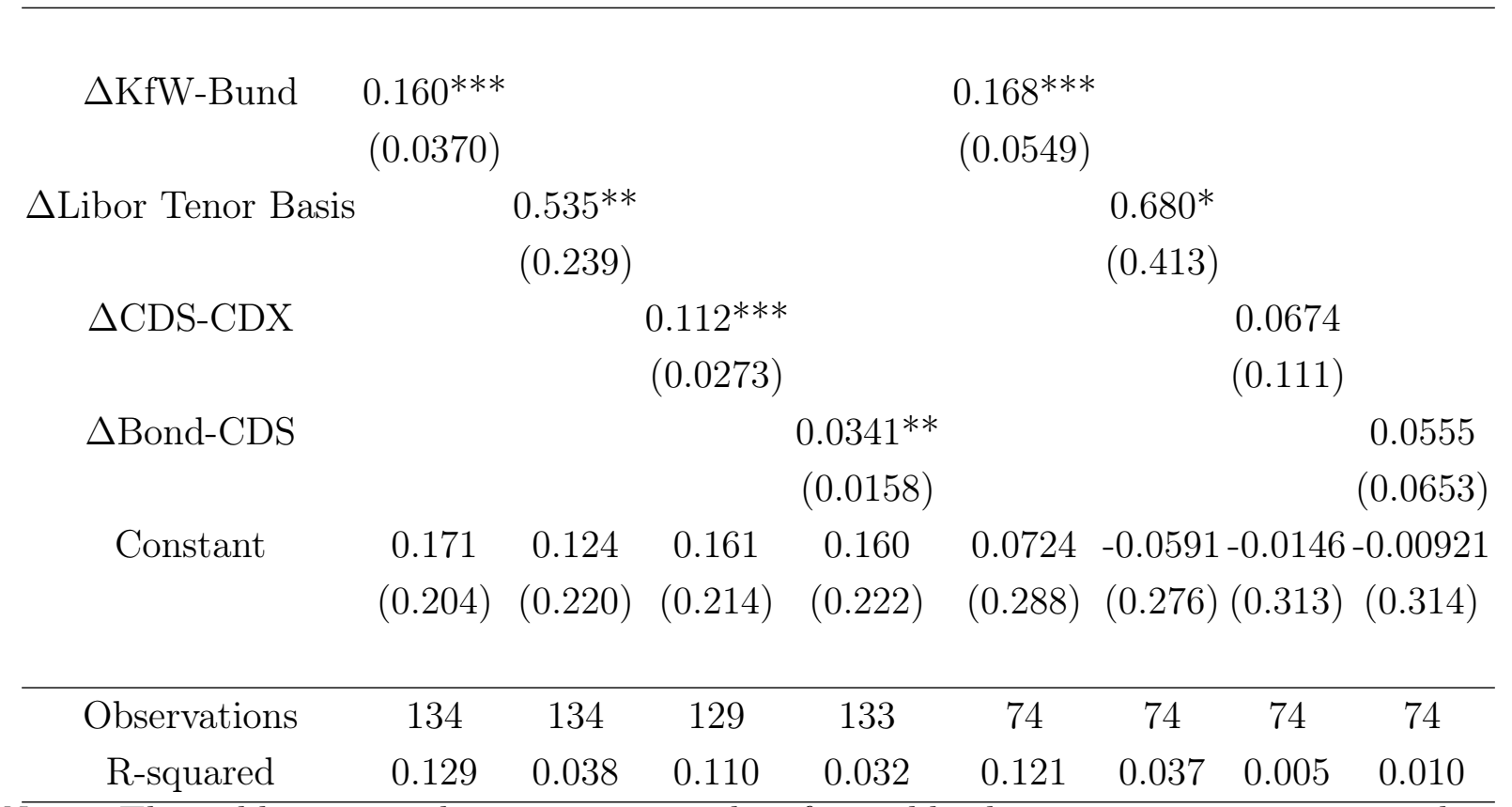

Notes: This table reports the regression results of monthly changes in average currency basis on the changes in other fixed-income spreads. The average currency basis is obtained as the average of the absolute value of the five-year Libor cross-currency bases of G10 currencies. The other fixed-income spreads include: (1) the KfW-Bund spread, defined as the spread of a five-year euro-denominated KfW bonds over a five-year German Bund, obtained from Bloomberg, (2) the U.S. dollar Libor tenor basis spread, defined as the five-year spread of exchanging one-month U.S. dollar Libor against three-month U.S. dollar Libor, obtained from Bloomberg, (3) the bond-CDS spread for investment grade firms, obtained from Morgan Markets, and (4) the CDS-CDX spread, defined as difference between the average five-year CDS spreads on the 125 constituents of the NA.IG.CDX index and the spread on the NA.IG.CDX index, obtained from Markit. The first four columns focus on the $01 / 01 / 2005-02 / 01 / 2016$ sample and the last four columns on the $1 / 1 / 2010-12 / 31 / 2015$ sample. Newey-West standard errors are used with 12-month lags. One, two, and three stars denote significance levels at 10,5 , and 1 percent confidence levels. 


\section{Appendix}

Not For Publication

The Appendix contains additional information on the Libor panels and CDS spreads for each panel (Section A), the definition and time-series of KfW bond basis, along with the distribution of shorting costs for U.S. KfW bonds and the volume of KfW bonds outstanding in different currencies (Section B), the characteristics of issuer-specific bases (Section C), and time series plots for the IOER basis (Section D) and for the GCF-triparty repo spread (Section A7).

\section{A CDS Spreads for Interbank Panels}

We compute the average CDS spread for banks on the interbank panel in the respective currencies. The banks on each interbank panel are listed as follows. We obtain 5-year CDS spreads from Markit. A few banks do not have liquid CDS quotes and hence are excluded from the calculation. The asterisk denotes banks with CDS spreads.

- AUD: Australia and New Zealand Banking Group*, Commonwealth Bank of Australia*, National Australia Bank*, and Westpac Banking Corporation*.

- CAD: BMO Nesbitt Burns, CIBC World Markets*, HSBC Bank Canada*, National Bank Financial, RBC Dominion Securities, Scotia Capital Inc., and TD Securities Inc.

- CHF: Bank of Tokyo-Mitsubishi UFJ Ltd*, Barclays Bank plc*, Citibank NA*, Credit Suisse*, Deutsche Bank AG*, HSBC*, JP Morgan Chase*, Lloyds Banking Group*, Société Générale*, The Royal Bank of Scotland Group*, and UBS AG*

- DKK: Danske Bank*, Deutsche Bank*, Nordea Bank*, Jyske Bank, Nykredit Bank, Sydbank Spar, and Nord Bank.

- EUR: Belfius*, Nordea*, Pohjola, BNP-Paribas*, Crédit Agricole s.a.*, HSBC France*, Natixis-BPCE*, Société Générale*, Commerzbank*, Deutsche Bank*, DZ Bank Deutsche 
Genossenschaftsbank*, National Bank of Greece*, Intesa Sanpaolo*, Monte dei Paschi di Siena*, Unicredit*, Banque et Caisse d'Épargne de l'État*, ING Bank*, Caixa Geral De Depósitos (CGD)*, Banco Bilbao Vizcaya Argentaria*, Banco Santander Central Hispano*, CECABANK, CaixaBank S.A.*, Barclays Capital*, Den Danske Bank*, Bank of Tokyo - Mitsubishi*, and J.P. Morgan Chase \& Co*.

- GBP: Abbey National plc*, Bank of Tokyo-Mitsubishi UFJ Ltd*, Barclays Bank plc*, BNP Paribas*, Citibank NA*, Credit Agricole CIB*, Deutsche Bank AG*, HSBC*, JP Morgan Chase*, Lloyds Banking Group*, Mizuho Corporate Bank*, Rabobank*, Royal Bank of Canada, The Royal Bank of Scotland Group*, Société Générale* and UBS AG*.

- JPY: Bank of Tokyo-Mitsubishi UFJ Ltd*, Barclays Bank plc*, Credit Agricole CIB*, Deutsche Bank AG*, HSBC*, JP Morgan Chase*, Lloyds Banking Group*, Mizuho Corporate Bank*, Société Générale*, Sumitomo Mitsui Banking Corporation*, The Norinchukin Bank*, The Royal Bank of Scotland Group*, and UBS AG*.

- NOK: DNB Bank ASA*, Danske Bank*, Handelsbanken*, Nordea Bank*, Norge $\mathrm{ASA}^{*}, \mathrm{SEB} \mathrm{AB}^{*}$, and Swedbank*.

- NZD: ANZ National Bank*, ASB Bank Ltd, Bank of New Zealand Ltd, Kiwibank Ltd, and Westpac Banking Corporation Ltd*.

- SEK: Danske Bank*, Handelsbanken*, Länsförsäkringar Bank, Nordea*, SEB*, and Swedbank*.

- USD: Bank of America*, Bank of Tokyo-Mitsubishi UFJ Ltd*, Barclays Bank ple*, BNP Paribas*, Citibank NA*, Credit Agricole CIB*, Credit Suisse*, Deutsche Bank AG*, HSBC*, JP Morgan Chase*, Lloyds Banking Group*, Rabobank*, Royal Bank of Canada, Société Générale*, Sumitomo Mitsui Banking Corporation*, The Norinchukin Bank*, The Royal Bank of Scotland Group*, and UBS AG*. 


\section{B KfW Bonds in Different Currencies}

\section{B.1 Basis Definition with Coupon Bonds}

For each individual bond issued by KfW denominated in currency $j$, we denote the coupon rate of a $n$-year bond by $c$, paid $q$ times per year. The principal is paid at the maturity time $t+n$. The price of the bond in currency $j$ is equal to

$$
P_{t, t+n}^{j}=\sum_{i=1}^{n / q} \frac{c}{\left(1+y_{t, t+\tau}^{j, Y T M}\right)^{\tau}}+\frac{1}{\left(1+y_{t, t+n}^{j, Y T M}\right)^{n}},
$$

where $y_{t, t+\tau}^{j, Y T M}$ is the yield to maturity of the bond in currency $j$. We first compute the $\mathrm{z}$ spread of bond over the Libor interest rate swap rate of the respective currency. Using the

term structure of zero-coupon interest rate swap rates $y_{t, t+\tau}^{j, I R S}$ in currency $j$, the z-spread of the bond in currency $j, s_{t, t+n}^{j}$, is given as by the following equation:

$$
P_{t, t+n}^{j}=\sum_{i=1}^{n / q} \frac{c}{\left(1+y_{t, t+\tau}^{j, I R S}+s_{t, t+n}^{j}\right)^{\tau}}+\frac{1}{\left(1+y_{t, t+n}^{j, I R S}+s_{t, t+n}^{j}\right)^{n}}
$$

To compare z-spreads in different currencies, we use the term structure of the cross-currency basis swaps to convert all floating benchmarks to the U.S. dollar Libor, and define synthetic spread of bond in currency $j$ over the U.S. dollar Libor, $\tilde{s}_{t, t+n}^{j}$, by

$$
P_{t, t+n}^{j}=\sum_{i=1}^{n / q} \frac{c}{\left(1+y_{t, t+\tau}^{j, I R S}+x_{t, t+\tau}^{x c c y}+\tilde{s}_{t, t+n}^{j}\right)^{\tau}}+\frac{1}{\left(1+y_{t, t+n}^{j, I R S}+x_{t, t+\tau}^{x c c y}+\tilde{s}_{t, t+n}^{j}\right)^{n}} .
$$

Therefore, the KfW basis between the U.S. dollar and currency $j$ is defined as

$$
x_{t, t+n}^{K f W, j} \equiv s_{t, t+n}^{\$}-\tilde{s}_{t, t+n}^{j},
$$


which gives the difference between the direct dollar borrowing cost, $s_{t, t+n}^{\$}$, and the synthetic dollar borrowing cost, $\tilde{s}_{t, t+n}^{j}$, both measured as spreads over U.S. Libor interest rate swap rates.

Figure A1 displays the KfW currency basis for the Australian dollar, the Swiss franc, the euro, and the Japanese yen, along with the Libor-based basis. In the case of the Australian dollar, the Libor basis is significantly positive post-crisis, but the KfW basis is closer to zero. For the three currencies with negative Libor basis post crisis (Swiss franc, the euro, and the Japanese yen), however, the KfW basis is also negative and tracks the Libor basis very closely.
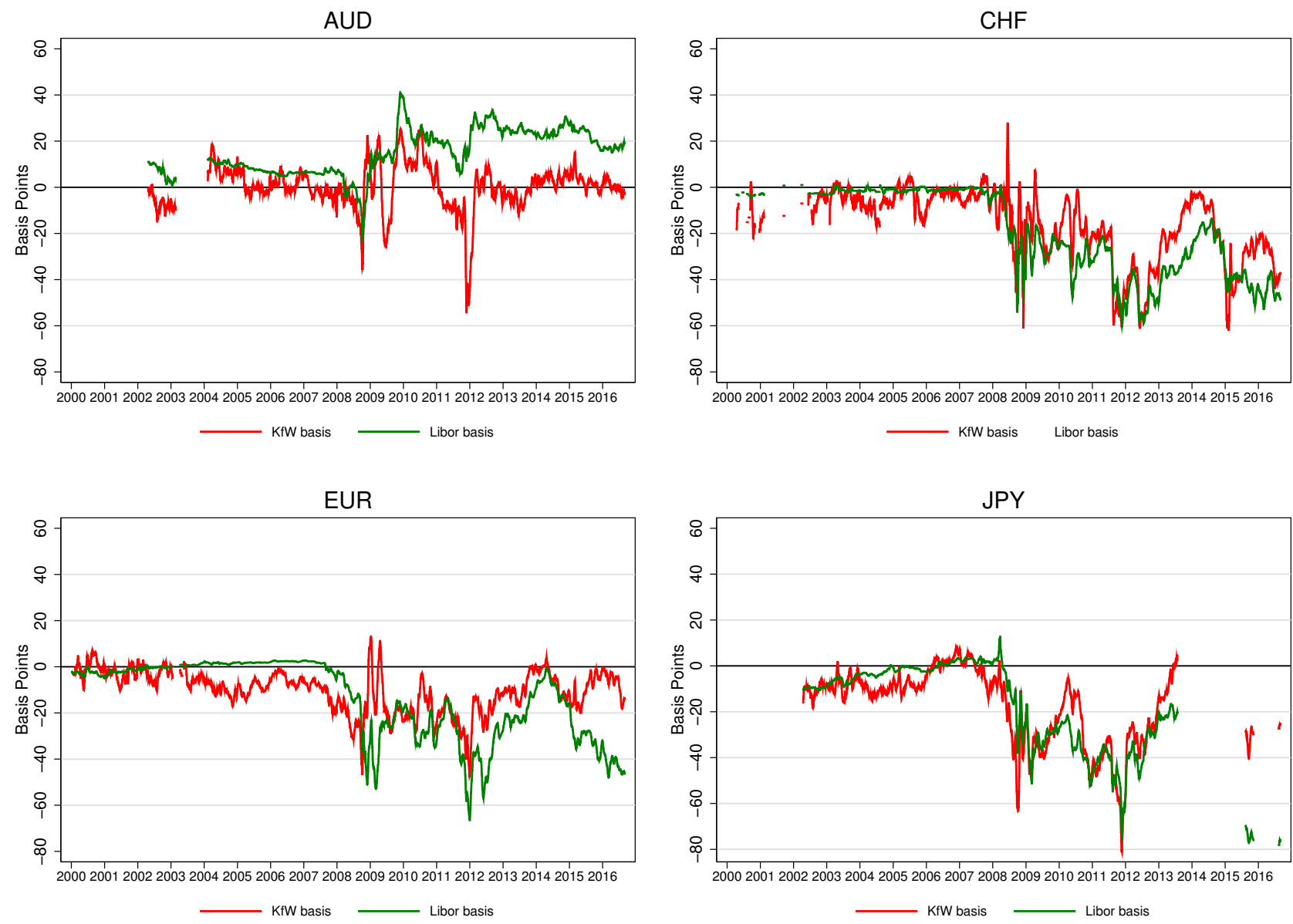

Figure A1: KfW Cross-Currency Basis: The red line plots the KfW crosscurrency basis: The red-line plots the cross-currency basis for KfW. The green line plots the Libor cross-currency basis. All U.S. dollar and foreign currency KfW bonds are matched by their maturity in years. 


\section{B.2 Shorting Costs}

Figure A2 reports the 25 percentile, median and 75 percentile of shorting costs for U.S. dollar bonds issued by KfW.

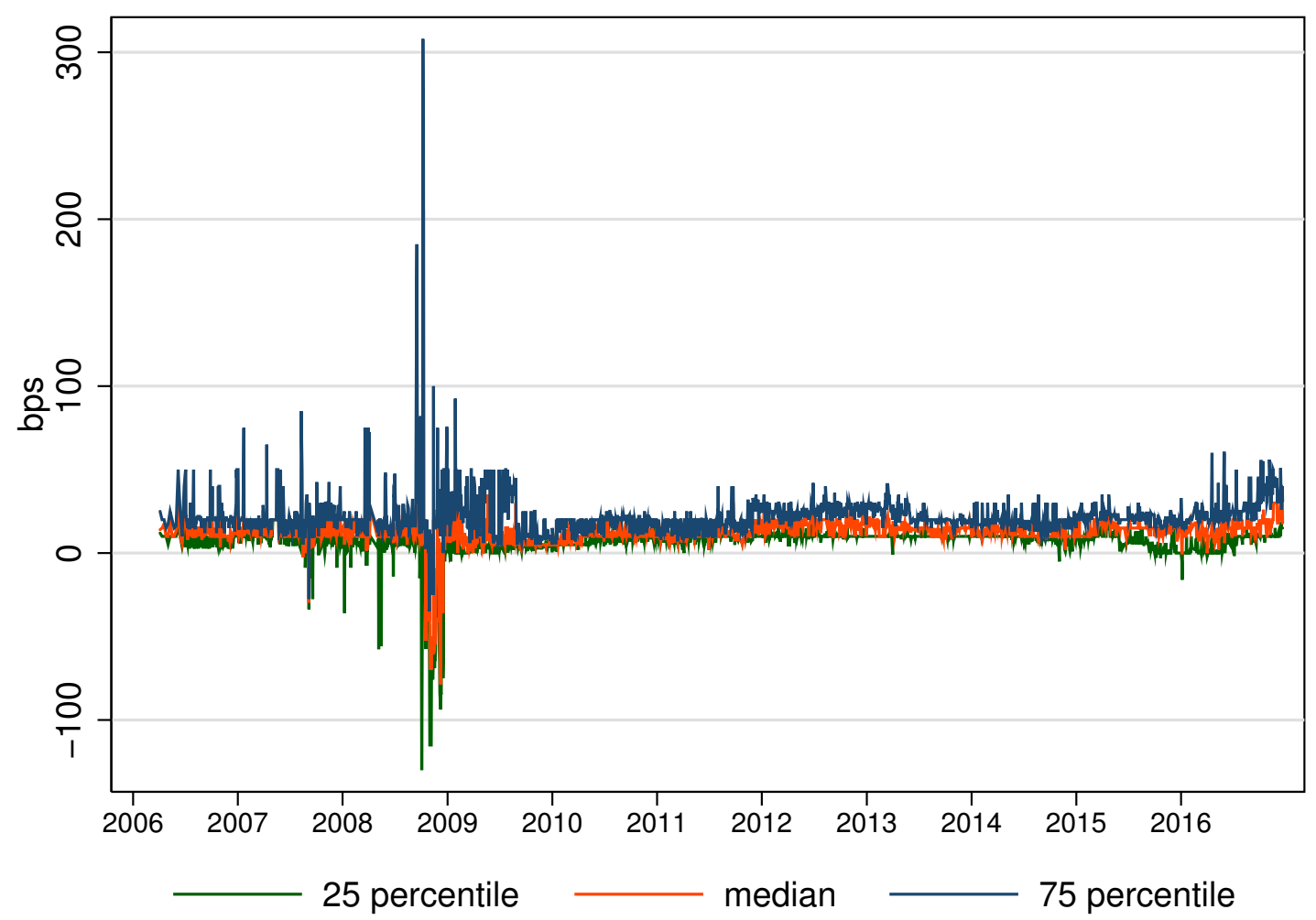

Figure A2: Shorting Costs for KfW USD Bonds: This figure shows the 25 percentile, median and 75 percentile of fees across all transactions for shorting U.S. dollar denominated KfW bonds. Data Source: Markit Securities Finance.

\section{B.3 KfW Basis versus Volume Outstanding}

We obtain KfW volume outstanding by currencies from the KfW Investor Relations online. Figure A3 plots the KfW basis computed in Section 3.3 against the log KfW bond volume outstanding by currency. 


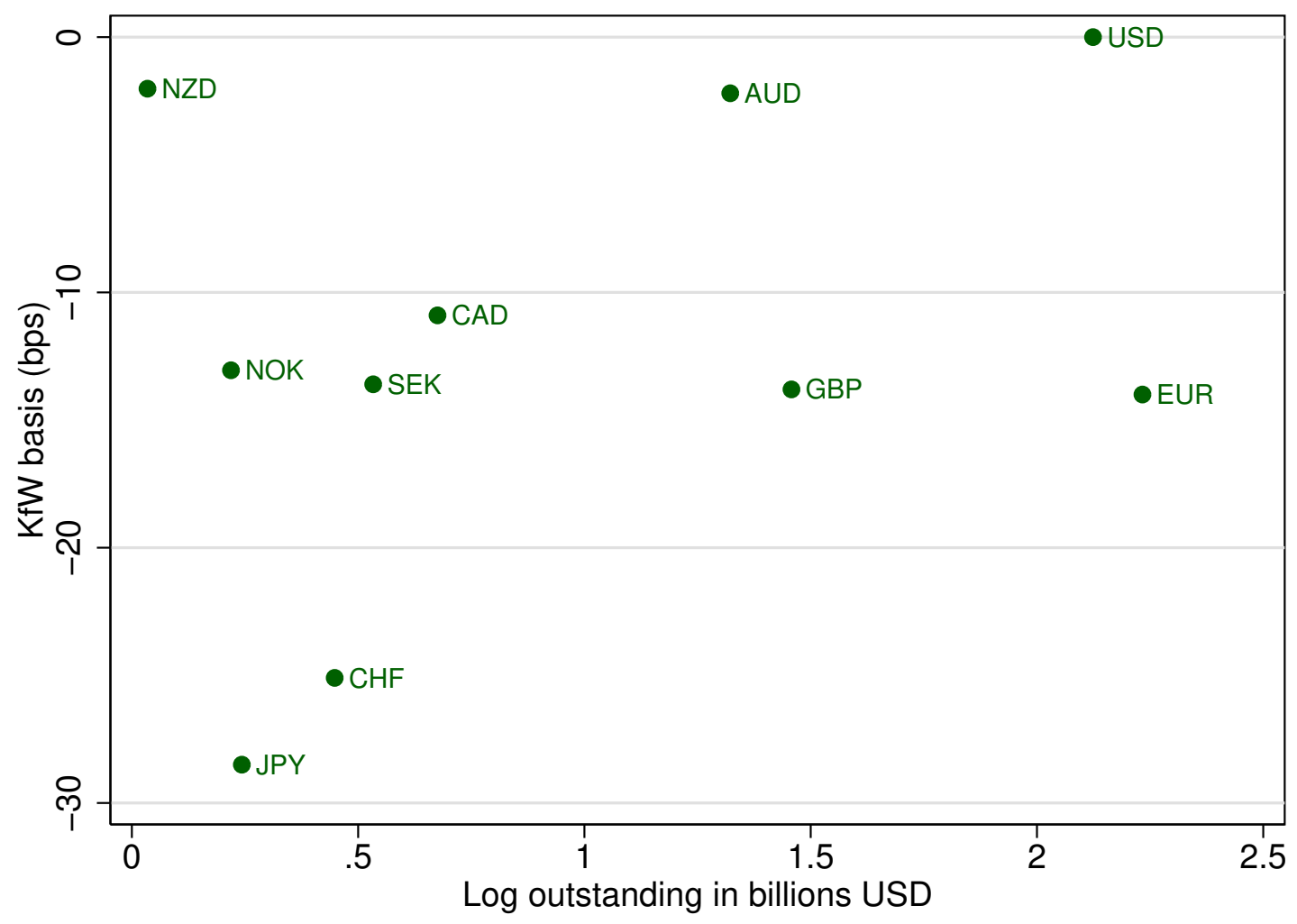

Figure A3: KfW Basis vs. Bond Volume Outstanding by Currency: This figure plots the KfW basis computed in Section 3.3 against the log KfW bond volume outstanding by currency. The correlation between the two variables is 36\%. Data Source: KfW Investor Relations. 


\section{B.4 KfW Basis and Interest Rates}

We examine the cross-sectional differentials in synthetic dollar borrowing costs for KfW. Since KfW bond yields are not observed for all currencies at all tenors on each trading date, we obtain the mean KfW basis by running a fixed-effect regression controlling for the trading date and tenor over the 2010-2015 sample:

$$
\tilde{s}_{t, t+n}^{K f W, j}=\sum_{j \neq U S D} \beta_{j}^{K f W} D_{j}+\alpha_{t, n}
$$

where $\tilde{s}_{t, t+n}^{K f W, j}$ denotes the synthetic dollar spread of a $n$-year KfW bond denominated in currency $j$ over the U.S. Libor interest rate swap of the corresponding maturity, $D_{j}$ is a dummy indicating currency $j$, and $\alpha_{t, j}$ is a tenor-date pair fixed effect. Since the U.S. dollar-

denominated bonds are the omitted category in the regression, (minus) the coefficient $-\beta_{j}^{K f W}$ on currency dummy $D_{j}$ gives the mean KfW basis for currency $j$. As shown in the middle left panel of Figure 10, the KfW basis is strongly correlated with the nominal KfW bond yields. For KfW, all mean bases are negative, suggesting that the KfW is better off funding in U.S. dollars instead of any other G10 currencies. The Australian and New Zealand dollars are the cheapest funding currencies after the U.S. dollar, despite of their high nominal yields, and the Japanese yen and the Swiss franc are the most expensive funding currencies even though their nominal yields are among the lowest. The cross-sectional correlation between the KfW basis and the nominal interest rate is $95 \%$. We note that the liquidity across currencies does not explain the cross-sectional variation in the KfW basis. As shown in Appendix Figure A3, the correlation between the log KfW bond outstanding by currency and the KfW basis is much lower at $35 \%$.

Moreover, the same relationship between basis and interest rates holds for other multicurrency issuers, as shown in the middle right panel of Figure 10: the multinational basis 
again increases with nominal yield differentials. ${ }^{32}$ For both the KfW and multinational basis, the gap between the most expensive and the cheapest funding currency is about 30 to 40 basis points, which is smaller than the 100 basis point cost differentials between the Australian dollar and the Japanese yen based on Libor, but remains economically significant nevertheless. OIS rates and Treasury lead to similar results, as shown in the bottom two panels of Figure 10.

\section{Issuer-Specific Basis for Risky Issuers}

Near-arbitrage opportunities exist for bonds issued by the same risky issuer in different currencies. Under some additional assumptions, the CIP condition can be expressed in terms of defaultable rates. In a frictionless market, if $y_{t, t+n}^{\$}$ and $y_{t, t+n}$ correspond to yields on defaultable bonds with the same default probability and recovery rates, as long as the exchange rate process and the default process are independent, the currency basis is zero: $x_{t, t+n}=0$ (see Buraschi, Menguturk, and Sener, 2015, or Proposition 2 in Du and Schreger, forth.). In practice, the same default and recovery rates hold for bonds of the same issuer under the pari passu clause and the impact of the covariance between currency and corporate credit risk appears small. ${ }^{33}$

As for the KfW basis, we define the issuer-specific basis for any issuer $k$ as follows:

$$
x_{t, t+n}^{k}=y_{t, t+n}^{\$, k}-\left(y_{t, t+n}^{j, k}-\rho_{t, t+n}^{j}\right),
$$

\footnotetext{
${ }^{32}$ The following issuers with diverse funding currency mix are included in the regression: the European Investment Bank, the World Bank, the four largest Australian banks (Commanwealth Bank, Westpac, Australia and New Zealand Banking Group and National Australia Bank), Citi, JP Morgan, Goldman Sachs and General Electric.

${ }^{33} \mathrm{Du}$ and Schreger (Forthcoming) give a simple calibration as follows. Assume that the foreign currency depreciates against the U.S. dollar by $\alpha$ percents in the event of a corporate default compared to the nondefault state, and assume that the U.S. dollar bond yield is equal to $y_{t}^{* \$}+s p_{t}$, where $y_{t}^{* \$}$ is the risk-free rate in the U.S. dollar and $s p_{t}$ is the credit spread. Then the synthetic dollar yield by swapping a foreign currency bond into the U.S. dollar should be equal to $(1-\alpha) s_{t}+\rho_{t}+y_{t}^{* \$}$. Suppose that the credit spread is equal to $s p_{t}=100$ basis points and that $\alpha=5 \%$, and then the deviations from CIP for the corporate issuer should be around $\alpha s_{t}=5$ basis points. Even an exchange rate depreciation of $20 \%$ at the time of a corporate default would only entail a CIP deviation of 20 basis points. As we shall see, the CIP deviations are much larger than that.
} 
where $y_{t, t+n}^{\$, k}$ denotes the dollar bond yield of issuer $k$ and $y_{t, t+n}^{i, k}$ denotes the bond yield of currency $j$ issued by the same issuer $k$. We focus on the issuer-specific basis for a panel of global banks with active multi-currency long-term debt issuance, including three U.S. banks (Citi, JP Morgan and Goldman Sachs), six European banks (Barclays, Deutsche Bank, BNP Parisbas, Societe Generale, Credit Suisse and UBS), four Australian banks (National Australia Bank, Commonwealth, Australia and New Zealand Banking Group and Westpac) and one Japanese bank (Bank of Tokyo Mitsubishi). In addition, we also included debt issuance by the financing arms of Honda and Toyota in the case of Japan . We construct the issuer-specific basis by matching the maturity year and seniority of the dollar and foreign currency bonds of issuer $k$. All data on bond yields in the secondary market are from Bloomberg.

Figure A4 shows the issuer-specific bases for the Australian dollar, the Swiss franc, the euro and the yen across different issuers, together with the Libor cross-currency basis. Issuerspecific bases were also close to zero before the global financial crisis. Since the crisis, there has been a large cross-sectional dispersion in the basis across issuers. The sign of the crosscurrency basis for each currency depends on the specific issuer. In particular, as shown in Figure A5, U.S. banks, on average, have a persistently lower issuer-specific basis than foreign banks since the global financial crisis, which points to a comparative advantage of U.S. banks over foreign banks in direct funding in dollars. The significant differences in relative funding costs can potentially explain why foreign banks heavily rely on funding in their local currencies and then swap into U.S. dollars rather than borrowing directly in the U.S. dollar markets, especially during the periods of distress (Ivashina, Scharfstein, and Stein, 2015). For U.S.-domiciled entities and AAA-rated agencies and supranationals (like KfW described in the previous subsection), it is more advantageous, from a pure funding cost perspective, to borrow directly in U.S. dollars. In addition, we note the average bankspecific basis can be closer to zero than the Libor basis, which suggests that bank treasuries are engaging in funding cost arbitrage using long-term debt. However, compared to the pre- 
crisis period, the average issuer-specific basis is significantly larger and more volatile after the crisis, which implies a reduction in the effectiveness of the arbitrage.
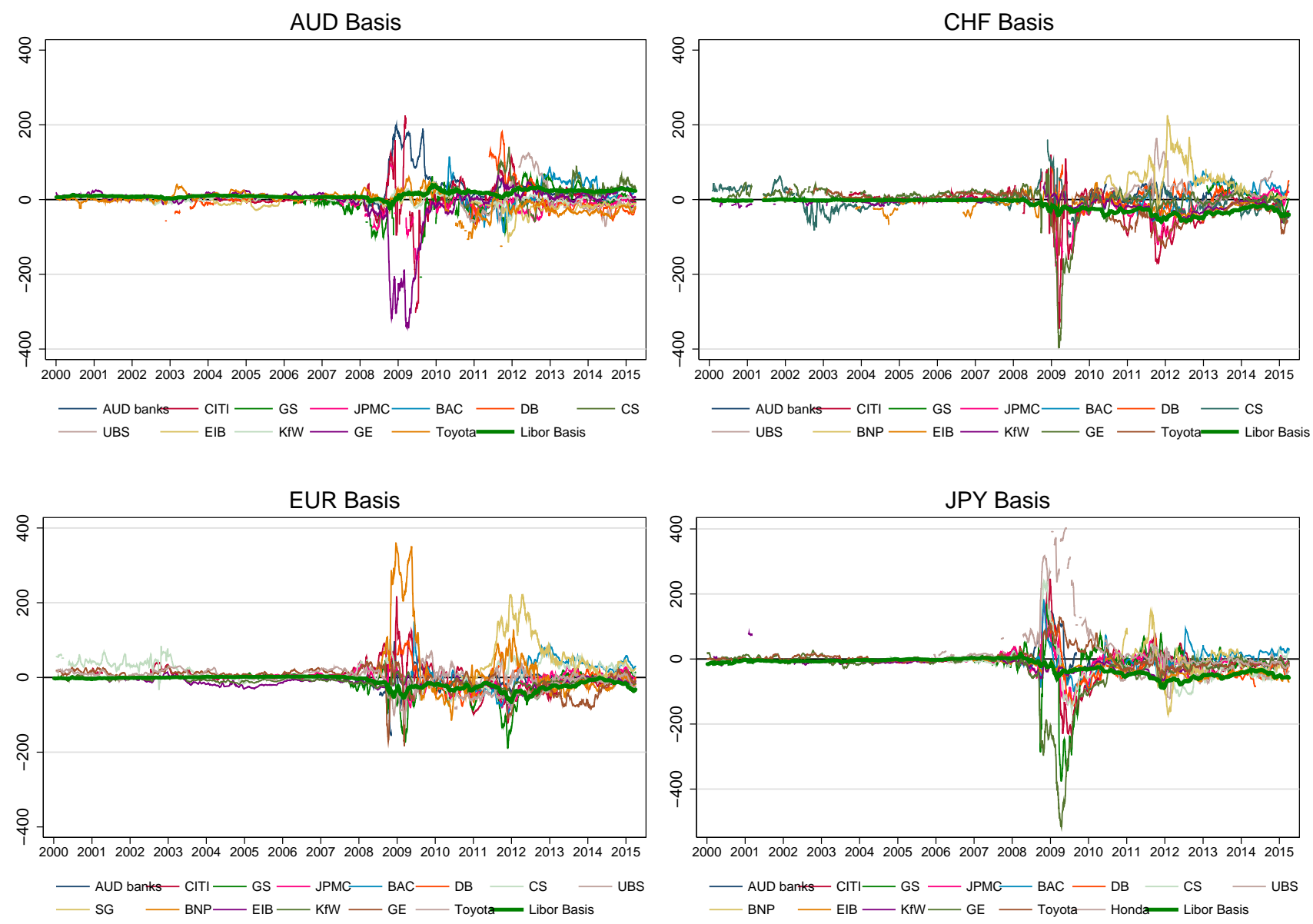

Figure A4: Issuer-Specific Cross-Currency Bases for Multi-currency Issuers: The figure shows issuer-specific cross-currency bases, together with the Libor cross-currency basis. All bonds for the same issuer are matched by the maturity year and seniority. 

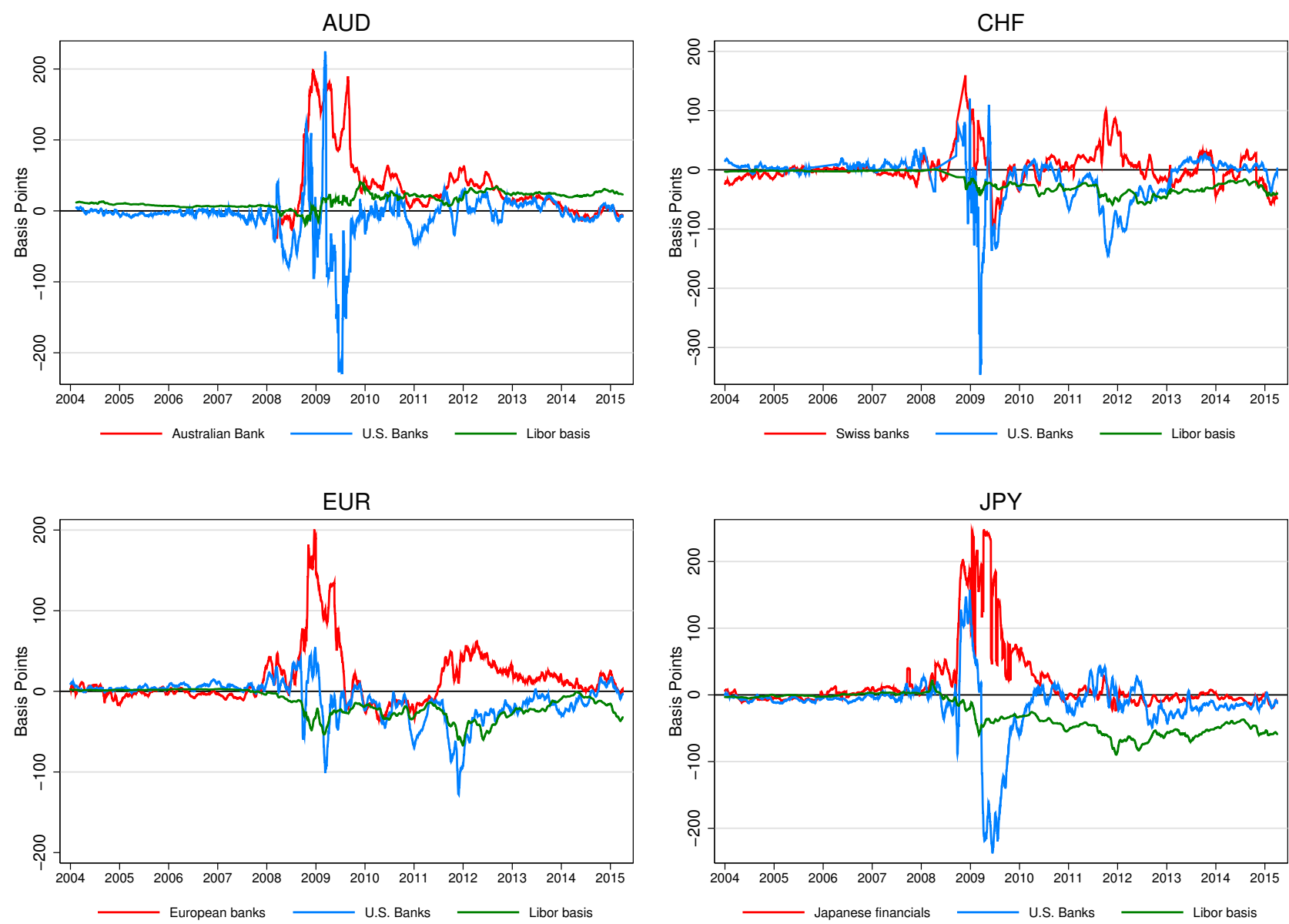

Figure A5: Average Issuer-Specific Basis by Issuer Type: The figure shows the average issuer-specific cross-currency bases by issuer types, together with the Libor cross-currency basis. All bonds for the same issuer are matched by the maturity year and seniority. "Australia Banks" include Australia and New Zealand Banking Group, Commonwealth Bank of Australia, National Australia Bank, and Westpac Banking Corporation; "Swiss Banks" include Credit Suisse and UBS; "European Banks" include Barclays, Deutsche Bank, BNP Parisbas, Societe Generale, Credit Suisse and UBS; "Japanese Financials" include Bank of Tokyo, Honda and Toyota; "U.S. banks" include Citi, Goldman Sachs and JP Morgan.

\section{IOER Basis}

Figure A6 plots the IOER basis, together with the Libor basis and the modified Libor basis by "funding" in the IOER. 

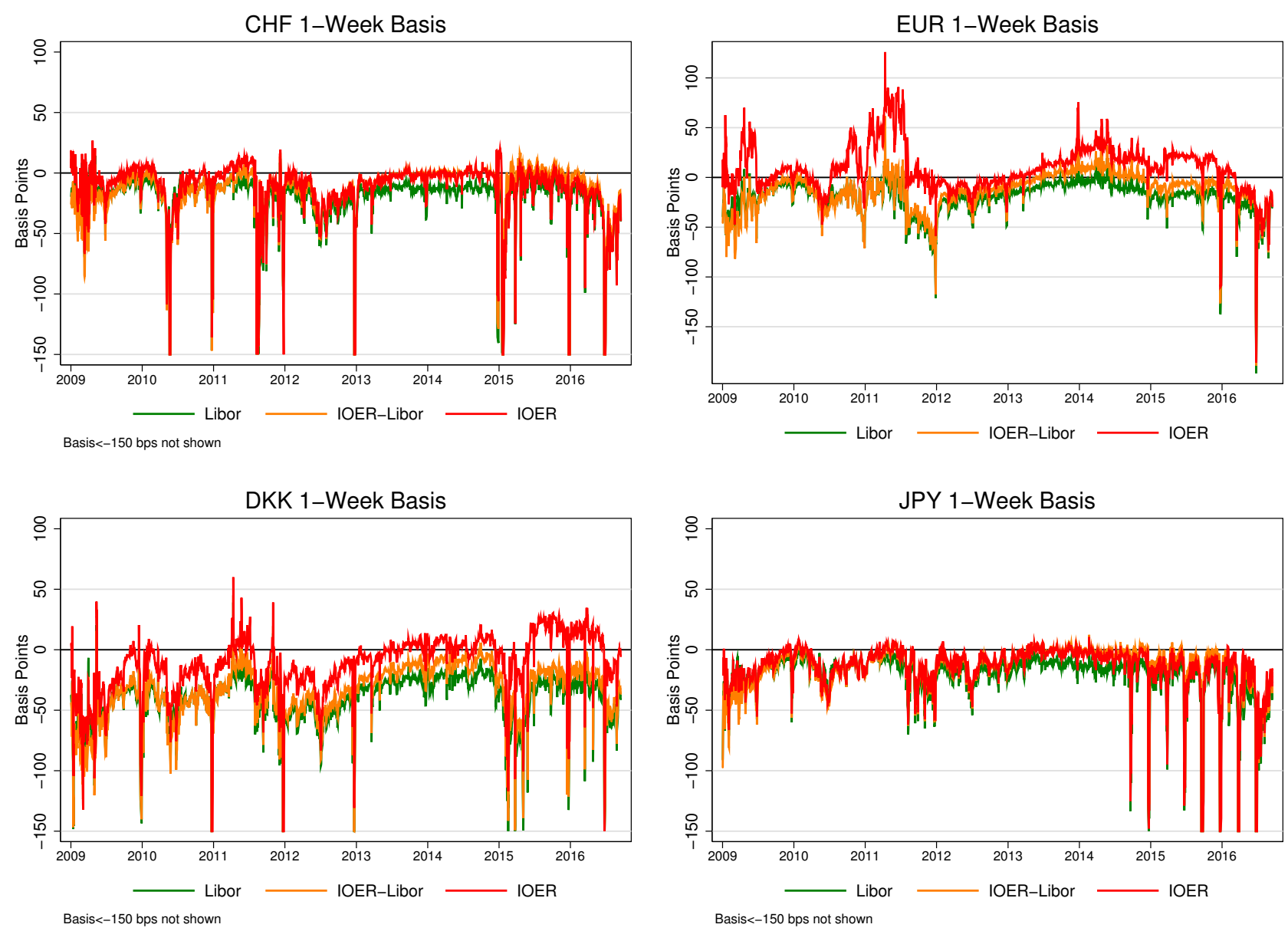

Figure A6: CIP Deviations using Interest on Excess Reserves: This figure plots the one-week cross-currency basis for the Swiss franc (CHF), the euro (EUR), the Danish Krone (DKK), and the Japanese yen (JPY). The green line, denoted "Libor," refers to the conventional Libor cross-currency basis. The orange line, denoted "IOER-Libor," refers to the basis obtained by borrowing at the U.S. IOER rate and investing in foreign currency at the Libor rate, while hedging the currency risk. The red line, denoted "IOER," refers to the basis obtained by borrowing at the U.S. IOER rate and investing in foreign currency at the IOER rate, while hedging the currency risk. 


\section{E Repo-GCF Spreads}

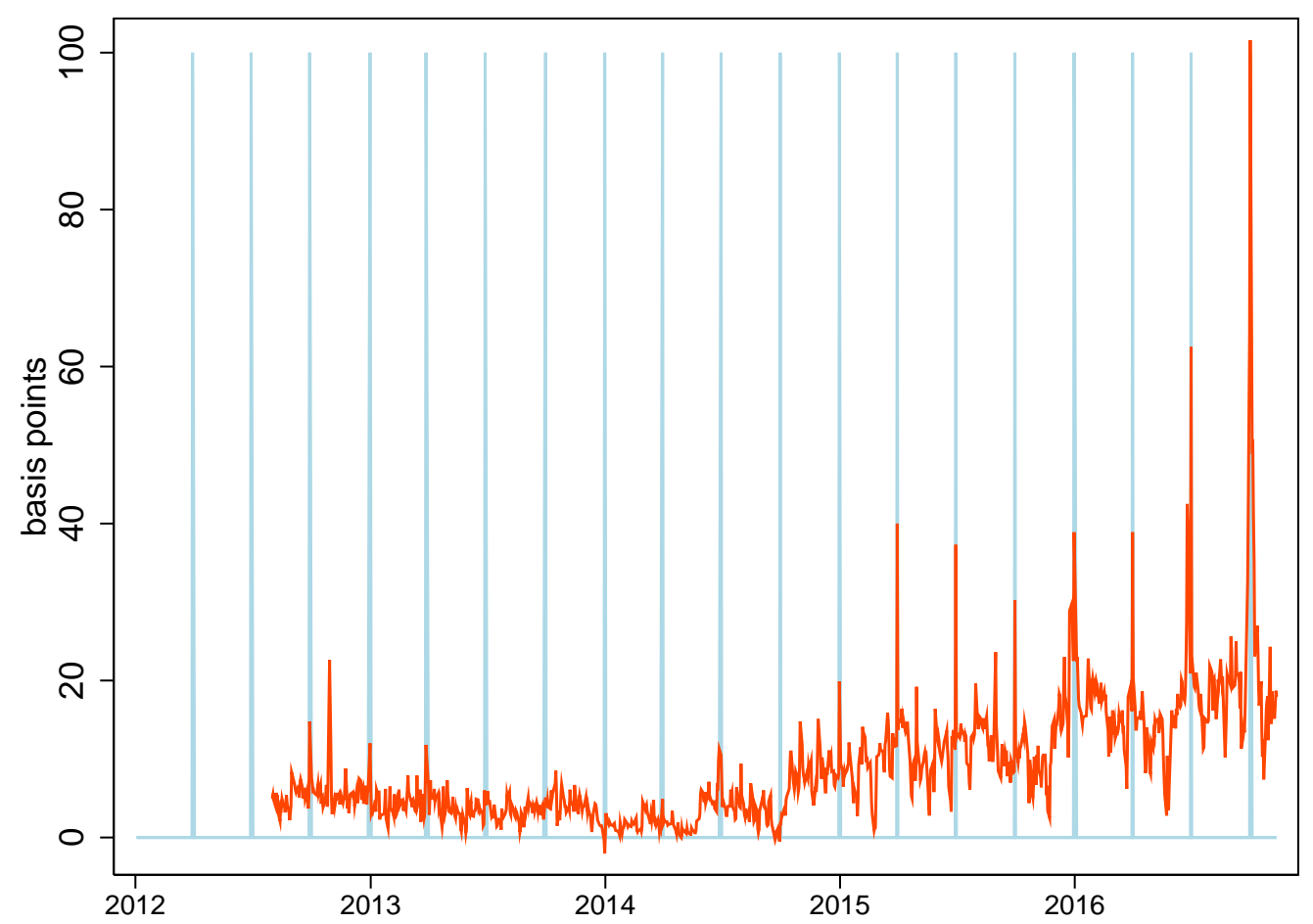

Figure A7: GCF-Triparty Treasury Repo Spread: This figure plots the difference between the repo rates backed by Treasury securities traded in the GCF and the triparty markets. The triparty repo rates are from the BNY Mellon repo index and the GCF rates are from the DTCC GCF index. The shaded area denotes quarter ends. 